Universidade de São Paulo Instituto de Química

\title{
DETERMINAÇÃO DA ATIVIDADE ANTI-RADICALAR DE FLAVONÓIDES E EXTRATOS DE ESPÉCIES DE BACCHARIS ATRAVÉS DA REAÇÃO QUIMILUMINESCENTE DO LUMINOL
}

Camila Rodrigues Eckert

Dissertação de Mestrado

Orientador: Prof. Dr. Josef Wilhelm Baader

São Paulo

$10 / 10 / 2006$ 


\section{Índice}

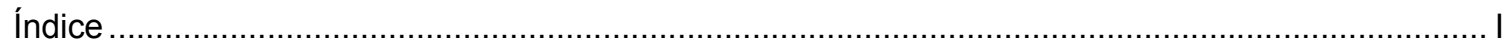

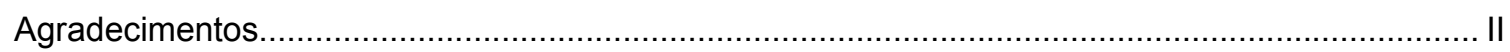

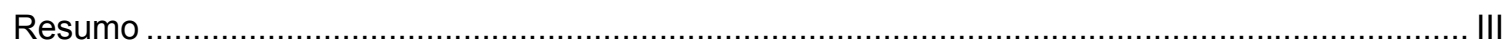

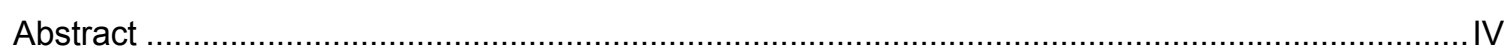

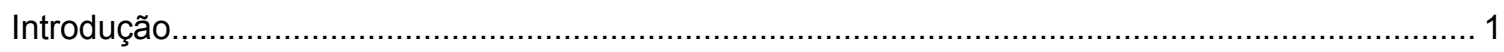

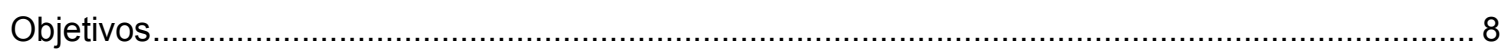

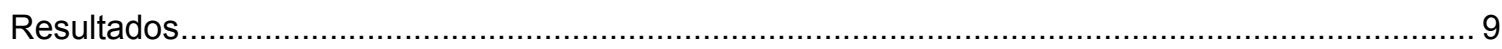

Determinação da Capacidade Anti-radicalar de Flavonóides e Fenóis com o Ensaio Luminol ..... 9

Determinação da Capacidade Anti-radicalar de Compostos-modelo Utilizando-se DPPH........... 23

Estudos das Propriedades Antioxidante de Espécies de Baccharis .......................................... 34

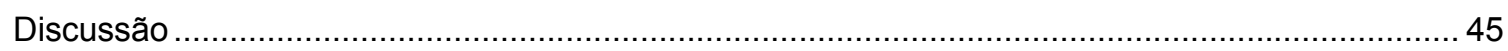

Estudos da Atividade Anti-radicalar de Flavonóides e Compostos-Modelo ................................ 45

Ensaio Fitoquímico Monitorado de Espécies de Baccharis......................................................... 55

Conclusão

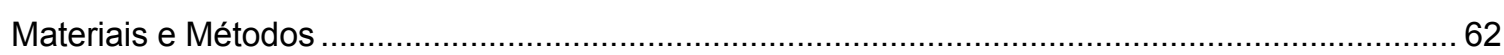

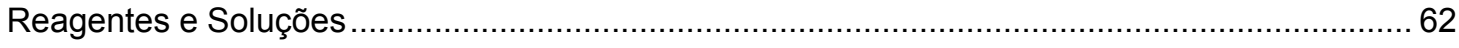

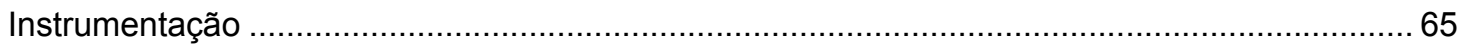

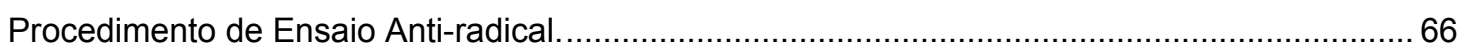

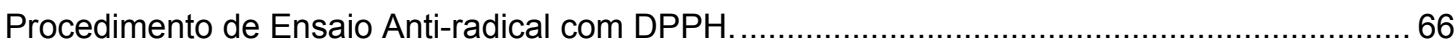

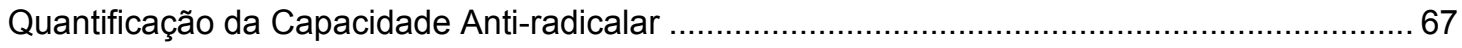

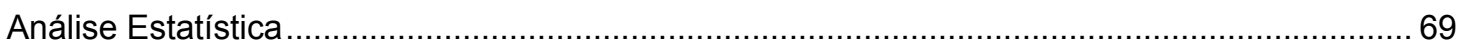

Anexos

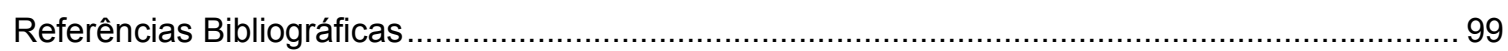




\section{Agradecimentos}

Primeiramente, agradeço aos meus pais por todo apoio e amor necessário nas horas mais difíceis, à minha irmã Daniela que vem me acompanhando mesmo de longe, ao meu namorado Ramirez por me fazer rir e por estar ao meu lado, e não posso me esquecer do apoio e carinho da minha família que mesmo de longe, por telefone, também vem acompanhando minha trajetória.

Agradeço ao meu orientador Willi pela forma como me conduziu, pelas conversas, risadas, pelo aprendizado e principalmente porque se não fosse por ele eu jamais poderia estar onde estou, à Pauletinha por toda força e dedicação, ao João pela ajuda, ao pessoal do Mackenzie e ao pessoal do laboratório André, Cassius, Cerize, Erick, Joey, Lolo, Luiz, Marcelo, Mônica e principalmente ao aluno de iniciação científica Boza, agradeço a vocês pela paciência, compreensão, risadas e boas discussões.

Ao pessoal do IQ, incluindo as amizades que fiz nesse período, aos laboratórios dos professores Maurício, Lique e Etelvino e, finalmente a todos meus amigos que contribuíram de alguma forma, obrigada.

À FAPESP pelo apoio financeiro. 


\section{Resumo}

Nesse trabalho foi realizado um estudo da atividade anti-radicalar de flavonóides frente ao ensaio com o sistema luminol/hemina/ $\mathrm{H}_{2} \mathrm{O}_{2}$ desenvolvido por nosso Grupo de Pesquisa. Na tentativa de esclarecer a relação estrutura-atividade de flavonóides, foi realizada também uma investigação das propriedades de derivados fenólicos como compostos-modelo utilizando-se a reação quimiluminescente do luminol. Os resultados obtidos com os compostos-modelo com o ensaio luminol foram comparados com aqueles obtidos para estes aditivos em um ensaio que utiliza o radical estável DPPH como sonda.

Além disso, foi realizado um estudo fitoquímico monitorado através da atividade anti-radicalar de extratos de Baccharis. Foram identificados dois componentes ativos da fase em acetato de etila obtida das folhas de Baccharis regnellii. e a sua atividade antiradicalar determinada. 


\begin{abstract}
In this work a systematic study on the antiradical activity of flavonoids was performed, using the assay luminol/hemin/ $\mathrm{H}_{2} \mathrm{O}_{2}$ developed by our research group. With the objective to establish a structure activity relationship for flavonoides, a study on the antioxidant properties of several phenolic derivatives as model compounds was also performed, using luminol chemiluminescence. The results obtained with the model compounds from the luminol assay are compared to those obtained by an assay which utilizes the stable DPPH radical as probe.

Furthermore, a phytochemical study, monitored by the antiradical activity, was performed on extracts of Baccharis. This study led to the identification of two active components in the ethyl acetate phase of Baccharis regnellii leafs and the determination of its antiradical activity.
\end{abstract}




\section{Introdução}

Oxigênio é essencial à vida, mas ao mesmo tempo é fonte contínua de agressão aos organismos vivos. $\mathrm{O}$ oxigênio molecular, $\mathrm{O}_{2}$, é encontrado no estado fundamental triplete que é pouco reativo, mas pode dar origem a outras espécies mais agressivas, incluindo oxigênio singlete $\left({ }^{1} \mathrm{O}_{2}\right)$, peróxido de hidrogênio $\left(\mathrm{H}_{2} \mathrm{O}_{2}\right)$, ânion superóxido $\left(\mathrm{O}_{2}{ }^{-}\right)$, radical hidroxil $\left(\mathrm{OH}^{-}\right)$e vários radicais peroxil e alcoxil. Essas espécies reativas de oxigênio são formadas por rotas que podem ser agrupadas em reações de transferência de energia ou transferência de elétron. ${ }^{1}$ Geração de radicais livres é parte integral do metabolismo normal. Entretanto, quando a produção de espécies reativas de oxigênio é inadequadamente controlada, essas espécies em excesso causam a destruição das estruturas biológicas. Sabe-se que espécies reativas de oxigênio causam estresse oxidativo em macromoléculas biológicas ${ }^{2}$, alterando suas propriedades e o funcionamento das células. Radicais livres podem estar envolvidos em um grande número de patologias incluindo a causa de maior índice de morte, o câncer, e a arteriosclerose. Além disso, também são reportados por estarem envolvidos em asma, artrites, inflamações, neurodegeneração, doença de Parkinson e também no envelhecimento. ${ }^{3-7}$

De fato, muitos compostos são capazes de seqüestrar ou inativar espécies ativas de oxigênio e nitrogênio. Todavia, demonstrar que um determinado composto é capaz de atuar através de um mecanismo antioxidante in vivo consiste em tarefa bastante difícil. ${ }^{4}$

Halliwell e Gutteridge questionam a validade de métodos para a determinação da capacidade antioxidante total de substâncias puras e misturas, definindo um antioxidante como "qualquer substância que, quando presente em baixa concentração, comparada com um substrato oxidável, diminui significativamente ou previne a oxidação daquele substrato". Segundo os autores, esta definição indica a importância da fonte de estresse oxidativo e o alvo do ataque. ${ }^{3}$

Uma grande variedade de testes, incluindo métodos químicos, físicos e bioquímicos têm sido utilizados na investigação e caracterização de antioxidantes naturais e sintéticos. Algumas destas abordagens foram descritas em diversos artigos de revisão. ${ }^{8,9}$

Diversos procedimentos espectrofotométricos foram desenvolvidos para monitorar a peroxidação lipídica através da detecção de produtos de degradação de ácidos graxos, em particular dienos conjugados e aldeído malônico (MDA). ${ }^{7}$ Métodos cromatográficos incluem cromatografia gasosa (CG) da produção de etileno e a 
análise por cromatografia líquida de alta eficiência (CLAE) dos produtos de oxidação de ácidos graxos. Eles fornecem informações necessárias na caracterização dos produtos e acerca dos rendimentos das reações.

Métodos colorimétricos também foram desenvolvidos para avaliar a capacidade anti-radicalar. O cátion radical 2,2'-azobis-(3-etilbenzotiazolina-6sulfonato) $\left(\mathrm{ABTS}^{+}{ }^{+}\right.$) é gerado pela oxidação de ABTS com persulfato de potássio e é reduzido na presença de um antioxidante. A capacidade antioxidante é definida pela porcentagem de inibição da formação de $\mathrm{ABTS}^{+}{ }^{+}$utilizando-se trolox, um análogo da vitamina E, como padrão. ${ }^{10} \mathrm{O}$ radical estável orgânico 2,2'-difenil-1-picrilidrazil (DPPH), de cor púrpura, também pode ser utilizado para avaliar a capacidade antiradicalar. O método consiste basicamente na abilidade de um antioxidante em reduzir a espécie DPPH: A capacidade anti-radicalar pode ser medida por Ressonância Paramagnética de Elétron (EPR) ou por um decréscimo no valor de absorbância em $515 \mathrm{~nm}^{9,11}$

Técnicas quimiluminescentes têm sido amplamente utilizadas no desenvolvimento de sistemas analíticos para substâncias com interesse clínico. Elas oferecem vantagens consideráveis sobre os métodos convencionais como grande sensibilidade com instrumentos relativamente simples, rápida obtenção de dados analíticos e linearidade da resposta luminescente mesmo através de várias ordens de magnitude. ${ }^{9}$

Métodos analíticos relacionados ao fato da quimiluminescência do luminol ser induzida por radicais livres ou processos de oxirredução avaliam diferentes tipos de espécies ativas de oxigênio e a especificidade e eficiência de aditivos seqüestradores destes radicais. Dados obtidos no estudo da emissão do luminol induzida pelos radicais superóxido, hidroxil, alcoxil e hidroperoxil, e oxigênio singlete, mostram que existe um certo grau de especificidade em relação a um determinado aditivo, dependendo da espécie de oxigênio ativo que se forma inicialmente no meio de reação. ${ }^{12,13}$

Atividade antioxidante é a habilidade de um composto em reduzir espécies pró-oxidantes ou espécies reativas de significância patológica Muitos métodos, que têm sido definidos como métodos de inibição, envolvem espécies reativas, que normalmente são radicais livres. O parâmetro de seqüestro total de radicais ("Total Radical Antioxidant Parameter" [TRAP]) desenvolvido por WAYNER et al. é o método mais amplamente utilizado para medir a capacidade antioxidante de plasma durante a última década. ${ }^{12}$ 
Esta técnica envolve a iniciação da peroxidação lipídica através da produção de radicais peroxila hidrossolúveis a uma velocidade constante pela decomposição térmica de cloreto de 2,2'-azobis-(2-amidinopropano) (ABAP). Este processo é inibido por antioxidantes encontrados em fluidos como o plasma, e o tempo de indução observado na iniciação da peroxidação lipídica, medido pelo consumo de oxigênio, pode ser comparado com o obtido quando da utilização de uma solução padrão de Trolox (6-hidroxil-2,5,7,8-tetrametilcroman-2-óico), um antioxidante originalmente desenvolvido para preservação de alimentos, que tem uma estrutura cromano similar à encontrada no $\alpha$-tocoferol, mas sem a cauda hidrofóbica, e que vem apresentando alto potencial antioxidante, atuando com sucesso na prevenção de enfartes do miocárdio e prevenção da necrose do fígado. ${ }^{14}$

Apesar do ensaio TRAP original ser sensível a todos os antioxidantes de interrupção de cadeia, sua realização é relativamente complexa e demanda muito tempo, requerendo algum grau de especialização e experiência. Este procedimento tem sido modificado empregando-se outras fontes de radical além de outras técnicas para monitorar a velocidade do processo.

Métodos desenvolvidos recentemente baseiam-se na reação de oxidação do luminol pelos radicais peroxil formados pela termólise de ABAP, o que resulta em uma emissão de quimiluminescência. Antioxidantes na amostra inibem esta quimiluminescência por um tempo diretamente proporcional à concentração total de aditivo. O valor obtido é, então, comparado com o antioxidante padrão, Trolox, e reportado como a capacidade antioxidante da amostra.

Lisse et al. utilizando um método de avaliação de TRAP muito similar estenderam o procedimento para a avaliação da capacidade do aditivo em diminuir a concentração de radicais livres no estado estacionário, originando um novo índice antioxidante conhecido como TAR (Reatividade Antioxidante Total). ${ }^{15}$ Este parâmetro constitui um índice útil capaz de modular o dano associado ao aumento da produção de radicais livres.

Whiteread et al. relataram um ensaio quimiluminescente aperfeiçoado para medir a capacidade antioxidante em fluidos biológicos em $1992 .{ }^{16} \mathrm{O}$ princípio deste método baseia-se na oxidação de luminol por peróxido de hidrogênio ou perborato catalisada por peroxidase de raiz forte (HRP), que resulta em numa emissão de intensidade baixa e decaimento rápido. As características da reação podem ser alteradas substancialmente com a adição de um amplificador, como o $p$-iodofenol, que resulta numa emissão mais estável, intensa e prolongada, e que permanece sensível à interferência de substâncias antioxidantes. Quando na presença de uma substância 
potencialmente redutora, a emissão de luz é inibida, sendo restabelecida apenas após o total consumo do antioxidante. ${ }^{16}$

Foi desenvolvido em nosso laboratório um ensaio quimiluminescente baseado na oxidação do luminol por peróxido de hidrogênio, na presença de hemina, que resulta em uma emissão constante de decaímento compatível com o sistema luminol/ABAP tendo, no entanto, uma intensidade de emissão mais alta e tempo de resposta mais curto. A emissão pode ser suprimida por substâncias que apresentem atividade antioxidante, sendo que a área de supressão apresenta boa correlação com a concentração da amostra. $O$ trolox é utilizado como antioxidante padrão. ${ }^{17}$

\section{Aspectos Químicos e Biológicos do Gênero Baccharis (Asteraceae)}

O interesse pela ação de produtos naturais sobre a saúde é muito antigo, e a humanidade sempre utilizou o poder terapêutico de extratos vegetais na forma de chás, pomadas, emplastos, vapores, tinturas e até mesmo de incensos, sendo utilizados até hoje, principalmente em países subdesenvolvidos ou por seguidores de terapias alternativas. ${ }^{18}$ No Brasil, somente $20 \%$ da população consome $63 \%$ dos medicamentos disponíveis, enquanto que o restante encontra nos medicamentos de origem natural, especialmente nas plantas medicinais, a única fonte de recurso terapêutico. ${ }^{19}$ Até o momento, ainda não se conhece quase nada sobre a composição química de $99,6 \%$ das plantas de nossa flora, estimadas entre 40 mil a 55 mil espécies. $^{18}$

As plantas são importantes fontes de produtos naturais. Os estudos das substâncias biossintetizadas pelo metabolismo secundário dos vegetais vêm aumentando consideravelmente, sendo que a maioria tem por objetivo encontrar metabólitos secundários biologicamente ativos, muitos dos quais se constituem em modelos para síntese de fármacos, que é de grande interesse comercial. ${ }^{19}$

Calcula-se que existam de 250.000 a 500.000 espécies de plantas no planeta, entretanto, só uma pequena porcentagem delas são utilizadas como alimento ou no preparo de medicamentos. Os vegetais têm uma capacidade quase ilimitada de sintetizar substâncias, que em muitos casos são utilizados como defesa contra microrganismos, insetos e herbívoros, ou na geração de odores, cores e sabor. ${ }^{20}$

Além disso, uma grande quantidade de compostos secundários das plantas medicinais já isolados e com estrutura química determinada ainda não foram estudados quanto a suas atividades biológicas. Esses compostos pertencem a várias 
classes distintas de substâncias químicas, como alcalóides, terpenos, lignanas, flavonóides, cumarinas, quinonas, xantonas, lactonas e esteróides, entre outras. ${ }^{21}$

Considerando-se suas propriedades antioxidantes, os flavonóides compreendem os produtos naturais mais investigados neste contexto. Flavonóides constituem um grupo de compostos fenólicos presentes em frutos e vegetais. ${ }^{19}$ Estas substâncias são constituídas por unidades $\mathrm{C}_{6}-\mathrm{C}_{3}-\mathrm{C}_{6}$, nas quais cada unidade $\mathrm{C}_{6}$ é um anel aromático. A atividade antioxidante de flavonóides está relacionada a três características estruturais: (i) o sistema orto-dihidroxi no anel B; (ii) a presença da ligação dupla entre $\mathrm{C}_{2}-\mathrm{C}_{3}$ conjugada com a função 4-oxo; (iii) a presença de um grupo hidroxílico em $\mathrm{C}_{3}{ }^{22}$ Foi realizado um estudo da influência do $\mathrm{pH}$ sobre a propriedade antioxidante e o mecanismo de ação antioxidante de hidroxiflavonas em um intervalo de $\mathrm{pH}$ 4,5-9,5. Lemanska et al. sugerem que há um aumento do potencial antioxidante com a desprotonação, ou seja, em altos valores de $\mathrm{pH}$ para as hidroxiflavonas estudadas. $^{23}$

O gênero Baccharis, pertencente à família Asteraceae, é constituído por mais de 500 espécies distribuídas principalmente no Brasil, Argentina, Colômbia, Chile e México, ocupando as áreas mais elevadas. ${ }^{24,25}$ No Brasil estão descritas 120 espécies de Baccharis, localizadas na região sudeste. São normalmente plantas de pequeno porte, como ervas e arbustos, muitas das quais utilizadas na medicina popular para o controle ou tratamento de várias doenças, como desordens hepáticas e renais, diabetes, processos inflamatórios e outros. Por outro lado, algumas espécies são reconhecidamente tóxicas, tendo sido relatados casos de morte de bovinos e ovinos ao se alimentarem com folhas de Baccharis.

A composição química deste gênero baseia-se principalmente na ocorrência de substâncias terpenicas e flavonóides. Além de estudos fitoquímicos, foram realizados alguns estudos de atividade biológica, destacando-se os efeitos antimicrobianos, citotóxicos e antiinflamatórios. ${ }^{26}$ Os flavonóides são compostos de grande ocorrência no gênero Baccharis, sendo considerados bons marcadores quimiotaxonômicos para a família Asteraceae. ${ }^{27}$ As substâncias que ocorrem neste gênero são principalmente flavonas e flavonóis, as quais apresentam diversas atividades biológicas.

Substâncias isoladas de B. pedunculata, incluindo os flavonóides 5,7-diidroxi6,4'-dimetoxiflavona (pectolinaringenina) e 5,4'-diidroxi-3,6,7-trimetoxiflavona (penduletina), foram avaliados quanto a atividade antifúngica, tendo sido observado que a pectolinaringenina era responsável por tal atividade. ${ }^{28}$

A espécie B. trimera, conhecida popularmente como carqueja, é usada na medicina popular para o tratamento de doenças do fígado e reumatismo. ${ }^{29}$ Do extrato 
metanólico das folhas desta espécie, foram isolados quatro flavonóides, 5,4'-diidroxi-7metoxiflavona (genkwanina), 5,4'-diidroxi-6,7-dimetoxiflavona (cirsimaritina), 5,4'diidroxi-6,7-dimetoxiflavona (cirsimaritina), 5,7,4'-triidroxi-6-metoxiflavona (hispidulina) e 5,7,4'-triidroxiflavona (apigenina), os quais apresentaram atividade atimutagênica. Do extrato em acetato de etila da mesma planta foram isolados outros três flavonóides, 3,5,7,3',4'-pentaidroxiflavona (quercetina), 5,7,3',4'-tetraidroxiflavona (luteolina) e 5,7,3',4'-tetraidroxi-6-metoxiflavona (nepetina), os quais apresentaram atividade anti-hepatotóxica, utilizando ratos como modelo, justificando o uso desta planta na medicina popular. Nagasugi et al reportam que o extrato metanólico de $B$. trimera reduziu significamente a mutagenicidade de Trp-P-2 com baixa toxicidade. ${ }^{30}$ Torres et al. reportam que um diterpeno isolado dessa espécie, apresenta efeito relaxante no músculo intestinal de ratos, justificando o uso desta planta na medicina popular. ${ }^{31}$ Além disso, recentemente foi reportado pela primeira vez o efeito do potencial antidiabético da fase aquosa de extrato etanólico de $B$. trimera em ratos diabéticos induzidos por estrepotozotocina. ${ }^{32}$

Estudos realizados principalmente com técnicas de HPLC, demonstram evidências que a própolis brasileira origina-se de constituintes químicos observados na espécie B. dracunculifolia. ${ }^{33,34}$ Os extratos de B. conferta, assim como algumas substâncias puras (incluindo flavonóides), apresentaram ação espasmolítica, o que está de acordo com o uso desta planta no tratamento de cólicas gastrointestinais. ${ }^{35} \mathrm{~A}$ atividade antiinflamatória dos extratos das partes aéreas de $B$. medullosa e $B$. rufescens foi determinada a partir de edemas em ratos, induzidos por carragenina. Os extratos em n-hexano, acetona e clorofórmio inibiram a fase aguda da inflamação neste modelo. ${ }^{36}$

Algumas espécies de Baccharis apresentam atividade antioxidante. Os extratos etanólicos de quinze espécies medicinais do Equador foram avaliados quanto às atividades antiinflamatória e antioxidante. Usando-se o modelo de peroxidação lipídica, observou-se que o extrato etanólico de $B$. trinervis mostrou-se ativo em seqüestrar radicais peroxidicos e hidroxílicos. O extrato aquoso de $B$. coridifolia apresentou atividade antioxidante em diferentes bioensaios, e a partir do estudo fitoquímico os autores pretendem determinar as substâncias responsáveis por tal atividade. ${ }^{37}$

Os extratos etanólico e aquoso de $B$. genistelloids foram avaliados quanto a sua atividade antiviral. in vitro. $O$ extrato aquoso mostrou-se muito mais ativo que $o$ etanólico contra herpes "simplex" tipo 1 (HSV-1) e vírus vesicular "stomatitis" (VSV) com baixa toxicidade. ${ }^{38}$ 
B. gaudichaudiana é usada como remédio antidiabético no Paraguai, onde é conhecida como "chilca melosa". De suas partes aéreas foram isolados alguns diterpenóides, os flavonóides, apigenina e hispidulina, e o sesquiterpeno espatulenol, os quais foram submetidos à atividade citotóxica in vitro. Das substâncias testadas as que apresentaram maior potencial citotóxico foram: um novo diterpenóide isolado, apigenina e hispidulina. Esses compostos apresentaram baixos valores de $E D_{50}$ para quase todos os tipos de células cancerígenas as quais foram submetidos. ${ }^{39}$

Segundo Oh et al., várias doenças do trato gastrointestinal são induzidas por estresse oxidativo. ${ }^{40}$ Extratos e substâncias isoladas de partes aéreas de $B$. grisebachii, espécie muito utilizada na Argentina para o tratamento de doenças gastrointestinais, mostraram alta atividade antioxidante e anti-radicalar utilizando-se diferentes ensaios in vitro. ${ }^{41}$

Foram realizadas pesquisas bibliográficas minuciosas a respeito de substâncias derivadas de ácido cinâmico, bem como a ocorrência dessas substâncias. A maior ocorrência desses derivados cinâmicos trata-se de própolis. Dentre as espécies de Baccharis pesquisadas, é citado apenas um artigo onde um derivado de ácido caféico foi isolado. Apesar de encontrar referências sobre a ocorrência, não foi possível obter informações a respeito da capacidade anti-radicalar dessas substâncias, o que deixa claro a importância de estudar esse tipo de substância. 


\section{Objetivos}

Os objetivos deste trabalho são relacionados ao estudo da atividade antioxidante de frações e substâncias isoladas de espécies vegetais brasileiras. Foram utilizadas as seguintes abordagens:

- Determinação da atividade anti-radicalar de flavonóides utilizando-se o ensaio quimiluminescente com luminol/ $\mathrm{H}_{2} \mathrm{O}_{2} /$ hemina, desenvolvido no nosso grupo de pesquisa.

- Estudo da relação entre a estrutura do flavonóide e a sua atividade anti-radicalar estudando-se, além de flavonóides, derivados fenólicos como compostosmodelo.

- Comparação dos resultados obtidos através do ensaio luminol com aqueles medidos por um ensaio anti-radicalar que utiliza o radical estável DPPH como sonda.

- Realização de um estudo fitoquímico, monitorado pela atividade anti-radicalar, de extratos e fases obtidos de folhas de Baccharis regnellii. 


\section{Resultados}

\section{Determinação da Capacidade Anti-radicalar de Flavonóides e Fenóis com o Ensaio Luminol}

Dando continuidade aos estudos do Grupo de Pesquisa, dos quais participei durante a minha iniciação científica, foram determinados os valores do potencial antiradicalar de uma série de flavonóides e derivados análogos, utilizando-se o ensaio baseado na quimiluminescência do luminol. ${ }^{14}$

Com o objetivo de esclarecer a relação estrutura-atividade dos flavonóides.(Esquema 1), foram estudados os flavonóides, rutina (quercetina 3-Oglicosídeo), kaempferol (3,4',5,7-tetraidroxiflavona), fisetina (3,7,3', $4^{\prime}$ tetraidroxiflavona), morina (3,5,7,2',4'- pentaidroxiflavona), 3,6-diidroxiflavona, 3,7diidroxiflavona, crisina (5,7-diidroxiflavona), 7-hidroxiflavona, 3-hidroxiflavona e, como compostos-modelos, os derivados fenólicos (Esquema 2) : fenol, catecol (ohidroxifenol), resorcinol ( $m$-hidroxifenol), hidroquinona ( $p$-hidroxifenol), pirogalol $(1,2,3-$ triidroxibenzeno), floroglucinol (1,3,5-triidroxibenzeno), $p$-fluorofenol, $p$-clorofenol, $p$ bromofenol, $p$-iodofenol, $p$-nitrofenol, $p$-cianofenol, $p$-metoxifenol e $p$-aminofenol.
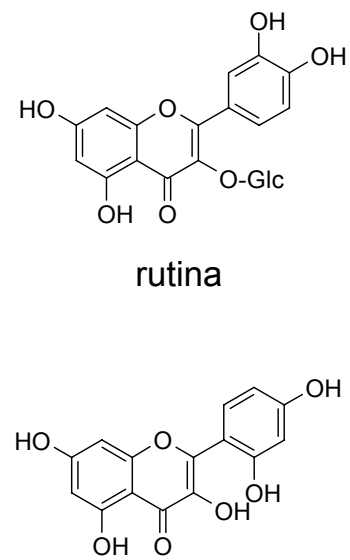

morina<smiles>O=c1cc(-c2ccccc2)oc2cc(O)cc(O)c12</smiles>

crisina<smiles>O=c1c(O)c(-c2ccc(O)cc2)oc2cc(O)cc(O)c12</smiles>

kaempferol<smiles>O=c1c(O)c(-c2ccccc2)oc2ccc(O)cc12</smiles>

3,6-diidroxiflavona<smiles>O=c1cc(-c2ccccc2)oc2cc(O)ccc12</smiles>

7-hidroxiflavona<smiles>O=c1c(O)c(-c2ccc(O)c(O)c2)oc2cc(O)ccc12</smiles>

fisetina<smiles>O=c1c(O)c(-c2ccccc2)oc2cc(O)ccc12</smiles>

3,7-diidroxiflavona<smiles>O=c1c(O)c(-c2ccccc2)oc2ccccc12</smiles>

3-hidroxiflavona

Esquema 1 
<smiles>Oc1ccccc1</smiles><smiles>Oc1ccccc1O</smiles>

fenol<smiles>Oc1cc(O)cc(O)c1</smiles>

floroglucinol<smiles>O=[N+]([O-])c1ccc(O)cc1</smiles>

p-nitrofenol<smiles>Oc1cccc(O)c1</smiles>

resorcinol<smiles>Oc1ccc(Cl)cc1</smiles>

p-clorofenol p-bromofenol

p-iodofenol<smiles>Oc1cccc(O)c1O</smiles>

pirogalol<smiles>Oc1ccc(Br)cc1</smiles><smiles>Oc1ccc(I)cc1</smiles><smiles>Nc1ccc(O)cc1</smiles>

$p$-aminofenol

\section{Esquema 2}

As figuras 1 e 2 mostram alguns exemplos de curvas cinéticas obtidas com trolox (anti-radical padrão), com o flavonóide, rutina e com os derivados fenólicos, fenol, catecol, resorcinol, hidroquinona, floroglucinol e pirogalol, respectivamente. Outras curvas cinéticas obtidas com os demais flavonóides e compostos-modelo não são mostradas, pois apresentam perfis semelhantes às curvas mostradas (Figuras $1 \mathrm{e}$ 2).

Essas curvas cinéticas foram obtidas em dois espectrofluorímetros diferentes, pois o laboratório conta com uma procura muito grande desses equipamentos por se tratar de um laboratório de quimiluminescência. As curvas cinéticas que possuem intensidade por volta de 500 referem-se ao espectrofluorímetro da marca Hitachi, enquanto que as que possuem intensidade em torno de 100 referem-se ao espectrofluorímetro da marca Varian. Os valores das intensidades de emissão são relatados em unidades arbitrárias (u.a.) e para o cálculo da capacidade anti-radicalar utiliza-se o padrão trolox. ${ }^{17}$ Sendo assim, o uso de dois instrumentos diferentes para este ensaio, não apresenta nenhum problema. Para a obtenção dos valores de capacidade anti-radicalar foram efetuadas ao menos duas séries de experimentos e as figuras 1 e 2 indicam resultados representativos. 
A

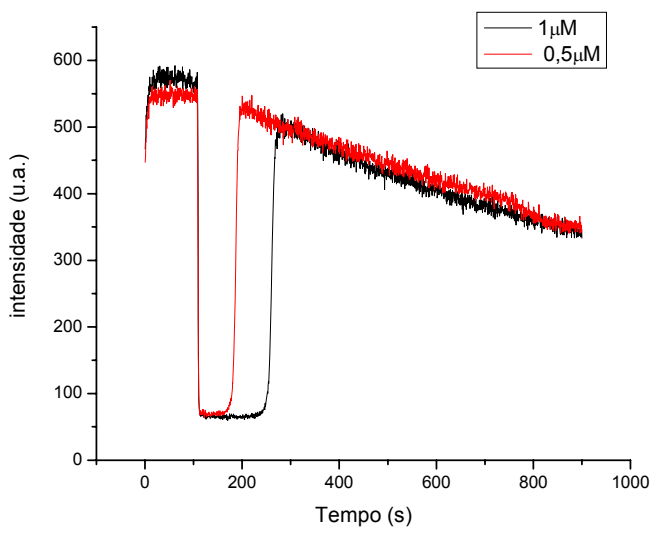

B

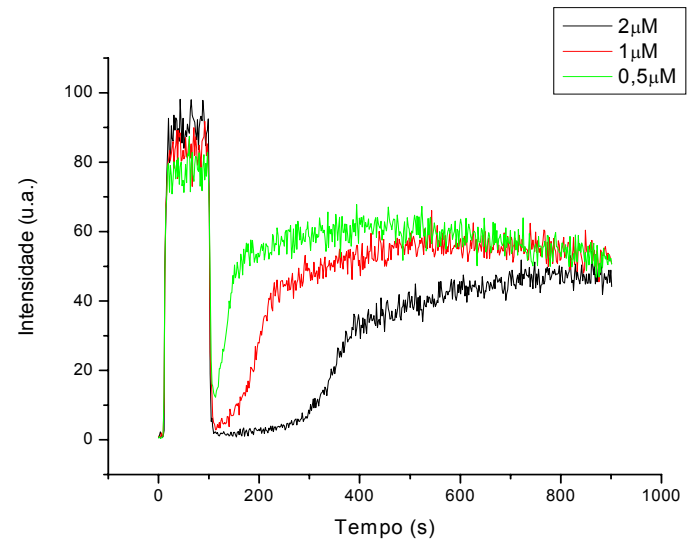

C

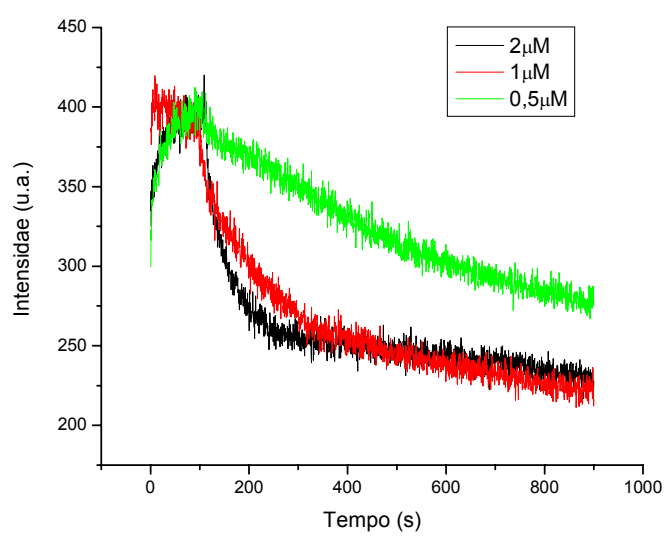

Figura 1: Cinética de decaimento da intensidade de emissão do sistema luminol/ $/ \mathrm{H}_{2} \mathrm{O}_{2} /$ hemina frente à adição de A: trolox, B: rutina, C: crisina após 100 s de seu início. 
A

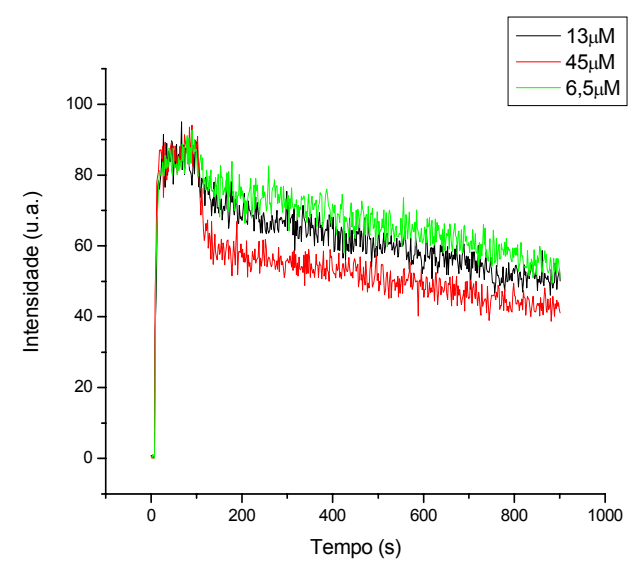

C

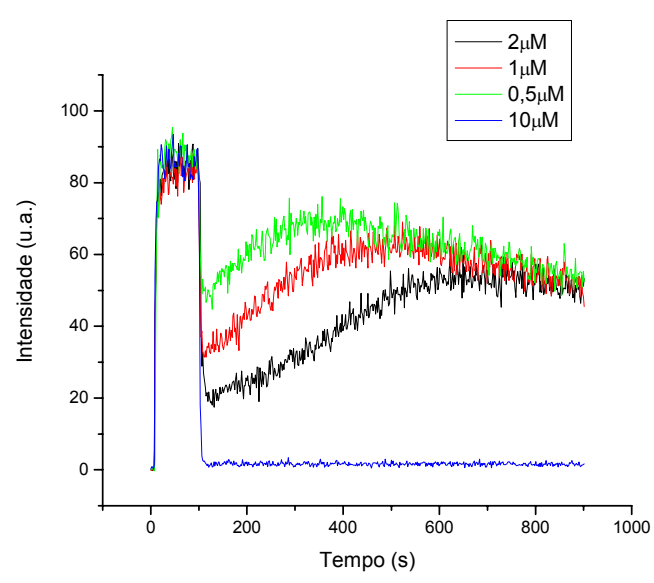

E

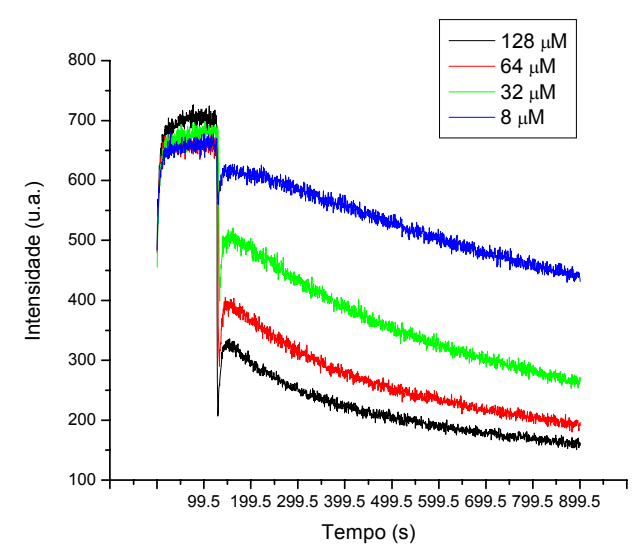

B

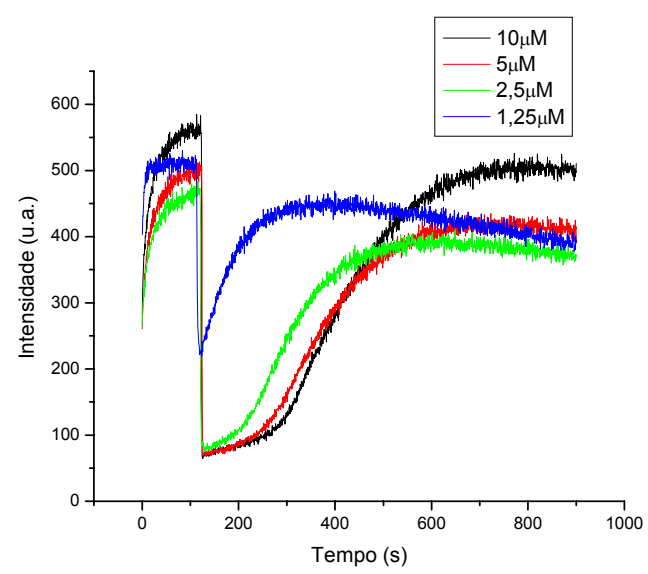

D

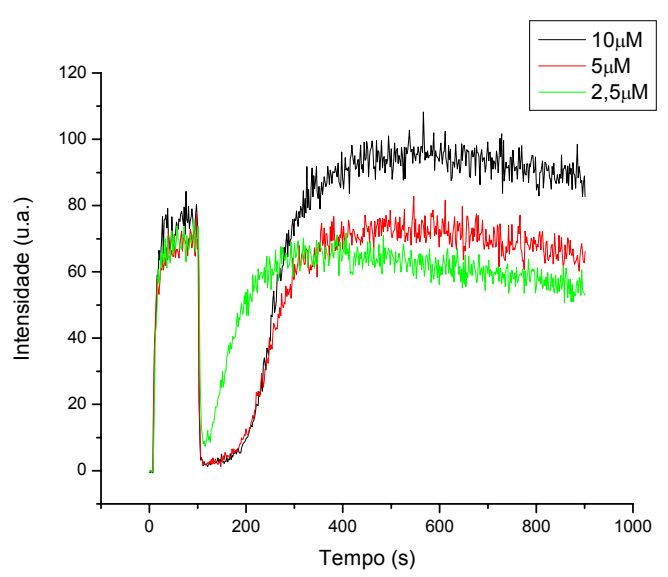

$\mathbf{F}$

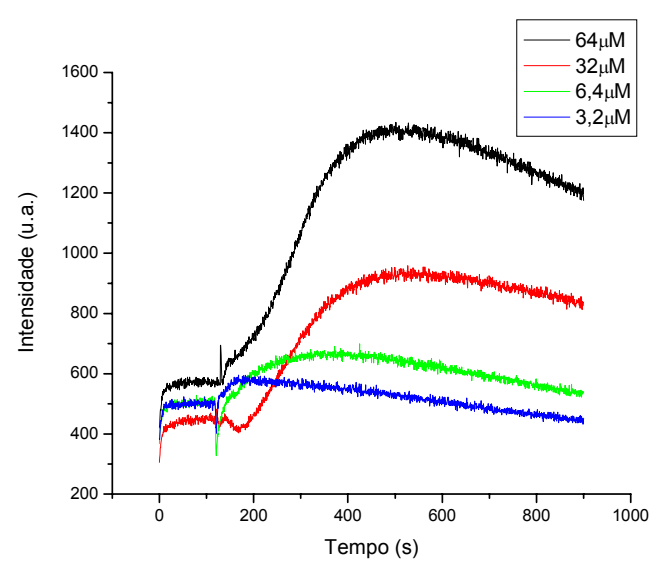

Figura 2: Cinética de decaimento da intensidade de emissão do sistema luminol $/ \mathrm{H}_{2} \mathrm{O}_{2} /$ hemina frente à adição de A: fenol, B: catecol, C: resorcinol, D: hidroquinona, E: floroglucinol e F: pirogalol após 100 s de seu início.

Observa-se que o aspecto das curvas cinéticas obtidas muda conforme 0 composto estudado (Figuras 1 e 2). As curvas cinéticas obtidas com trolox apresentam 
um comportamento típico ou convencional, ao qual se observa a diminuição da intensidade até quase a linha base após a adição do mesmo, seguido pelo rápido retorno da emissão de luz de acordo com a concentração utilizada (Figura 1A). Os ensaios realizados com rutina permitiram a obtenção de curvas cinéticas que não seguem exatamente o mesmo padrão que as curvas cinéticas obtidas com trolox, mesmo assim foi possível calcular as áreas de supressão para cada concentração utilizada subtraindo a curva cinética obtida sem adição de anti-radical da curva cinética obtida com a adição da rutina (Figura 1A e B).

As curvas cinéticas obtidas com kaempferol e morina são bastante semelhantes às obtidas com trolox (Figura 1A) com isso obteve-se com facilidade, como ocorre na maioria dos casos, um gráfico que relaciona a área de supressão com a concentração.

Já as curvas cinéticas obtidas com fisetina 3,6-diidroxiflavona e 3,7diidroxiflavona apresentam aspecto similar àquele obtido com rutina, ou seja, não seguem o mesmo padrão que as curvas obtidas com o trolox (Figura 1A e B). As áreas de supressão observadas nas curvas cinéticas obtidas por esses flavonóides não atingem o nível da linha base, pois devem possuir reatividades consideravelmente menores do que trolox frente ao ensaio quimiluminescente de luminol, mesmo assim foi possível calcular as áreas de supressão para cada concentração utilizada desses antiradicais.

Os ensaios realizados com crisina, 7-hidroxiflavona e 3-hidroxiflavona utilizados como antiradicais, permitiram a obtenção de curvas cinéticas (Figura 1C) nos quais se observa a diminuição da intensidade após a adição do anti-radical, porém, não ocorre a retomada da emissão, o que impossibilitou o cálculo das áreas de supressão para estes compostos. Utilizando a abordagem padrão, curvas cinéticas obtidas com crisina $2 \mu \mathrm{M}$ e $1 \mu \mathrm{M}$ apresentam uma queda significativa da intensidade de luz, mas não há retorno de luz ao término dos $900 \mathrm{~s}$, porém o experimento realizado com crisina 0,5 $\mu \mathrm{M}$ apresentou uma curva cinética que possui uma queda quase imperceptível de intensidade de luz seguido de um decaimento muito lento (Figura 1C).

A partir das curvas cinéticas que apresentaram comportamentos típicos onde foi possível o cálculo das áreas de acordo com as concentrações utilizadas de antiradical frente ao ensaio de quimiluminescência do luminol foi possível obter as correlações lineares entre a área de supressão (vide Parte Experimental) e a concentração do composto anti-radicalar (Figuras 3 e 4). 
A

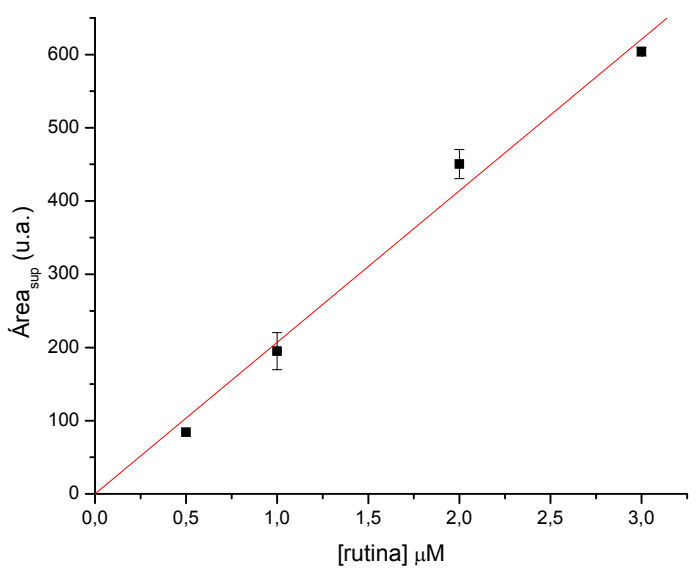

C

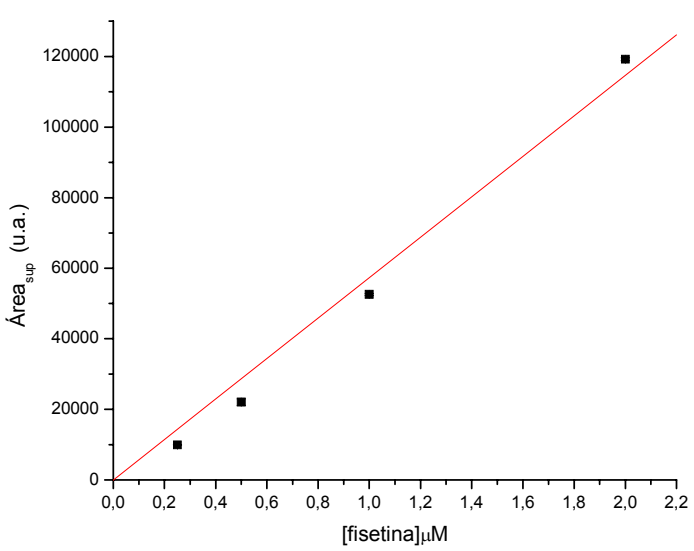

E

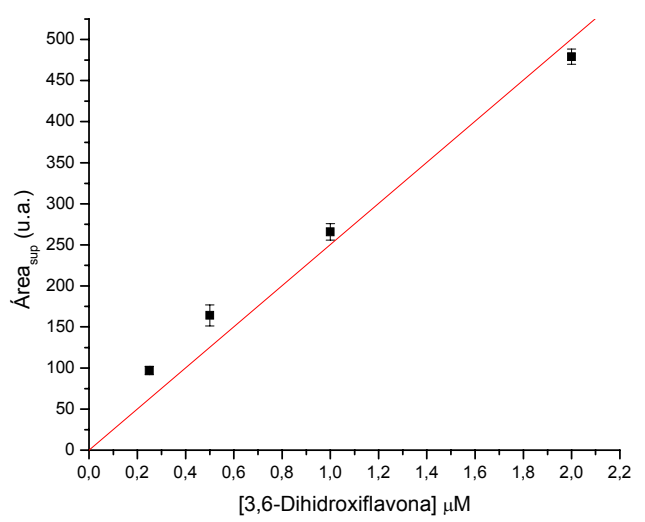

B

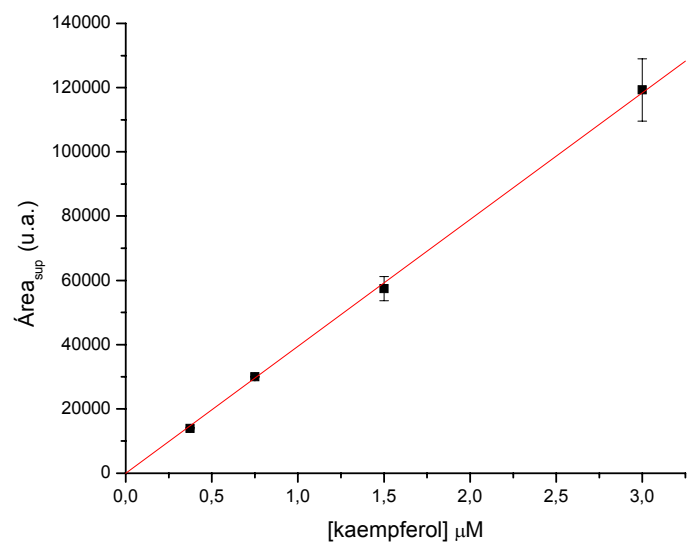

D

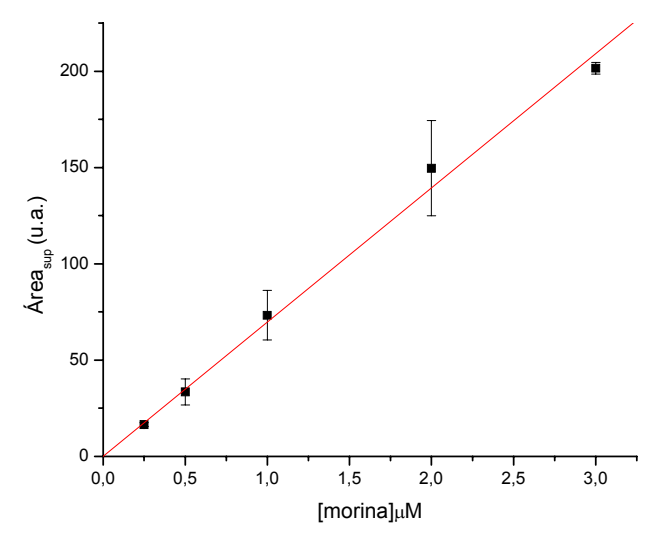

$\mathbf{F}$

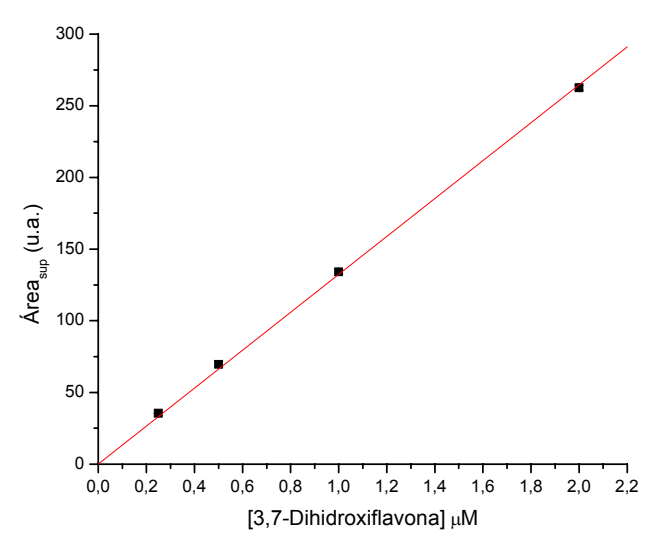

Figura 3: Dependência entre a concentração de A: rutina, B: kaempferol, C: fisetina, D: morina, E: 3,6dihidroxiflavona e F: 3,7-dihidroxiflavona e a área calculada pela integral de supressão. 
A

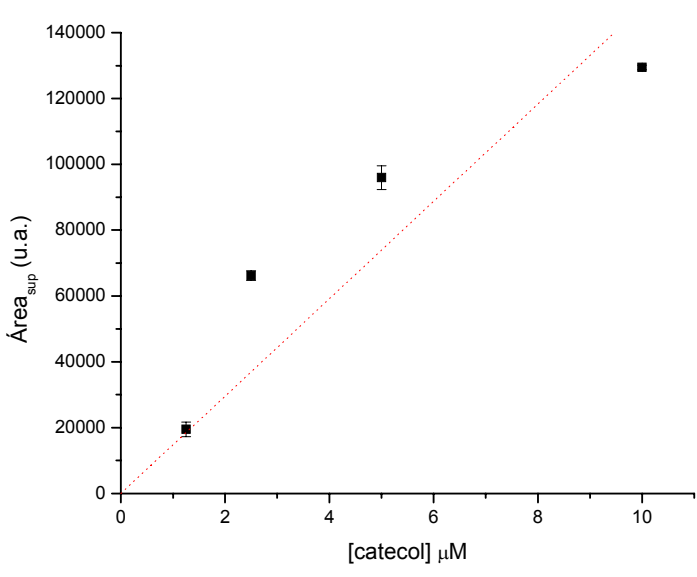

C

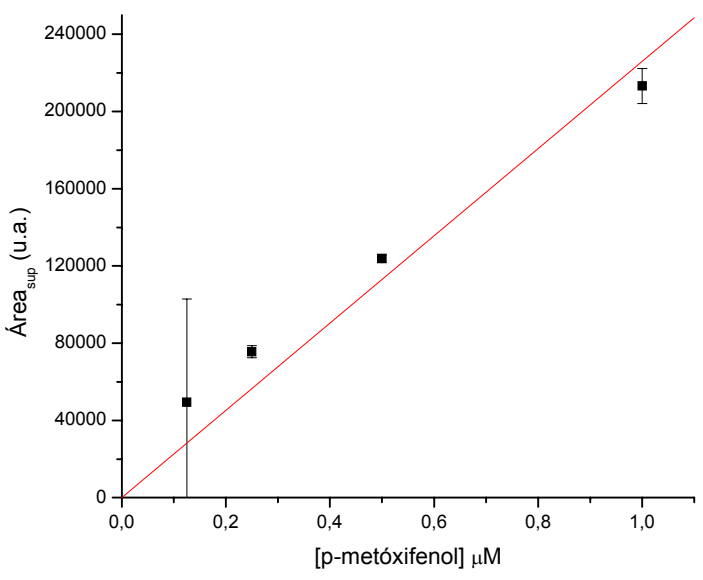

B

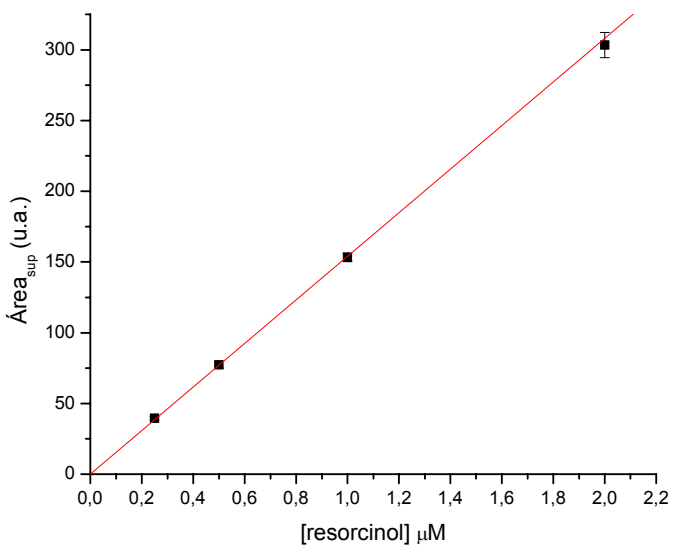

D

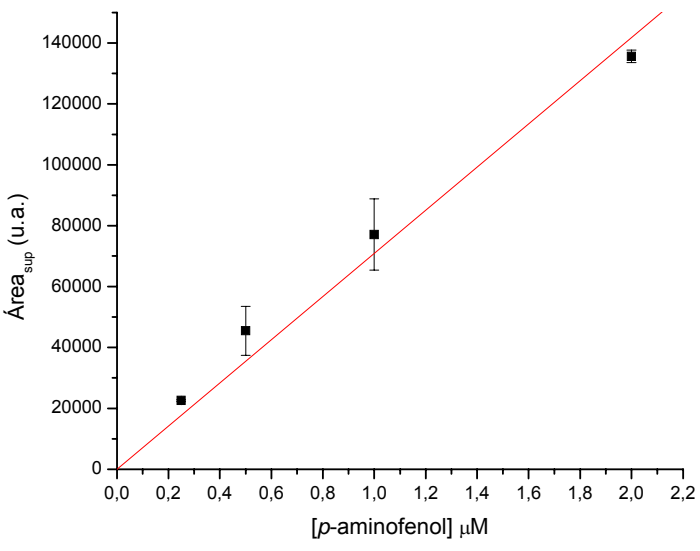

E

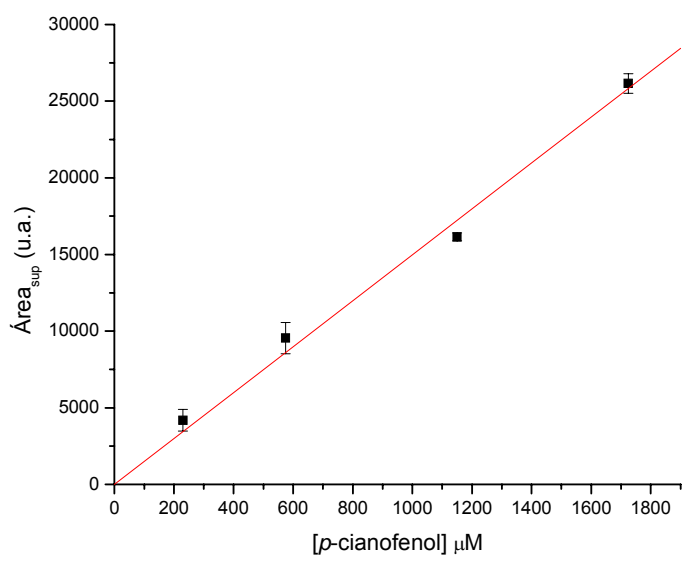

Figura 4: Dependência entre a concentração de A: catecol, B: resorcinol, C: p-metoxifenol, D: $p$-aminofenol e E: $p$-cianofenol e a área calculada pela integral de supressão.

De acordo com os gráficos obtidos a partir do cálculo das áreas de supressão vs concentração de anti-radical utilizado (Figuras 3 e 4) foi possível obter os valores de 
n para os flavonóides e derivados fenólicos testados utilizando-se um valor de $n=2$ para trolox como padrão (Tabela 1).

Tabela 1: Atividade anti-radical expressa em termos de número de radicais seqüestrados por molécula de anti-radical (n), intervalo de concentrações utilizadas e as inclinações das retas obtidas com trolox e com os antiradicais estudados. Os erros obtidos das inclinações das retas indicam o erro do ajuste linear da curva.

\begin{tabular}{ccccc}
\hline Anti-radical & $\begin{array}{c}\text { Intervalo } \\
\text { de [ ] } \mu \mathrm{M}\end{array}$ & $\begin{array}{c}\text { Inclinação } \\
\text { Trolox }\end{array}$ & $\begin{array}{c}\text { Inclinação Anti- } \\
\text { radical }\end{array}$ & $\mathbf{n}$ \\
\hline 3,6-diidroxiflavona & $0,25-2,00$ & $290 \pm 4,30$ & $250 \pm 14,8$ & $1,72 \pm 0,05$ \\
fisetina & $0,25-2,00$ & $76700 \pm 828$ & $57300 \pm 2580$ & $1,50 \pm 0,03$ \\
3,7-diidroxiflavona & $0,25-2,00$ & $197 \pm 2,90$ & $132 \pm 1,30$ & $1,35 \pm 0,01$ \\
rutina & $0,50-3,00$ & $308 \pm 6,45$ & $207 \pm 7,05$ & $1,34 \pm 0,03$ \\
kaempferol & $0,37-3,00$ & $76700 \pm 828$ & $39700 \pm 167$ & $1,04 \pm 0,01$ \\
morina & $0,25-3,00$ & $185 \pm 1,90$ & $69,7 \pm 1,76$ & $0,75 \pm 0,01$ \\
\hline resorcinol & $0,25-2,00$ & $97500 \pm 980$ & $53100 \pm 612$ & $1,10 \pm 0,01$ \\
catecol & $1,25-10,00$ & $80500 \pm 1350$ & $14800 \pm 2050$ & $0,37 \pm 0,02$ \\
$p$-metoxifenol & $0,12-1,00$ & $94000 \pm 1040$ & $188000 \pm 9600$ & $4,00 \pm 0,10$ \\
$p$-aminofenol & $0,25-2,00$ & $88600 \pm 502$ & $70900 \pm 3550$ & $1,60 \pm 0,04$ \\
$p$-cianofenol & $230-1725$ & $88600 \pm 502$ & $15,0 \pm 0,44$ & $0,00034 \pm 0,000005$ \\
\hline
\end{tabular}

Através da tabela 1 é possível observar que o intervalo de concentrações utilizado é bem próximo para quase todos os antiradicais, com exceção do catecol que foi estudado até $10 \mu \mathrm{M}$ e do $p$-cianofenol que foi estudado até $1725 \mu \mathrm{M}$ devido à baixa atividade anti-radicalar frente ao sistema luminol/hemina/ $/ \mathrm{H}_{2} \mathrm{O}_{2}$.

Devido às diferenças entre os sistemas de detecção dos dois espectrofluorímetros utilizados, os valores de inclinação obtidos não podem ser comparados diretamente. Todavia, valores relativos em função do coeficiente angular obtido para trolox são os mesmos, ou seja, valores de $\mathrm{n}$ são comparáveis independentemente do equipamento utilizado.

Dentre os flavonóides estudados, 3,6-diidroxiflavona obteve o maior valor de $n$ calculado ( $n=1,72)$, ou seja, possui a maior atividade anti-radical frente à reação quimiluminescente do luminol, seguido por fisetina $(n=1,50)$, 3,7-diidroxiflavona e rutina $(n=1,35$ e $n=1,34$ respectivamente), kaempferol $(n=1,04)$ e morina $(n=0,75)$. (Tabela 1) 
Já entre os compostos-modelos, dos quais somente cinco permitiram obter o valor de $n$, observa-se que $p$-metoxifenol é capaz de seqüestrar mais radicais por molécula $(n=4,00)$ que p-aminofenol $(n=1,60)$, resorcinol $(n=1,16)$, catecol $(n=$ $0,37)$ e p-cianofenol $(n=0,00034)$, respectivamente (Tabela 1$)$.

Dos compostos-modelos estudados, o fenol mostra, conforme esperado, baixa reatividade e mesmo em altas concentrações $(45 \mu \mathrm{M})$ a redução da intensidade de emissão $\left(I_{0}\right)$ é somente de $20 \%$ (Figura $2 \mathrm{~A}$ ). Isso também ocorre com floroglucinol (Figura 2E), $p$-nitrofenol e com os derivados halogenados $p$-fluorofenol, $p$-clorofenol, $p$ bromofenol e $p$-iodofenol, cujas curvas cinéticas estão omitidas por mostrarem comportamento semelhante à curva cinética obtida com fenol (Figura 2A). Conforme explicitado anteriormente, não é possível, nestes casos, obterem-se valores para a capacidade anti-radical.

As curvas cinéticas obtidas com $p$-cianofenol, $p$-metoxifenol e $p$-aminofenol mostram comportamento semelhante às curvas cinéticas obtidas com catecol $\mathrm{e}$ resorcinol (Figura 2B e C) e estão no grupo de derivados fenólicos que apresentam reatividade intermediária, ou seja, mostram inibição incompleta e retomada gradual da emissão. Para esses compostos-modelo foi possível o cálculo da atividade antiradicalar (Figura 4).

As curvas cinéticas obtidas com floroglucinol apresentam uma queda na intensidade de luz de acordo com a concentração utilizada, porém, não há retorno de luz até os $900 \mathrm{~s}$ da duração do experimento, mesmo para baixas concentrações (8 $\mu \mathrm{M})$, o que impossibilitou o cálculo da capacidade anti-radicalar desta substância. Além disso, o floroglucinol deve possuir reatividade baixa comparada com o trolox frente ao ensaio quimiluminescente de luminol, ou seja, a constante de velocidade de inibição de quimiluminescência observada no passo XI (Esquema 5) deve ser pouco maior que a constante de velocidade de oxidação de luminol no passo IV (Esquema 4) pois as curvas cinéticas só atingem o nível da linha base para altas concentrações utilizadas $(128 \mu \mathrm{M})$ (Figura $1 \mathrm{~A}$ e $\mathrm{C}$ ). Os experimentos realizados com $p$-clorofenol não levaram a nenhum resultado, pois as curvas cinéticas obtidas com esse aditivo não eram reprodutíveis, além disso, para observar qualquer inibição da intensidade de luz gerada pelo sistema luminol era preciso usar concentrações muito altas.

Segundo esta abordagem, estudos preliminares foram realizados utilizando-se as curvas cinéticas obtidas com o floroglucinol, fenol, resorcinol (Figuras 2A C e E), $p$ fluorofenol, $p$-bromofenol, $p$-iodofenol e $p$-nitrofenol na tentativa de investigar a reatividade destes compostos frente ao ensaio. Para estas substâncias, a inibição inicial parcial da emissão de luz (de I para I), a qual depende da concentração do 
$\mathrm{AOH}$, pode ser utilizada como parâmetro para a reatividade do $\mathrm{AOH}$. A figura 5 mostra, como exemplo, uma curva cinética obtida com floroglucinol onde $I_{0}$ representa a intensidade de emissão do sistema anterior à adição de $\mathrm{AOH}$, e I representa a intensidade de emissão imediatamente após a adição do anti-radical. Através da diferença entre as intensidades inicial e final normalizadas, de acordo com as concentrações estudadas, foi possível a obtenção da figura 6 .

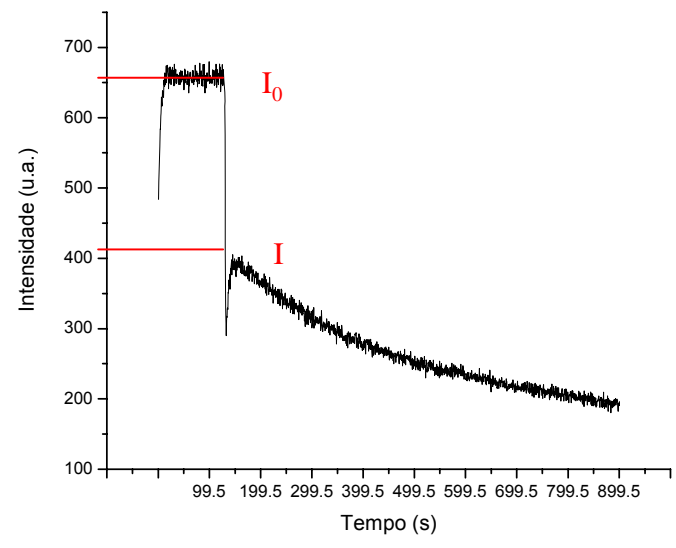

Figura 5: Cinética de decaimento do sistema luminol/ $\mathrm{H}_{2} \mathrm{O}_{2} /$ hemina frente à adição de floroglucinol $64 \mu \mathrm{M}$, após 100 s de seu início.

A figura 6A mostra que o gráfico obtido com o floroglucinol apresenta uma boa correlação linear entre o fator de inibição normalizado e as concentrações utilizadas, ou seja, há um aumento do fator de inibição com o aumento da concentração de acordo com o esperado. Embora os gráficos obtidos com fenol, resorcinol e com os derivados halogenados $p$-fluorofenol, $p$-bromofenol, $p$-iodofenol (Figura $6 \mathrm{~B}$ e $\mathrm{C}$ e Figura 7A, B e C) não apresentem boas correlações lineares, é possível observar um aumento do fator de inibição de acordo com o aumento da concentração, como no gráfico obtido com o floroglucinol. Já o gráfico obtido com $p$-nitrofenol o mostrou uma boa correlação linear (Figura 7D). 
A

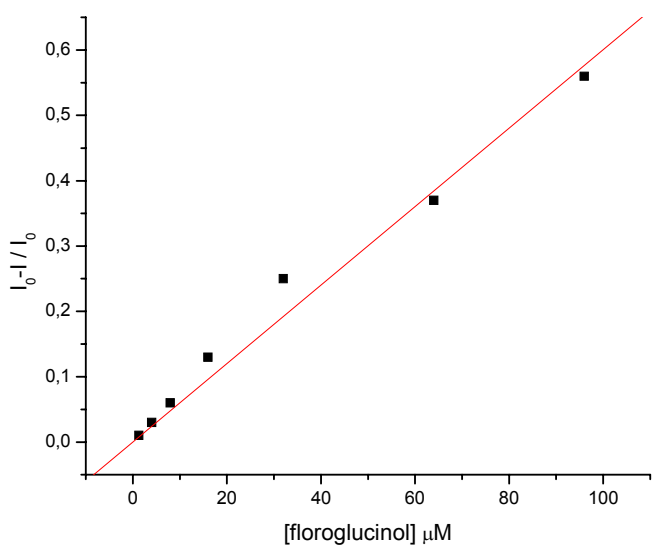

B

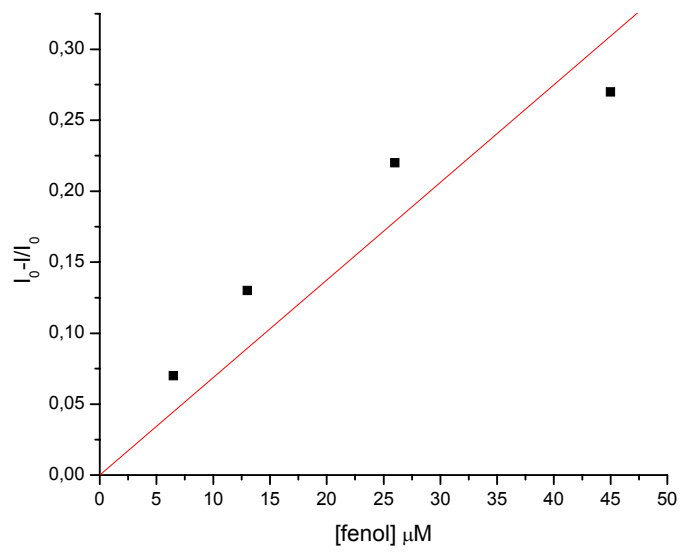

C

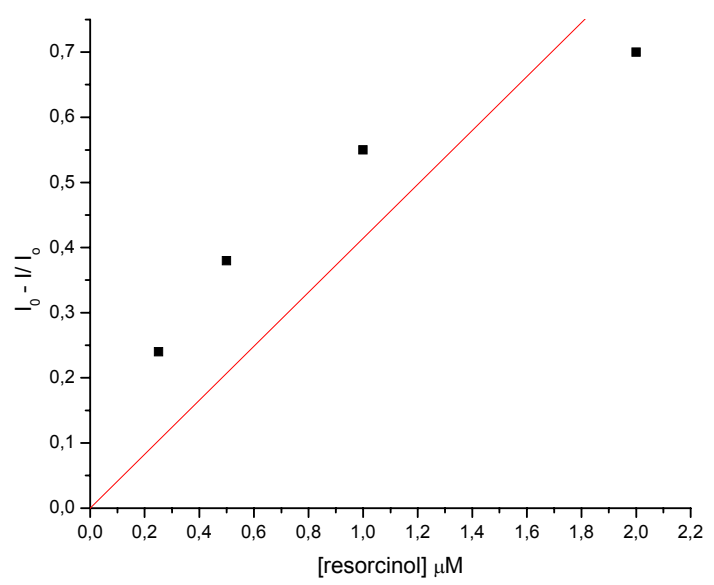

Figura 6: Correlação linear entre a concentração de A: floroglucinol, B: fenol e C: resorcinol e o fator de inibição normalizado $I_{0}-I / I_{0}$. Coeficientes angulares: $A: 0,00644 \pm 0,00036, B: 0,00687 \pm 0,00080$ e C: 0,414 $\pm 0,072$. 
A

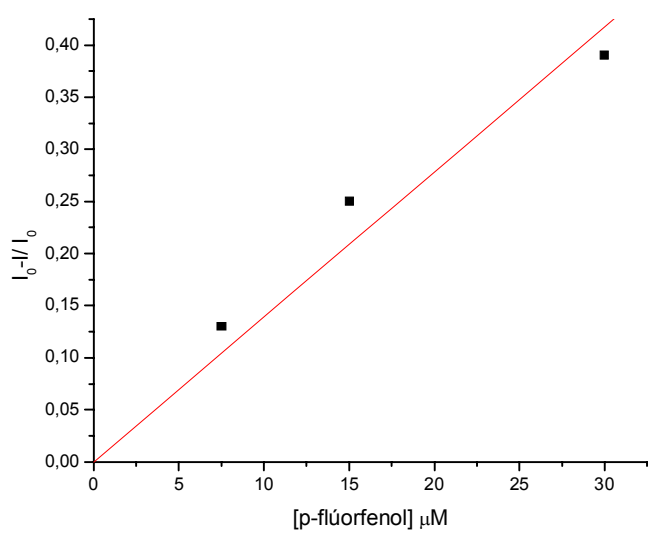

C

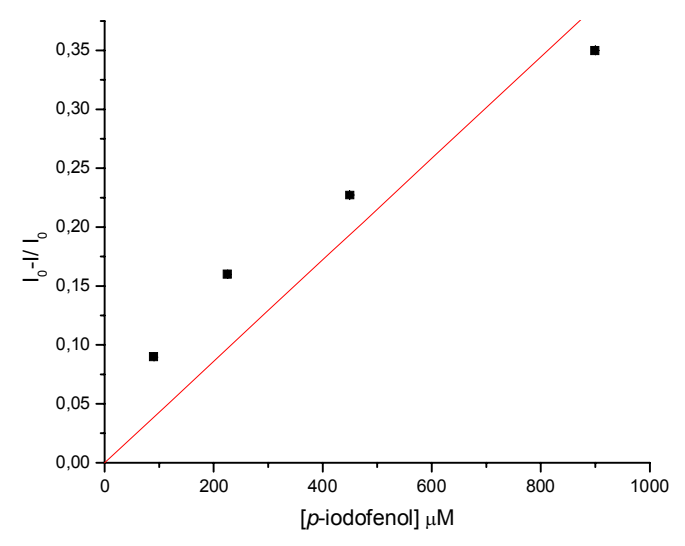

B

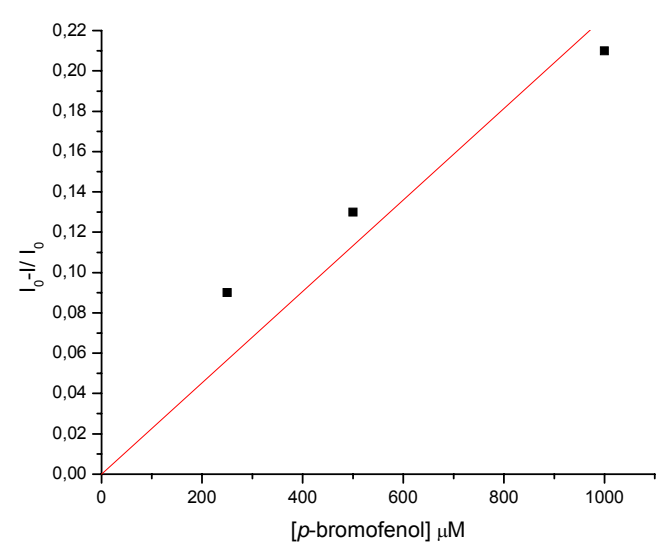

D

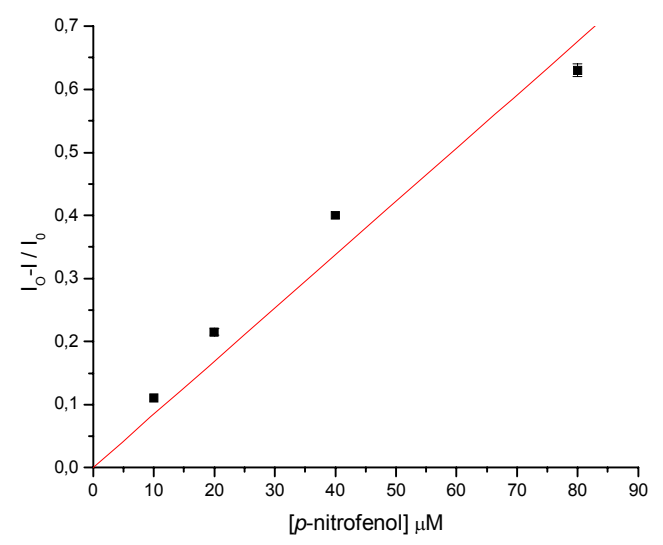

Figura 7: Correlação linear entre a concentração de A: p-fluorofenol, B: p-bromofenol, C: $p$-iodofenol e D: $p$-nitrofenol e o fator de inibição normalizado $I_{0}-I / I_{0}$. Coeficientes angulares: A: 0,01390 $\pm 0,00115$, B: $0,00023 \pm 0,00002$, C: $0,00043 \pm 0,00005$ e D: $0,00845 \pm 0,00060$.

Entretanto, não é possível relacionar a reatividade destes compostos com a reatividade do trolox frente à reação quimiluminescente do luminol, pois as curvas cinéticas obtidas com o anti-radical padrão não permitem a obtenção de $I_{0}-1 / I_{0}$ (Figura 1C), tendo em vista que a intensidade de emissão após a adição de trolox (mesmo em baixas concentrações) atinge valores muito próximos à zero (Figura 1A). Mas é possível obter um parâmetro de reatividade para eles utilizando-se os coeficientes angulares (Tabela 2). 
Tabela 2: Parâmetro de reatividade e reatividades relativas dos compostos anti-radicalares: floroglucinol, fenol, resorcinol, $p$-fluorofenol, $p$-bromofenol, $p$-iodofenol, $p$-nitrofenol, obtidos pela inclinação dos gráficos da dependência do fator de inibição normalizado com a $[\mathrm{AOH}]$.

\begin{tabular}{cccc}
\hline $\begin{array}{c}\text { Compostos- } \\
\text { Modelos }\end{array}$ & {$[\mathrm{AOH}](\mu \mathrm{M})$} & $\begin{array}{c}\text { Parâmetro de } \\
\text { Reatividade }\left(\mu \mathrm{M}^{-1}\right)\end{array}$ & $\begin{array}{c}\text { Reatividade } \\
\text { Relativa }\end{array}$ \\
\hline floroglucinol & $1,0-75,0$ & $0,00644 \pm 0,00036$ & 0,94 \\
fenol & $6,5-45,0$ & $0,00687 \pm 0,00080$ & $\mathbf{1 , 0 0}$ \\
resorcinol & $0,5-2,0$ & $0,41400 \pm 0,07200$ & 60,26 \\
$p$-fluorofenol & $7,5-30,0$ & $0,0139 \pm 0,00115$ & 2,02 \\
$p$-bromofenol & $125,0-1000,0$ & $0,00023 \pm 0,00002$ & 0,03 \\
$p$-iodofenol & $90,0-900,0$ & $0,00043 \pm 0,00005$ & 0,06 \\
$p$-nitrofenol & $10,0-80,0$ & $0,00845 \pm 0,00060$ & 1,23 \\
\hline
\end{tabular}

Para um efeito comparativo, foi atribuído um valor de reatividade relativa entre os compostos-modelo, do qual fenol possui valor 1. A tabela 2 mostra que fenol, floroglucinol e $p$-nitrofenol possuem reatividades próximas frente ao ensaio do luminol. Dentre os derivados halogenados, apenas p-fluorofenol possui uma reatividade considerável em comparação ao fenol, enquanto que de todos esses compostosmodelos dos quais foram possível atribuir um parâmetro de reatividade, o resorcinol mostrou-se bem mais reativo que os demais (Tabela2).

Já as curvas cinéticas obtidas com hidroquinona e pirogalol (Figura 2D e F) apresentaram um comportamento não convencional, cujo efeito aumenta com a concentração, o que não acontece com resorcinol em uma concentração elevada (10 $\mu \mathrm{M}$ ) (Figura 2C), onde, no caso da hidroquinona, observa-se primeiramente uma inibição de luz seguido por um retorno da emissão acima da intensidade de luz $\left(I_{0}\right)$ obtida no início do ensaio (Figura 2D), enquanto que as curvas cinéticas obtidas com pirogalol não apresentam inibição da emissão mesmo para baixa concentração $(3,2$ $\mu \mathrm{M}$ ) (Figura 2F), impossibilitando, nesses casos, o cálculo das áreas de supressão de acordo com as concentrações estudadas. Esse aumento significativo de intensidade pode ser devido a um efeito pró-oxidante destes compostos conforme também observado para o ácido ascórbico em altas concentrações e também pode ser chamado de efeito amplificador de quimiluminescência. ${ }^{14,42}$

As curvas cinéticas obtidas com o pirogalol sugerem que essa substância possui um efeito de amplificação de quimiluminescência muito mais importante que efeito anti-radicalar, pois é possível observar que há somente uma pequena área de supressão de luz, apenas para concentração de $32 \mu \mathrm{M}$ (Figura 2F). Pode-se observar ainda que o efeito da amplificação depende da concentração do $\mathrm{AOH}$ utilizado sendo 
mais intenso em altas concentrações (Figura 2F). Já as curvas cinéticas obtidas anteriormente com hidroquinona demonstram esse efeito amplificador de quimiluminescência dependente da concentração utilizada e do dia do experimento realizado (Figura 8).

A

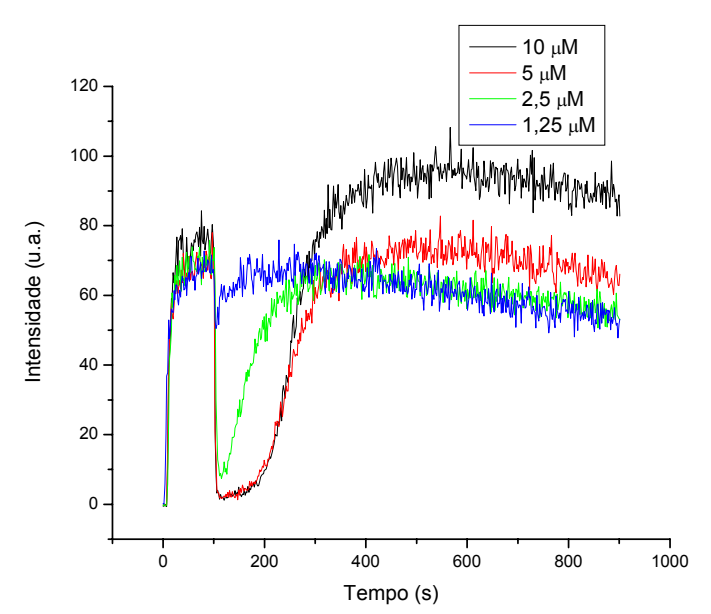

B

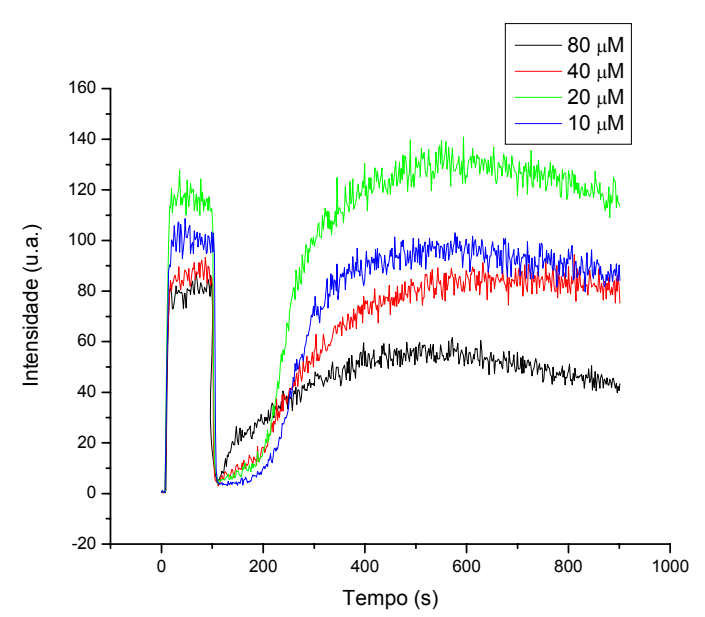

Figura 8: Cinética de decaimento do sistema luminol/ $\mathrm{H}_{2} \mathrm{O}_{2} /$ hemina frente à adição de hidroquinona em dias diferentes de experimento A: 24/05/05 e B: 09/06/05 após 100 s de seu início.

O efeito amplificador de quimiluminescência mais acentuado é observado para a curva cinética obtida com hidroquinona $10 \mu \mathrm{M}$, enquanto que para as demais concentrações esse efeito é pouco pronunciado (Figura 8A). Em contrapartida, as curvas cinéticas obtidas com hidroquinona em outro dia de experimento (Figura 8B) mostram esse efeito de amplificação de quimiluminescência acentuado para hidroquinona $20 \mu \mathrm{M}$ e pouco efeito para as concentrações 10 e $40 \mu \mathrm{M}$. Surpreendentemente, com o aumento da concentração para $80 \mu \mathrm{M}$ o efeito de amplificação de intensidade parece não ser mais importante (Figura 8B).

Com o objetivo de verificar uma possível interação entre pirogalol e hemina, a qual poderia ser responsável pelo efeito amplificador deste aditivo, alternativamente aos mecanismos de amplificação discutidos acima, bem como uma possível interação entre $p$-metoxifenol e hemina devido ao alto potencial anti-radicalar obtido para esse composto modelo, foram obtidos espectros de absorção em $\mathrm{NaOH} 1 \mathrm{M}$ da solução de hemina (hem) $8 \mu \mathrm{M}$, da solução de pirogalol (py) $177 \mu \mathrm{M}$, da solução de p-metoxifenol $\left(\mathrm{p}-\mathrm{OCH}_{3}\right) 250 \mu \mathrm{M}$ e da solução de hemina $8 \mu \mathrm{M}$ com a adição de pirogalol (17 a 82 $\mu \mathrm{M})$ e $p$-metoxifenol (100 a $200 \mu \mathrm{M})$ (Figura 9). 
A

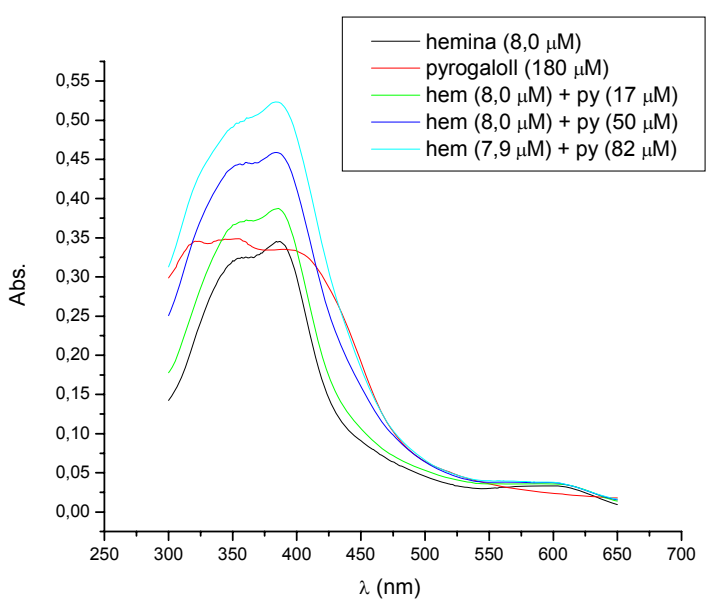

B

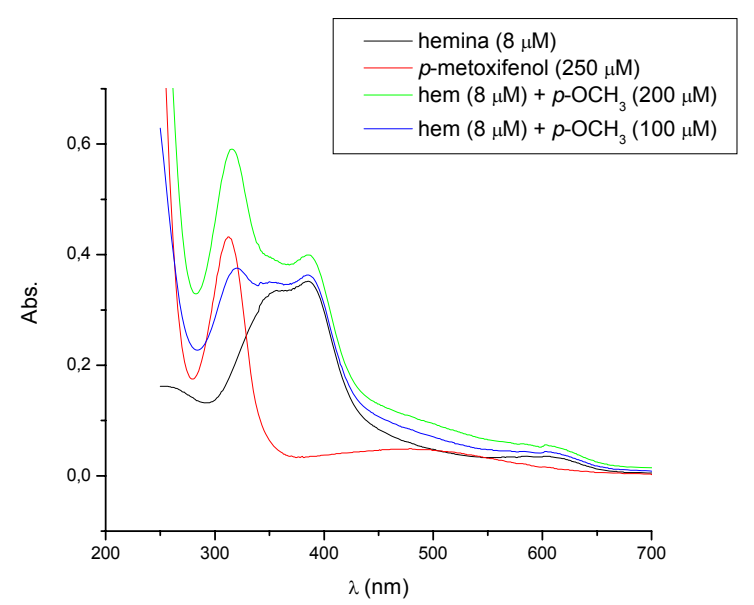

Figura 9: Espectros de absorção de hemina (hem), de pirogalol (py), de p-metoxifenol $\left(\mathrm{p}-\mathrm{OCH}_{3}\right)$ e de hemina (hem) na presença de pirogalol e na presença de $p$-metoxifenol.

Os espectros de absorção da mistura de hemina e pirogalol apresentaram apenas um aumento na absorbância entre 300 e 550 nm. Esses aumentos de absorbância observados nos espectros da hemina foram de acordo com as alíquotas de pirogalol adicionadas, ou seja, o espectro que apresentou um maior aumento de absorbância entre 300 e $550 \mathrm{~nm}$, é o que possui maior concentração de pirogalol (82 $\mu \mathrm{M})$. O mesmo acontece com os espectros de absorção obtidos da mistura entre hemina e $p$-metoxifenol, que apresentaram apenas um aumento na absorbância entre 300 e $550 \mathrm{~nm}$, intervalo de comrpimento de onda onde ambos aditivos absorvem (Figura 9).

Os espectros das misturas hemina / pirogalol e hemina / p-metoxifenol correspondem aproximadamente à soma dos espectros de absorção dos componentes puros e não foi observada nenhuma banda adicional a qual poderia indicar a formação de um complexo entre hemina / pirogalol e hemina / p-metoxifenol (Figura 9).

\section{Determinação da Capacidade Anti-radicalar de Compostos-modelo Utilizando- se $D P P H$}

Com o objetivo de correlacionar parâmetros experimentais obtidos com os compostos-modelo estudados, frente ao ensaio do luminol, foi proposto a utilização de 
um outro ensaio anti-radicalar, o ensaio com 2,2-difenil-1-picrilhidrazil (DPPH). O método baseia-se na medida da habilidade redutora de um anti-radical frente ao radical estável DPPH.

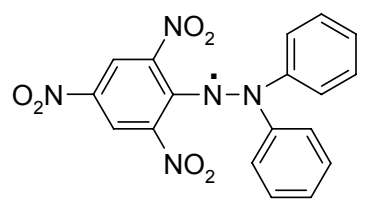

DPPH

O ensaio antioxidante é baseado na medida da perda da cor da solução de DPPH em $515 \mathrm{~nm}$ após a reação de um composto anti-radicalar, monitorada espectrofotometricamente. ${ }^{43,44}$

Foi utilizado, inicialmente, um espectrofotômetro (Shimadzu Multispec 1500 UV-Visível) com detector "diode-array", no qual a amostra é exposta à luz branca. Nestas condições foi observada a rápida degradação do radical DPPH, supostamente por uma foto-reação iniciada pela absorção no UV. Foi verificado ainda que esta fotodegradação não é influenciada pelo solvente (etanol ou metanol) e não depende da presença de oxigênio. Portanto, utilizando-se um espectrofotômetro que possui a grade de difração antes da entrada do feixe de luz na amostra (Shimadzu UV-2401 PC), não foi observada a degradação do DPPH, indicando que a excitação do radical em $515 \mathrm{~nm}$ (primeiro estado excitado singlete, $S_{1}$ ) não leva a sua degradação. As cinéticas de reação do DPPH com as amostras passaram a ser medidas então com o espectrofotômetro Shimadzu UV-2401 PC.

O trolox foi a primeira amostra testada e foi utilizado como anti-radical padrão também nesse ensaio. As curvas cinéticas obtidas da reação de DPPH com diferentes concentrações de trolox estão mostradas abaixo, junto com o controle na ausência de trolox (Figura 10). 


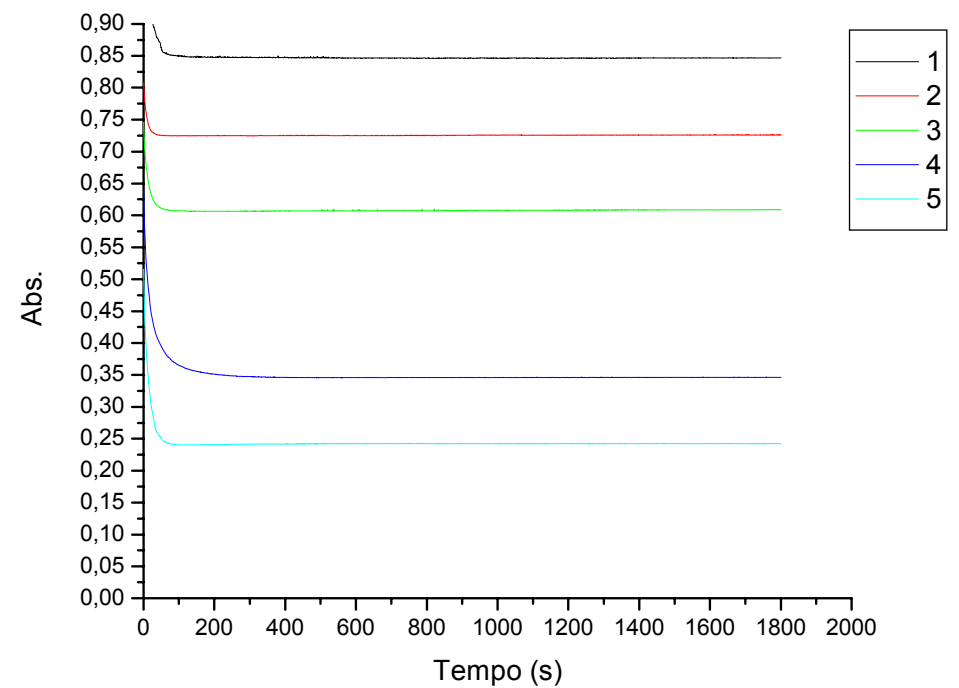

Figura 10: Cinética de reação de DPPH $80 \mu \mathrm{M}$ com e sem adição de trolox monitorada em $515 \mathrm{~nm}$ durante 30 minutos; 1: sem adição de trolox; 2: trolox 7,5 $\mu \mathrm{M}$; 3: trolox $15 \mu \mathrm{M}$; 4: trolox $30 \mu \mathrm{M}$ e 5: trolox $40 \mu \mathrm{M}$.

A curva cinética obtida com DPPH sem adição de trolox durante 30 minutos (Figura 10.1) representa praticamente uma reta sem decaimento, como esperado, por se tratar de um radical estável. Em $515 \mathrm{~nm}$ o valor da absorbância refere-se a 0,85. As demais curvas cinéticas obtidas com trolox mostram um decaimento inicial rápido da absorbância em aproximadamente 100 s, de acordo com a concentração utilizada. Após este decaimento, a absorbância mantém-se praticamente constante durante o período de observação (Figura 10). Através das curvas cinéticas obtidas com adição de trolox em quatro concentrações diferentes, foi possível obter uma curva de calibração da variação da absorbância ( $\triangle$ Abs) com a concentração do aditivo (Figura 11). 


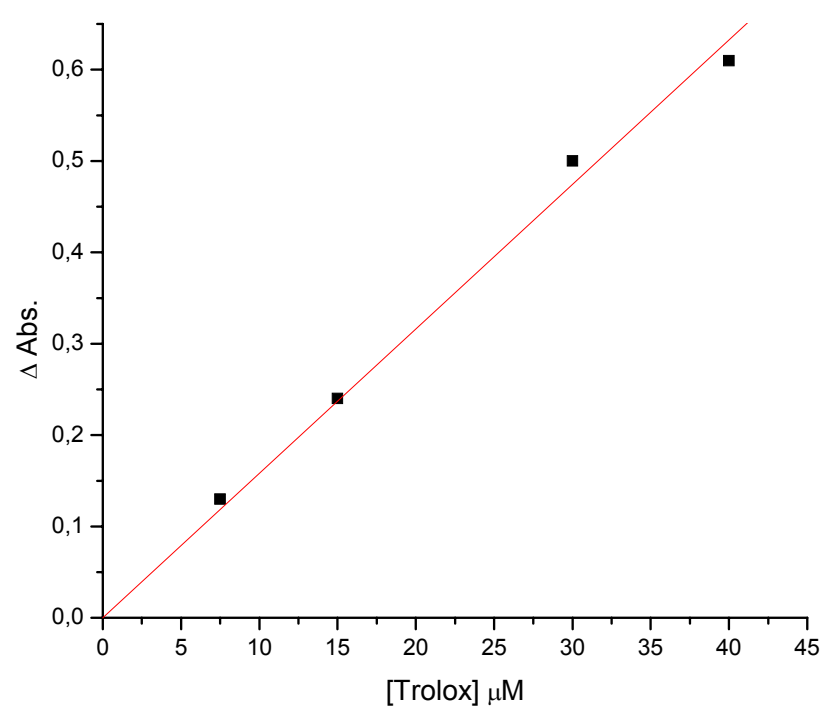

Figura 11: Correlação linear entre a concentração de trolox em $\mu \mathrm{M}$ e $\Delta$ Abs. Coeficiente angular: $0,0158 \pm$ $0,0004 \mu \mathrm{M}^{-1}$.

A Figura 4 mostra que há uma boa correlação linear entre a concentração de trolox utilizada e o $\Delta$ Abs, cujo coeficiente linear obtido foi $0,0158 \mu \mathrm{M}^{-1}$. Após os dados obtidos com trolox, o anti-radical padrão, foram realizados experimentos utilizando-se os mesmos derivados fenólicos, estudados anteriormente com o ensaio de luminol.

As curvas cinéticas obtidas com catecol (Figura 12A) mostram um comportamento diferente do observado com trolox, onde o decaimento da absorbância ocorre lentamente durante praticamente todo o tempo de observação (30 min) de acordo com a concentração utilizada. Já as curvas cinéticas obtidas com pirogalol (Figura 12B) assemelham-se mais às obtidas com trolox, onde há um decaimento mais rápido inicial da absorbância em cerca de $300 \mathrm{~s}$, seguido pelo decaimento muito lento, semelhante à cinética obtida somente com DPPH.

Através das curvas cinéticas obtidas com a adição de catecol e pirogalol como anti-radicais no ensaio de DPPH (Figura 12), em quatro concentrações diferentes, foi possível obter a correlação linear entre o $\Delta$ Abs e a concentração dos aditivos em ambos os casos (Figura 13). 
A

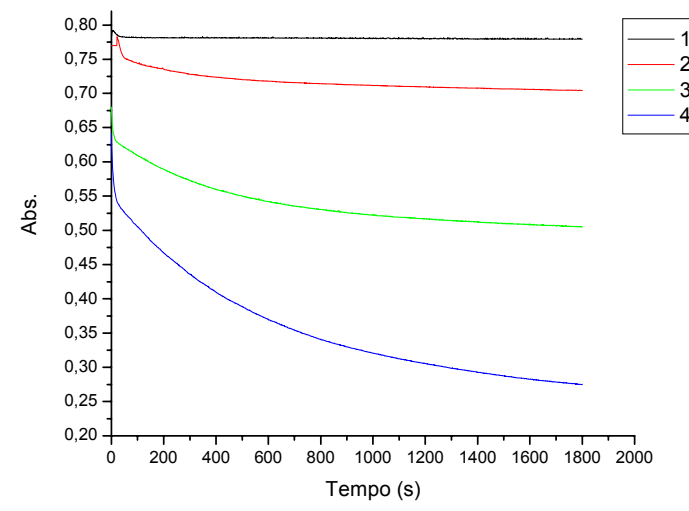

B

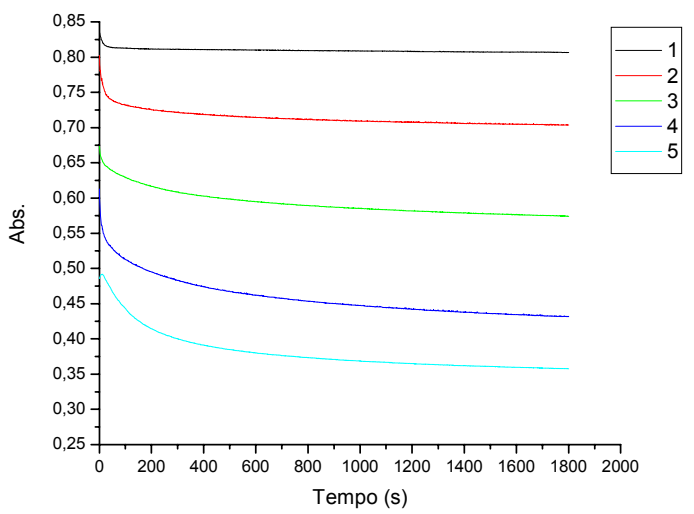

Figura 12: Cinética de reação monitorada em $515 \mathrm{~nm}$ durante 30 minutos de DPPH $80 \mu \mathrm{M}$ com e sem adição

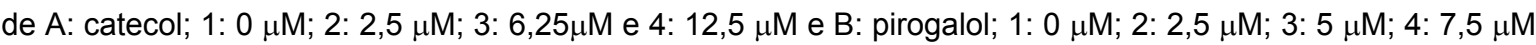
e 5: $10 \mu \mathrm{M}$.

A

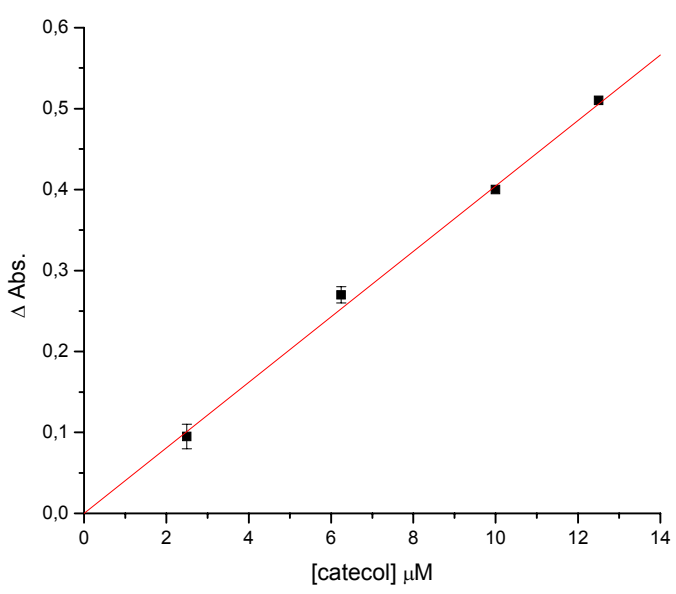

B

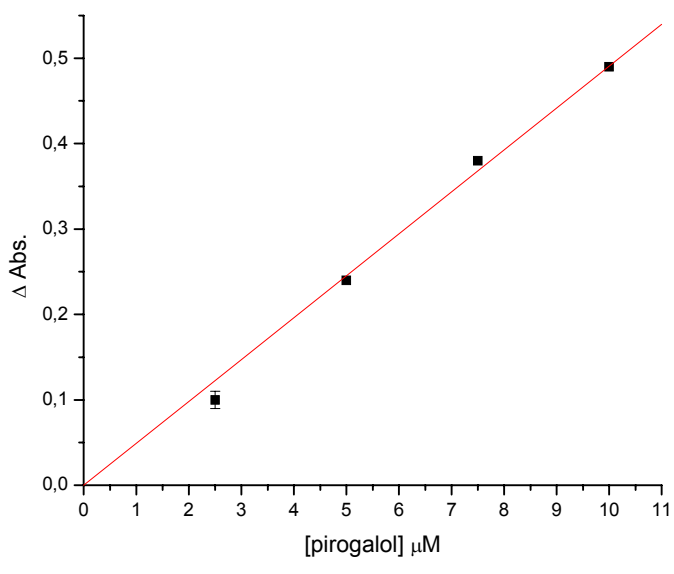

Figura 13: Correlação linear entre concentração de A: catecol em $\mu \mathrm{M}$ e B: pirogalol em $\mu \mathrm{M}$ e $\Delta$ absorbância. Os coeficientes angulares: A: 0,04079 $\pm 0,0006$ e B: $0,04907 \pm 0,0011$

Inicialmente, foi utilizada para estes dois primeiros experimentos com DPPH a mesma abordagem de tratamento de dados que para o ensaio com luminol, onde o coeficiente angular obtido do ajuste da correlação entre a concentração de trolox e a área de supressão $\left(\alpha_{T}\right)$, ao qual corresponde nesse caso o $\Delta$ Abs, é proporcional, por definição, a 2. ou seja, uma molécula de trolox pode seqüestrar dois radicais. ${ }^{45,46,47} \mathrm{O}$ coeficiente angular obtido da amostra $\left(\alpha_{\mathrm{a}}\right)$ através do ajuste da correlação entre a 
concentração e o $\Delta \mathrm{Abs}$, é utilizado para calcular o número de radicais seqüestrados por molécula de anti-radical (n), no caso a amostra (Equação 1).

$$
\mathrm{n}_{\mathrm{a}}=\stackrel{\alpha_{\mathrm{a}}}{-\alpha_{\mathrm{t}}} \cdot \cdot 2
$$

\section{Equação 1}

A partir do coeficiente angular obtido com trolox $(0,0158)$ foi possível calcular os valores de $n$ para os compostos-modelo estudados frente ao ensaio de DPPH. Os valores de $n$ obtidos foram 5,2 e 6,2 para catecol e pirogalol respectivamente. Pirogalol obteve um valor de $\mathrm{n}$ maior, ou seja, possui uma maior atividade anti-radicalar que catecol frente ao ensaio de DPPH. Esse resultado sugere que a capacidade antiradical, nesse ensaio, depende do número de hidroxilas presentes na amostra, lembrando que pirogalol possui três hidroxilas em sua estrutura enquanto catecol possui apenas duas.

Tendo em vista que o valor da absorbância da solução de DPPH $78 \mu \mathrm{M}$, nesse ensaio com trolox, foi 0,85 (Figura 10.1), é possível, utilizando-se uma segunda abordagem, determinar um valor absoluto $\left(n^{*}\right)$ para o número de radicais de DPPH seqüestrados pelo trolox. O número de radicais seqüestrados por molécula do composto anti-radicalarpode ser determinado diretamente pelo decréscimo da absorbância em $515 \mathrm{~nm}$, a qual corresponde ao seqüestro do radical DPPH pelo aditivo. O método baseia-se na obtenção da correlação da concentração do radical DPPH seqüestrado com a concentração de trolox adicionado. Destes dados obtém-se um valor de $n=1,4$ para o trolox, ou seja, uma molécula de trolox é capaz de seqüestrar 1,4 moléculas do radical DPPH (Figura 14). 


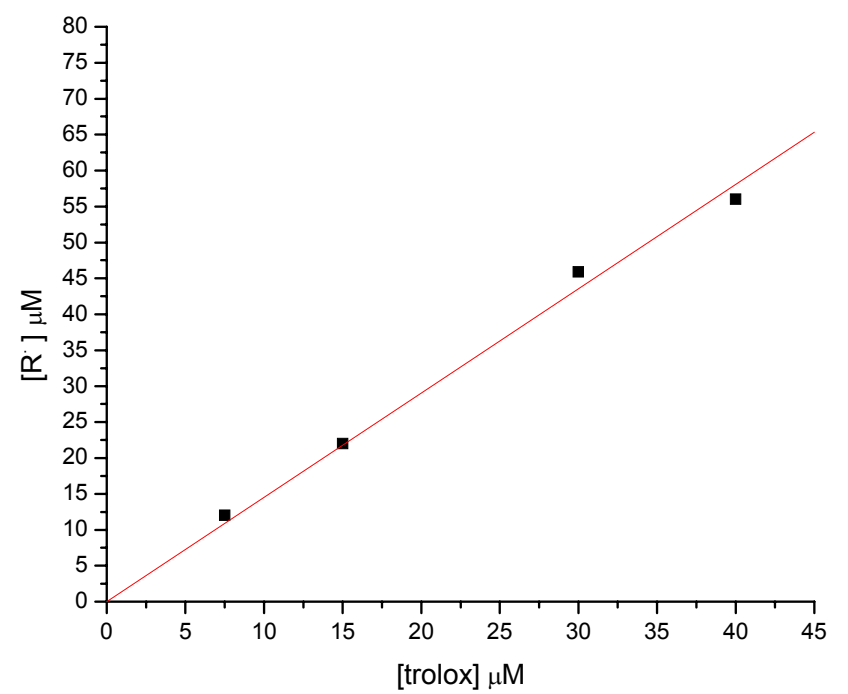

Figura 14: Correlação linear entre a concentração de trolox adicionado e a concentração do radical DPPH seqüestrado [Rं]. Coeficiente angular: $n^{*}=1,4$.

Da mesma maneira como realizado com trolox, é possível determinar os valores de $n^{*}$ para os compostos-modelo, ou seja, a capacidade anti-radicalar frente ao ensaio com DPPH. Foram obtidas correlações lineares entre a concentração dos aditivos e a concentração do radical DPPH seqüestrado (Figuras 15, 16 e 17). As demais curvas cinéticas, as quais permitiram o cálculo de $n^{*}$, estão omitidas, pois se assemelham às curvas cinéticas obtidas com catecol e pirogalol (Figura 12). 
A

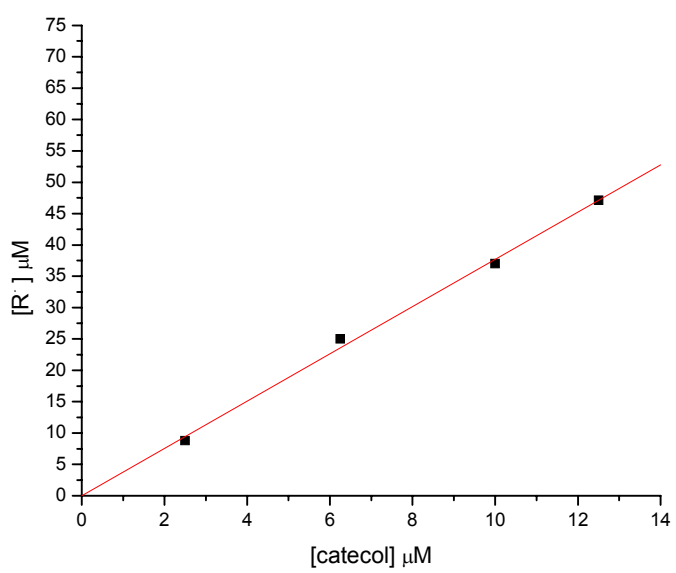

C

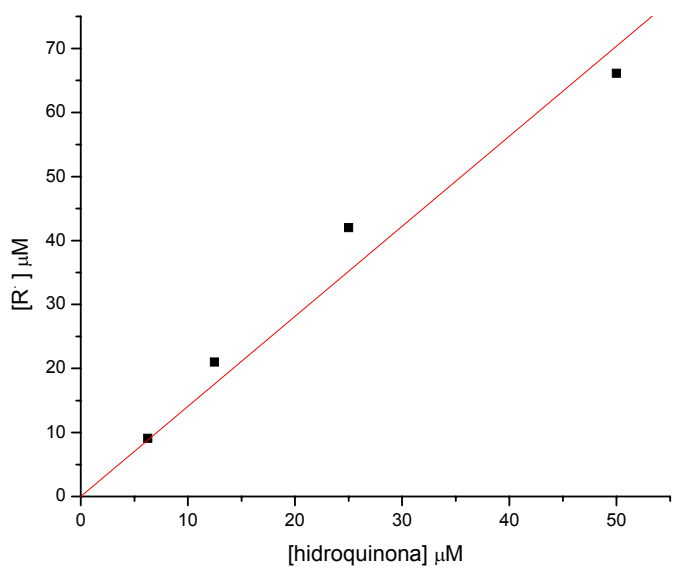

B

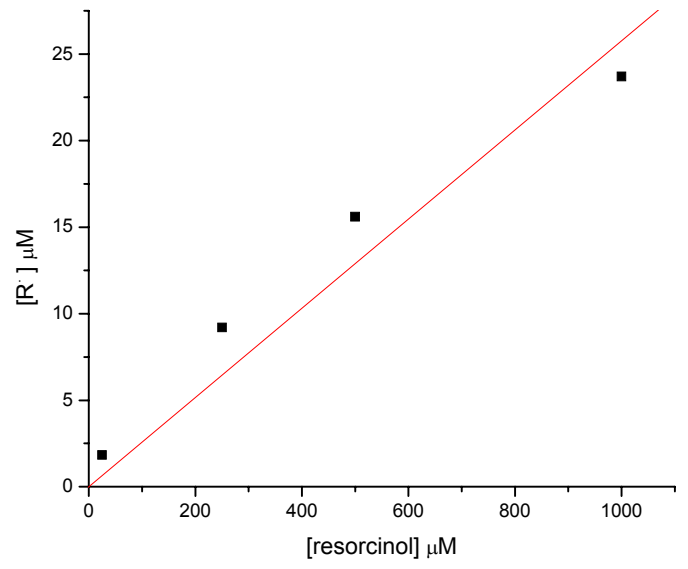

D

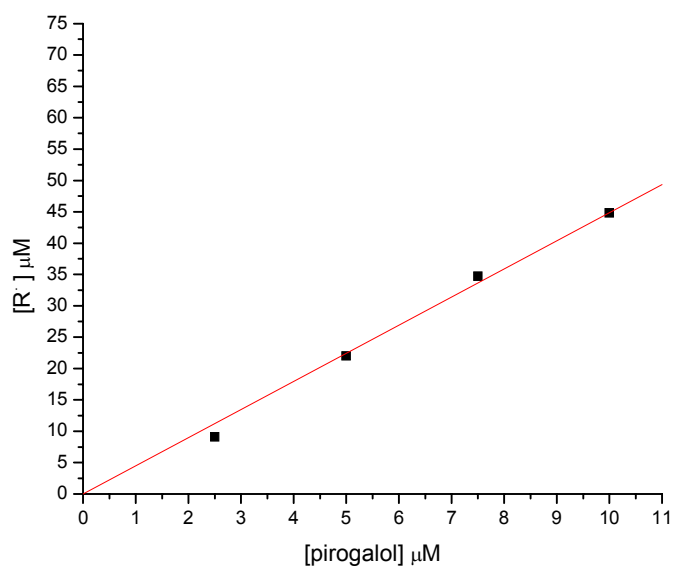

Figura 15: Correlação linear entre concentração do radical DPPH seqüestrado $[R]$ e a concentração de $A$ : catecol, B: resorcinol, C:hidroquinona e D: pirogalol. Coeficientes angulares: A: 3,8, B: 0,02, C: 1,4 e D: 4,5. 
A

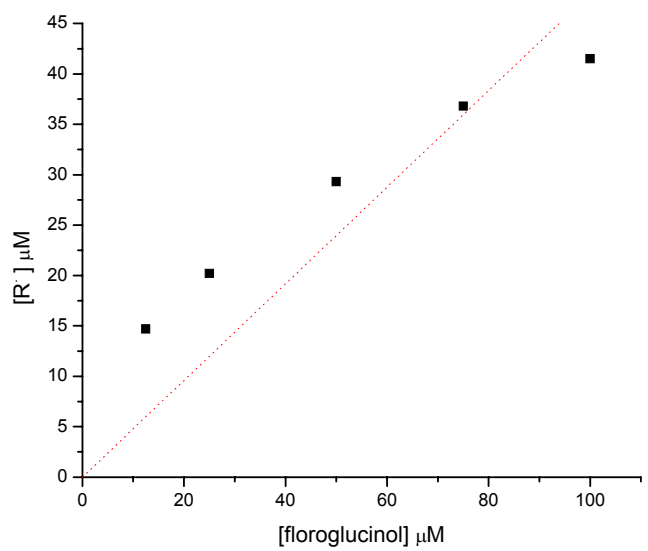

B

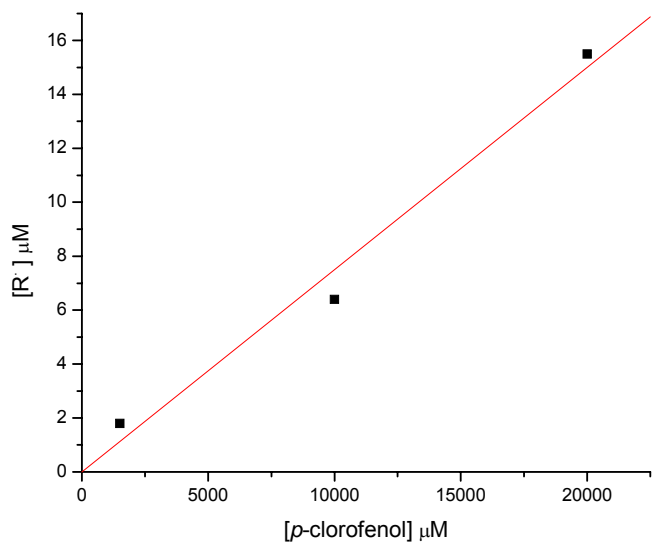

Figura 16: Correlação linear entre concentração do radical DPPH seqüestrado [R'] e a concentração de A: floroglucinol, B: p-clorofenol. Coeficientes angulares: A: 0,5 e B: 0,0007.

O coeficiente angular obtido através da correlação linear entre a concentração do composto-modelo e a concentração do radical DPPH seqüestrado indica agora o valor de n "absoluto" aparentemente nunca reportado antes na literatura desta maneira. Entre os compostos-modelo dos quais foi possível o cálculo de $\mathrm{n}^{*}$, a maioria apresentou uma boa correlação linear, exceto alguns aditivos como floroglucinol e no caso do $p$-clorofenol e $p$-cianofenol onde só foi possível obter a correlação linear utilizando-se três concentrações. Os valores de $\mathrm{n}^{*}$ variam entre $7.10^{-4}$ para o $p$ clorofenol e 4,5 para pirogalol, o aditivo com a maior capacidade anti-radicalar, ou seja, cada molécula de pirogalol é capaz de seqüestrar 4,5 radicais de DPPH (Tabela 2). 
A

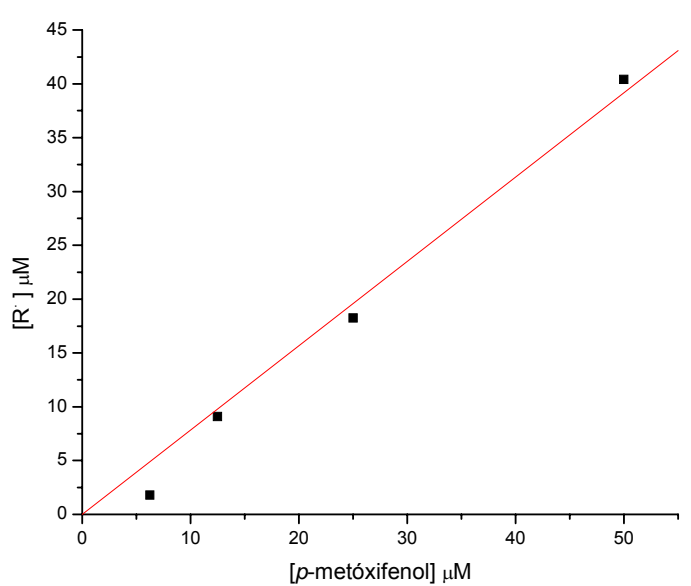

B

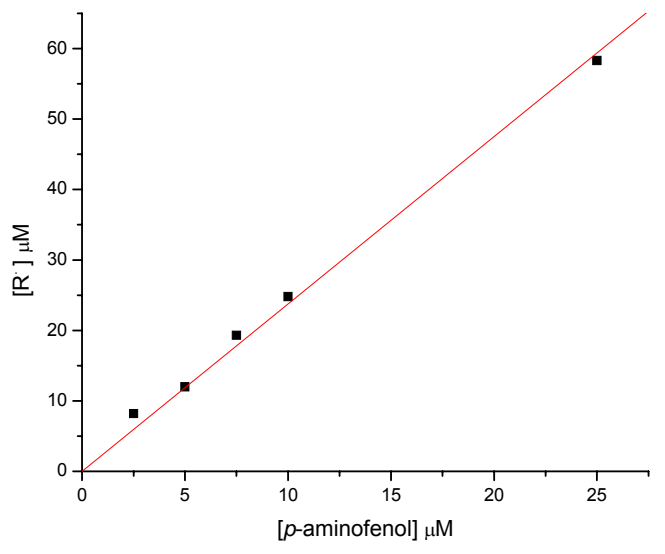

C

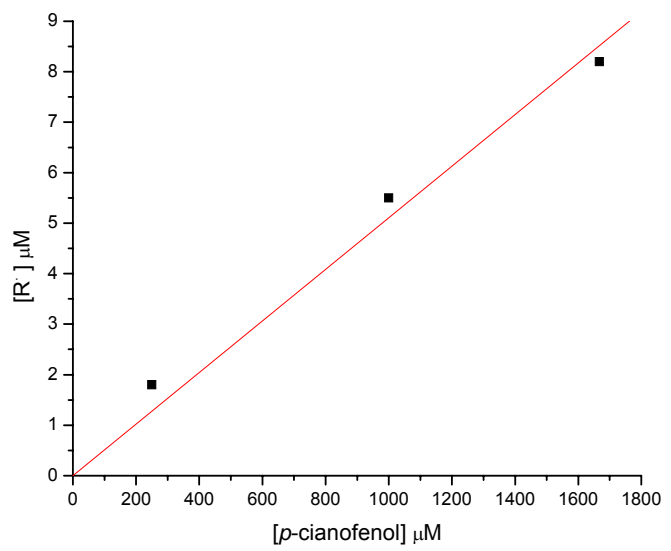

Figura 17: Correlação linear entre concentração do radical DPPH seqüestrado [R] e a concentração de A: $p$ metoxifeno, B: p-aminofenol e C: p-cianofenol. Coeficientes angulares: A: 0,8, B: 2,4 e C: 0,005. 
Tabela 2: Atividade anti-radical expressa em termos de número de radicais DPPH seqüestrados por molécula de anti-radical (n), intervalo de concentrações do composto-modelo utilizado e intervalo de concentrações do radical seqüestrado.

\begin{tabular}{cccc}
\hline Compostos-modelo & $\begin{array}{c}\text { Intervalo de } \\
{[\mathrm{AOH}] \mu \mathrm{M}}\end{array}$ & $\begin{array}{c}\text { Intervalo de } \\
{[\mathrm{R} \cdot] \mu \mathrm{M}}\end{array}$ & $\mathrm{n}^{*}$ \\
\hline catecol & $2,5-12,5$ & $8,8-47,1$ & \\
resorcinol & $25,0-1000,0$ & $1,8-23,7$ & 0,02 \\
hidroquinona & $6,2-50,0$ & $9,1-66,1$ & 1,4 \\
pirogalol & $2,5-10,0$ & $9,1-44,8$ & 4,5 \\
floroglucinol & $12,5-100,0$ & $14,7-41,5$ & 0,5 \\
p-clorofenol & $1500,0-20000,0$ & $1,8-15,5$ & 0,0007 \\
$p$-metoxifenol & $6,2-50,0$ & $1,8-40,4$ & 0,8 \\
p-aminofenol & $2,5-25,0$ & $8,2-58,3$ & 2,4 \\
$p$-cianofenol & $250,0-4750,0$ & $1,8-11,0$ & 0,005 \\
\hline
\end{tabular}




\section{Estudos das Propriedades Antioxidante de Espécies de Baccharis}

Com o objetivo de obter uma avaliação preliminar da atividade anti-radicalar de infusões de cinco espécies de Baccharis, sendo elas trimera, regnellii, dracunculifolia, microdonta e sp, estas foram submetidas ao ensaio luminol. Foram testadas preliminarmente as infusões devido ao uso como medicina alternativa desde a antigüidade. $^{48}$

A figura 18 mostra um exemplo de curvas cinéticas obtidas com a infusão de $B$. regnellii. As demais curvas cinéticas obtidas com outras espécies estão omitidas, pois possuem comportamento semelhante às curvas obtidas com $B$. regnellii. Os experimentos foram realizados três vezes para cada infusão.

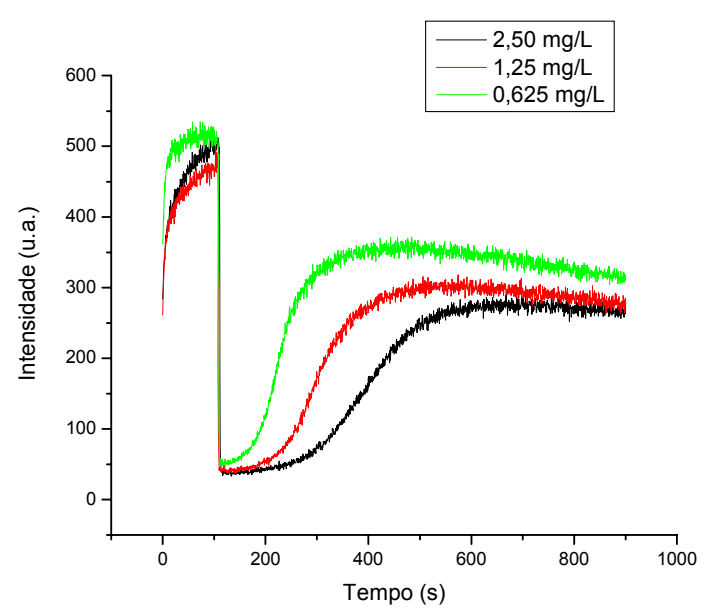

Figura 18: Cinética de decaimento do sistema luminol/ $\mathrm{H}_{2} \mathrm{O}_{2} /$ hemina frente à adição de infusão de $B$. regnellii após 100 s de seu início.

As curvas cinéticas obtidas com a infusão de $B$. regnellii não seguem o mesmo padrão que as curvas obtidas com o trolox (Figura 1A). As áreas de supressão observadas nas curvas cinéticas obtidas por essa infusão atingem o nível da linha base, mas o retorno da emissão é gradual, pois possuem reatividade intermediária frente ao ensaio quimiluminescente de luminol, conforme discutido anteriormente (Esquema 3), mesmo assim foi possível calcular as áreas de supressão para cada concentração utilizada, lembrando que para obter a dependência linear entre concentração e área de supressão, as concentrações mais altas não foram 
consideradas devido a um erro na determinação das áreas correspondentes. (Figuras 19 e 20).

A

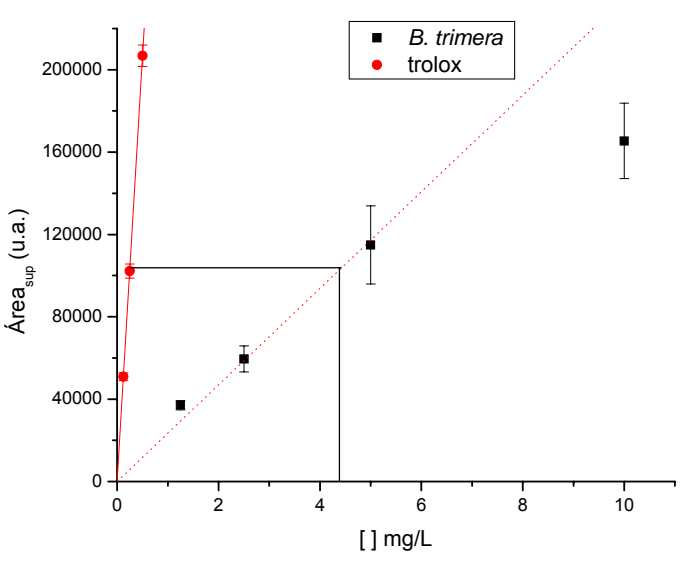

B

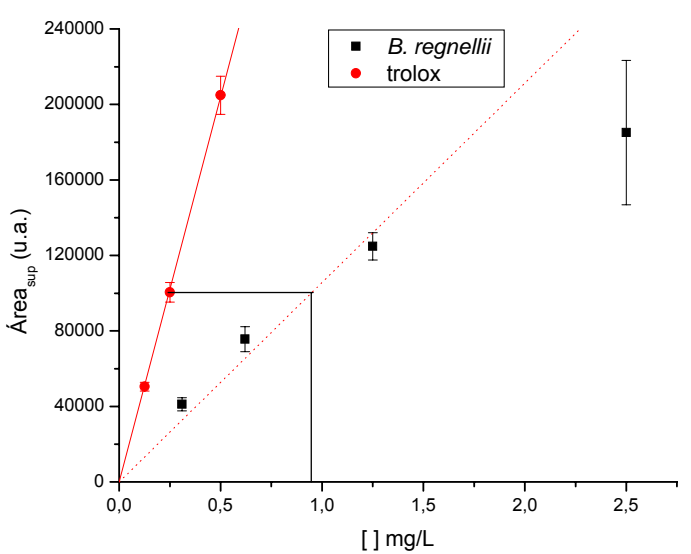

Figura 19: Dependência linear entre a concentração de extrato de A: B. trimera e B: B.regnellii e a área de supressão, em comparação com padrão trolox. Os valores para 10 e 2,5 mg/L não foram considerados. 
A

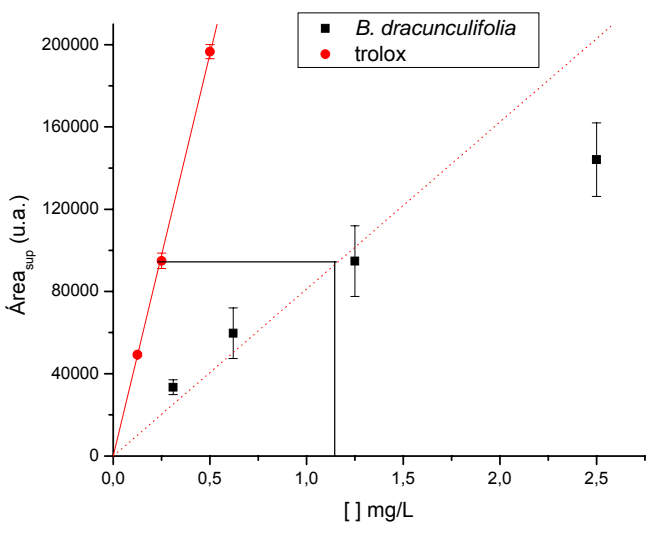

B

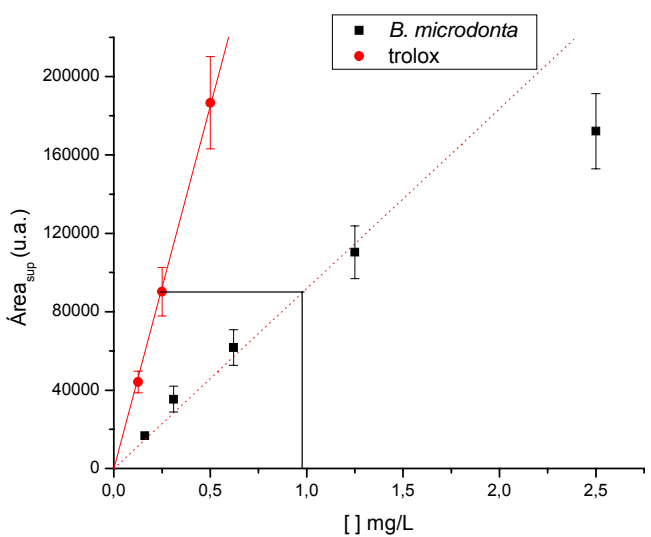

C

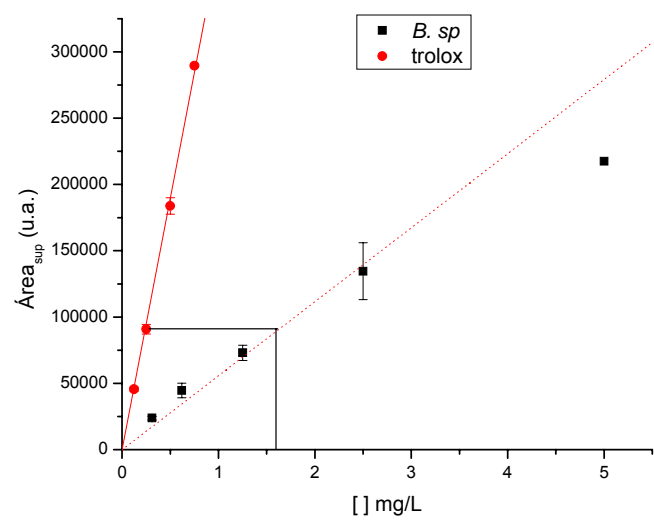

Figura 20: Dependência linear entre a concentração de extrato de A: B. dracunculifolia, B: B. microdonta e J: B.sp. e a área de supressão, em comparação com o padrão trolox. Os valores para 2,5 e $5 \mathrm{mg} / \mathrm{L}$ não foram considerados.

Por não se tratar de substâncias puras, foi necessário utilizar a metodologia de cálculo do parâmetro de seqüestro total de radicais (TRAP) para as infusões. (Tabela $3)^{14}$ 
Tabela 3: Potencial Anti-radical Total (TRAP) expresso em mg/L, intervalo de concentrações utilizadas e as inclinações das retas obtidas com trolox e com as infusões estudados.

\begin{tabular}{ccccc}
\hline $\begin{array}{c}\text { Espécies de } \\
\text { Baccharis }\end{array}$ & $\begin{array}{c}\text { Intervalo } \\
\text { de }[] \mathrm{mg} / \mathrm{L}\end{array}$ & $\begin{array}{c}\text { Inclinação } \\
\text { Trolox }\end{array}$ & Inclinação Infusão & TRAP (mg/L) \\
\hline trimera & $1,25-10,00$ & $412000 \pm 1510$ & $23400 \pm 1010$ & $4,38 \pm 1,08$ \\
regnellii & $0,15-2,50$ & $408000 \pm 2260$ & $106000 \pm 7460$ & $0,95 \pm 0,40$ \\
dracunculifolia & $0,30-2,50$ & $391000 \pm 3780$ & $812000 \pm 7000$ & $1,14 \pm 0,01$ \\
microdonta & $0,15-2,50$ & $370000 \pm 4320$ & $91800 \pm 4000$ & $0,98 \pm 0,25$ \\
sp & $0,30-5,00$ & $380000 \pm 5450$ & $56000 \pm 2700$ & $1,60 \pm 0,47$ \\
\hline
\end{tabular}

Através da tabela 3 é possível observar os intervalos de concentrações utilizados de cada infusão, todos os compostos foram estudados na mesma faixa de concentração, com exceção da $B$. trimera que foi estudada até $10,00 \mathrm{mg} / \mathrm{L}$ devido ao seu baixo potencial anti-radical total (TRAP). Além disso, também são mostradas as inclinações das retas obtidas com trolox e com as infusões, o que permitiu observar que os maiores valores de inclinação obtidos pelas infusões referem-se à espécie que possui menor TRAP, ou seja, maior potencial anti-radical.

Dentre as espécies de Baccharis estudadas, a microdonta e regnelli apresentaram menores valores de TRAP (0,98 e 0,95 respectivamente). Esse valor equivale à concentração de amostra em $\mathrm{mg} / \mathrm{L}$ necessária para produzir o efeito obtido por uma concentração de $1 \mu \mathrm{M}$ de trolox, o composto de referência, ou seja, essas espécies possuem maior atividade anti-radicalar que dracunculifolia $(1,14), s p(1,60)$ e trimera $(4,38)$ respectivamente.

Com o objetivo de dar continuidade ao estudo de espécies de Baccharis, a espécie $B$. regnellii foi escolhida por ter obtido um bom resultado preliminar de potencial anti-radicalar de sua infusão e principalmente por se tratar de uma espécie pouco estudada na literatura.

A partir das partes aéreas de $B$. regnellii, foram obtidos o extrato metanólico e suas fases em hexano, diclorometano, acetato de etila e n-butanol (Materiais e Métodos). Em caráter preliminar, foram obtidos espectros de Ressonância Nuclear de ${ }^{1} \mathrm{H}\left(\mathrm{RMN}{ }^{1} \mathrm{H}\right)$ para as fases. Os espectros obtidos das fases em diclorometano, acetado de etila e n-butanol apresentaram sinais entre $\delta 6$ e 7 ppm, característicos para hidrogênios aromáticos, o que poderia indicar a presença de flavonóides. Já o espectro obtido com a fase hexânica, não apresentou qualquer sinal entre 6 e 7 ppm, mas apresentou sinais em campo alto próximo a $1 \mathrm{ppm}$, o que sugere que essa fase é constituída principalmente de ácidos graxos. 
Com o intuito de avaliar a capacidade anti-radical, o extrato metanólico e suas respectivas fases (exceto a fase hexânica) foram submetidos ao ensaio quimiluminescente do luminol.

As curvas cinéticas obtidas com extrato metanólico e com as fases em diclorometano, n-butanol e acetato de etila apresentam um perfil que não segue exatamente ao perfil das curvas obtidas com trolox (Figura 1A), entretanto, apresentam um comportamento convencional onde há inibição imediata da emissão após a adição do composto anti-radicalar e observa-se o retorno da emissão de luz após um determinado tempo, o qual depende da concentração utilizada (Figura 6).

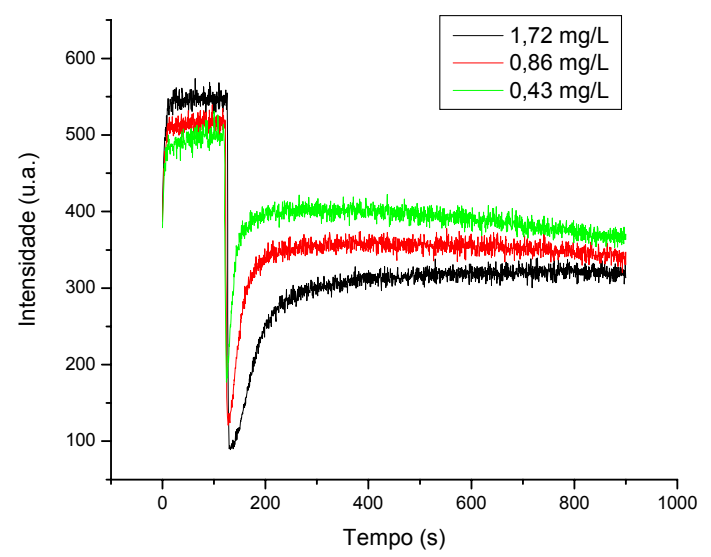

Figura 21: Cinética de decaimento do sistema luminol $/ \mathrm{H}_{2} \mathrm{O}_{2} /$ hemina frente à adição de fase em diclorometano após 100 s de seu início.

A figura 21 mostra somente exemplos de curvas cinéticas obtidas com a fase em diclorometano, pois as demais curvas cinéticas obtidas com as outras fases mostram comportamento semelhante às curvas cinéticas obtidas com a fase em diclorometano. Todos os ensaios foram realizados pelo menos duas vezes. Por apresentarem curvas cinéticas com comportamento convencional, foi possível obter correlação linear entre as concentrações dos extratos e a área de supressão (Figura 7). 
A

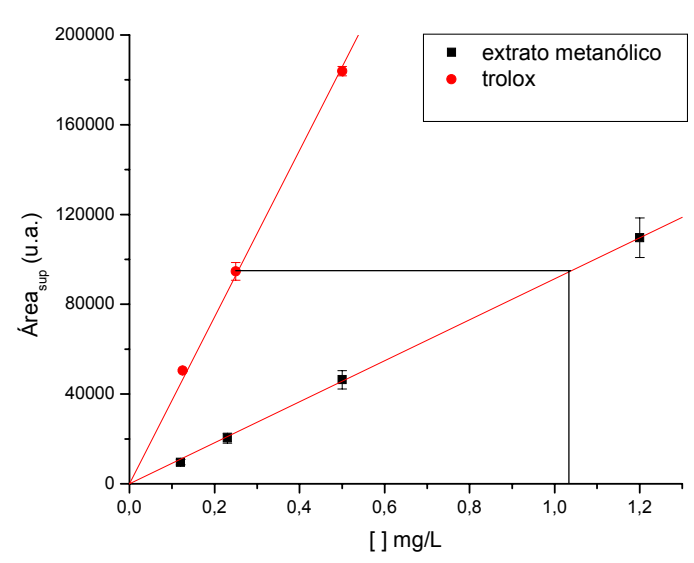

C

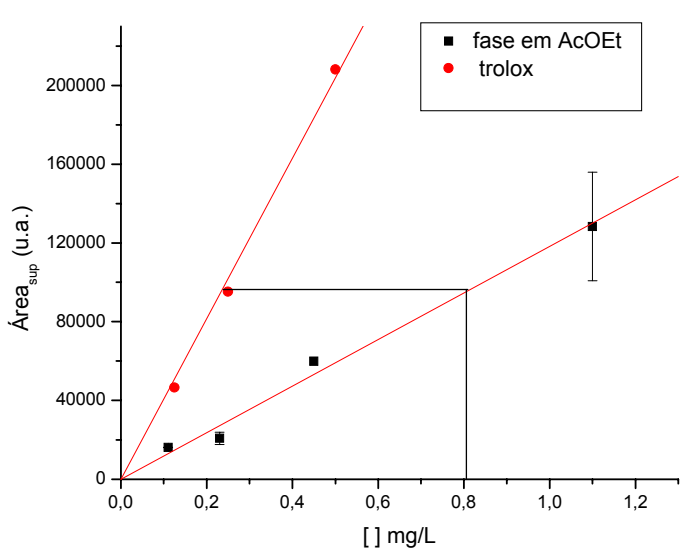

B

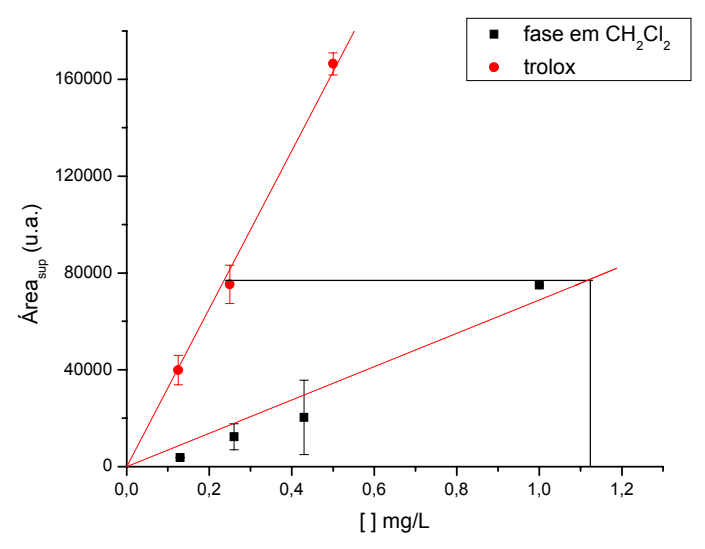

D

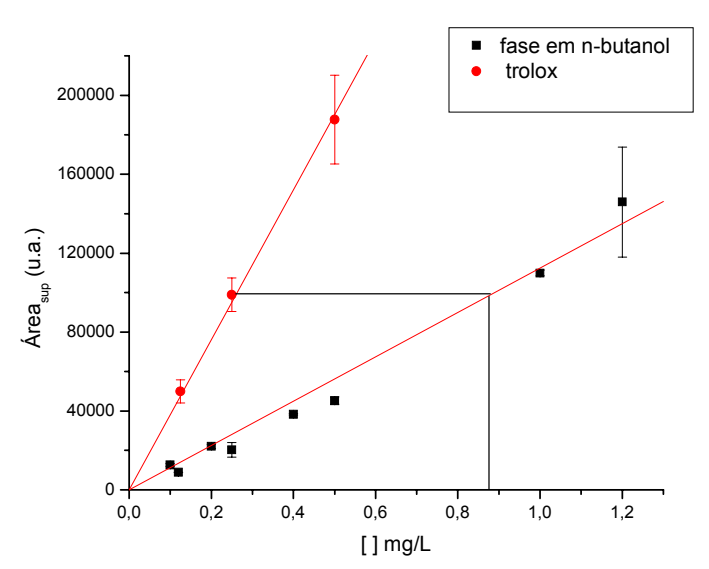

Figura 22: Dependência da área de supressão com a concentração do aditivo: $A$ : extrato metanólico, $B$ : fase em diclorometano, C: fase em acetato de etila e D: fase em n-butanol. Os valores para o padrão trolox mostrados nos gráficos correspondem a concentrações de 0,5, 1 e $2 \mu \mathrm{M}$.

Por não se tratar de substâncias puras, foi necessário utilizar a metodologia de cálculo de parâmetro de seqüestro total de radicais (TRAP) para os extratos. ${ }^{17}$ Através da tabela 3 é possível observar que o intervalo de concentrações estudado foi bem próximo para todos os extratos. São mostrados também os valores das inclinações obtidos com trolox e com os extratos, além disso, são mostrados os desvios padrão das medidas, das quais vale ressaltar um erro experimental relativamente alto para a fase em diclorometano. Os maiores valores de inclinação são atribuídos aos que possuem maior capacidade anti-radical, são estas para os quais são determinados os menores valores de TRAP obtidos refletem aos extratos com maior capacidade antiradicalar. 
Tabela 4: Potencial Anti-radical Total (TRAP) expresso em mg/L, intervalo de concentração utilizado e as inclinações das retas obtidas com trolox e com os extratos estudados.

\begin{tabular}{ccccc}
\hline $\begin{array}{c}\text { Baccharis } \\
\text { regnellii }\end{array}$ & $\begin{array}{c}\text { Intervalo } \\
\text { de [ ] mg/L }\end{array}$ & $\begin{array}{c}\text { Inclinação } \\
\text { Trolox }\end{array}$ & Inclinação Extrato & TRAP (mg/L) \\
\hline $\begin{array}{c}\text { extrato } \\
\text { metanólico } \\
\text { fase em }\end{array}$ & $0,1-1,2$ & $371000 \pm 6000$ & $91400 \pm 700$ & $1,0 \pm 0,08$ \\
$\begin{array}{c}\text { diclorometano } \\
\text { fase em }\end{array}$ & $0,1-1,7$ & $326000 \pm 8800$ & $69000 \pm 6900$ & $1,1 \pm 0,70$ \\
$\begin{array}{c}\text { acetato de etila } \\
\text { fase em } \\
\text { n-butanol }\end{array}$ & $0,1-1,1$ & $407000 \pm 11100$ & $118000 \pm 4740$ & $0,8 \pm 0,22$ \\
\hline
\end{tabular}

Apesar dos extratos estudados apresentarem valores de TRAP muito próximos, é possível atribuir uma maior capacidade anti-radical para a fase em acetato de etila, $(0,8)$, seguido pela fase em $n$-butanol $(0,9)$, extrato metanólico $(1,0)$ e fase em diclorometano $(1,1)$.

Por se tratar da fração que apresentou maior atividade anti-radicalar, a fase em acetato de etila foi submetida a um estudo fitoquímico monitorado o que resultou no isolamento de duas substâncias majoritárias nessa fase. (Esquema 1)

Foi realizada uma injeção da fase em acetato de etila em um cromatógrafo CLAE (Waters) munido de detector "diode-array" utilizando-se o gradiente de eluição descrito por Mattila et al para determinação de flavonóides em material vegetal. ${ }^{49} \mathrm{~A}$ corrida foi realizada até setenta minutos, mas somente observa-se sinais até os quinze minutos iniciais. O cromatograma foi registrado em $307 \mathrm{~nm}$, onde os sinais apresentaram maior intensidade e mostra que o gradiente de eluição foi eficiente (Figura 21). 


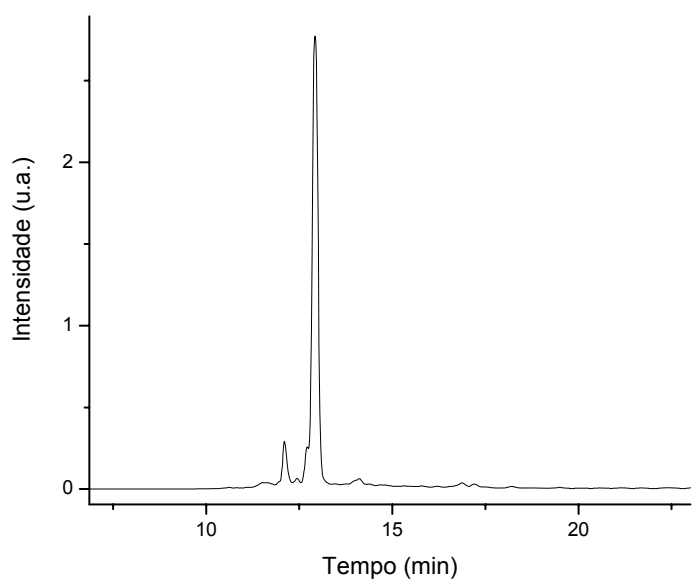

Figura 23: Cromatograma obtido com a fase em acetato de etila registrado em $307 \mathrm{~nm}$.

Através do cromatograma obtido com a fase em acetato de etila, é possível observar que essa fase apresenta apenas duas substâncias majoritárias que absorvem intensamente em $307 \mathrm{~nm}$, o que sugere que sejam derivados de ácidos cinâmicos, compostos que podem absorver nessa faixa (Figura 21). ${ }^{50}$

As duas substâncias presentes em maior quantidade na fase em interesse, foram isoladas como mostrado no Esquema 1 (veja Materiais e Métodos). De acordo com o cronograma de separação, as substâncias foram preliminarmente denominadas em F-8.1 e F-9.3 (Esquema 1). Os produtos isolados e purificados foram injetados com o mesmo gradiente utilizado anteriormente (Figura 22). ${ }^{49}$ 
A

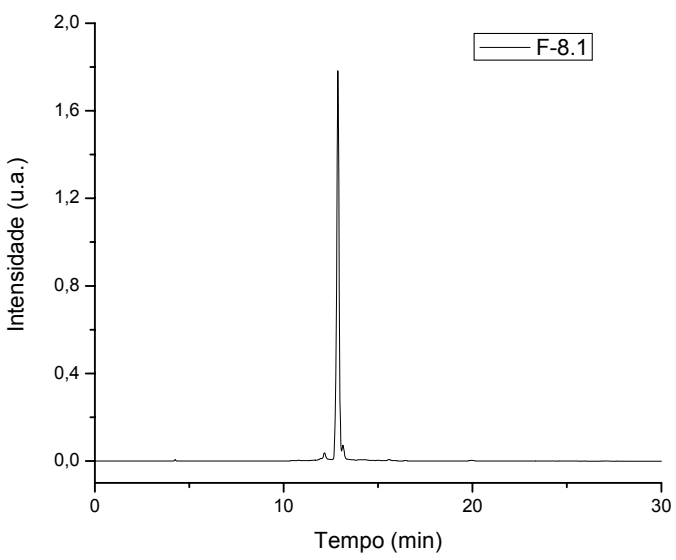

B

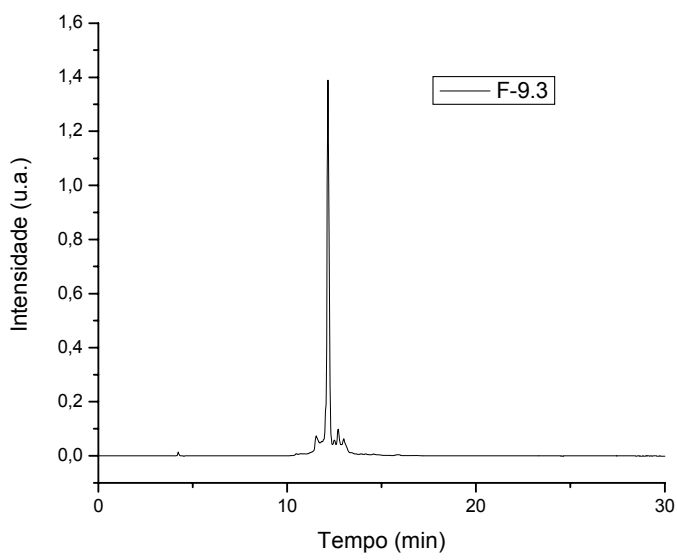

C

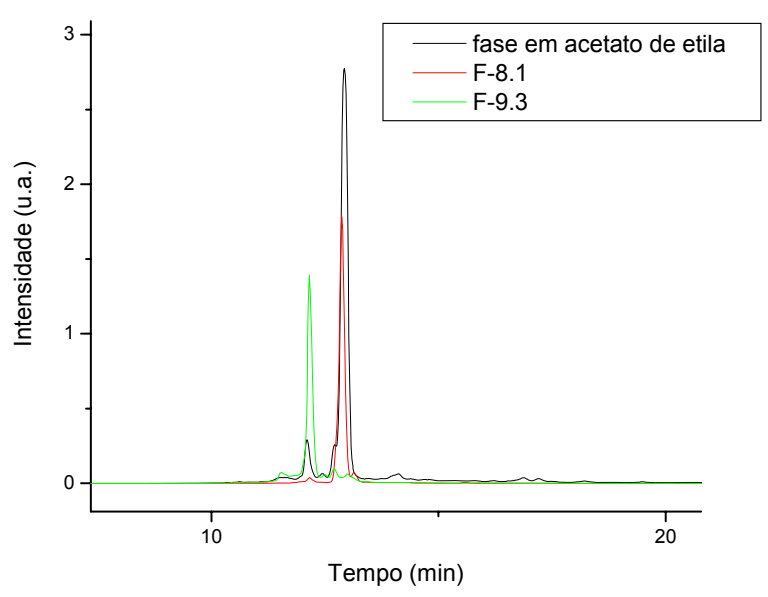

Figura 24: Cromatogramas refentes a A: F-8.1; B: F- 9.3 e C: efeito comparativo entre as duas frações e a fase em acetato de etila. Esses cromatogramas foram monitorados em $307 \mathrm{~nm}$.

Os cromatogramas obtidos com as substâncias isoladas, F-8.1 e F-9.3, mostram que os produtos obtidos são relativamente puros e que o gradiente utilizado foi eficiente (Figura 22). A substância F-8.1 possui um tempo de retenção de 12,9 min, enquanto que $\mathrm{F}-9.3$ possui um tempo de retenção de $12,1 \mathrm{~min}$, o que sugere que F-8.1 seja um pouco menos polar que F-9.3 (Figura 22). Além disso, os tempos de retenção dos picos observados no extrato e das substâncias isoladas são coincidentes (Figura 22). Os espectros de absorção dos picos das substâncias isoladas mostram-se muito similares (Figura 23). 


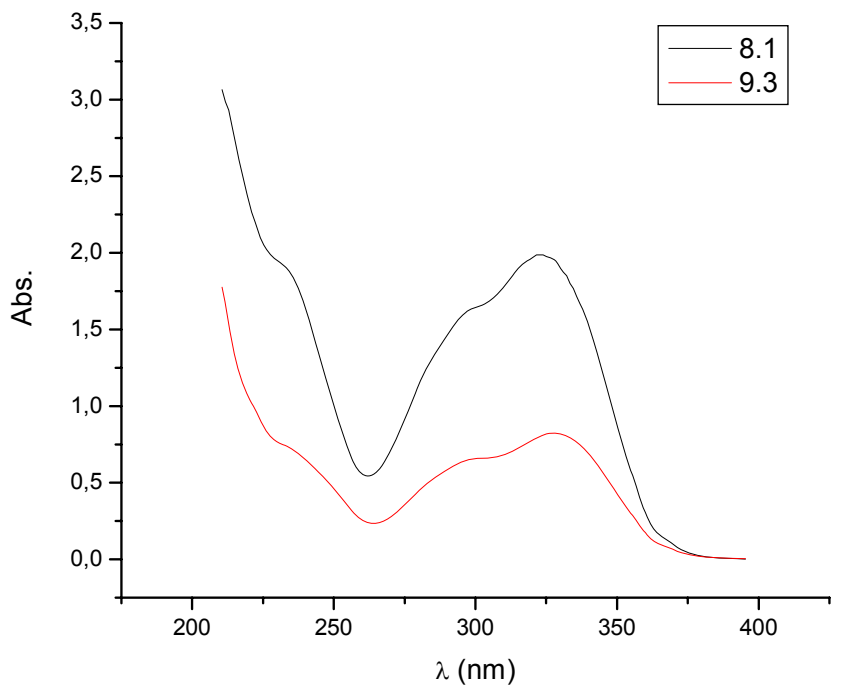

Figura 25: Espectros de absorção obtidos com: F-8.1 e F-9.3.

Os espectros de absorção mostram que as duas substâncias absorvem em aproximadamente 305 e $327 \mathrm{~nm}$ e que possuem espectros bem semelhantes além de tempo de retenção bem próximos.

Com o objetivo de dar continuidade ao estudo fitoquímico monitorado da $B$. regnelli, as duas substâncias isoladas foram submetidas ao ensaio luminol para determinar a capacidade anti-radicalar (Figura 24).

A

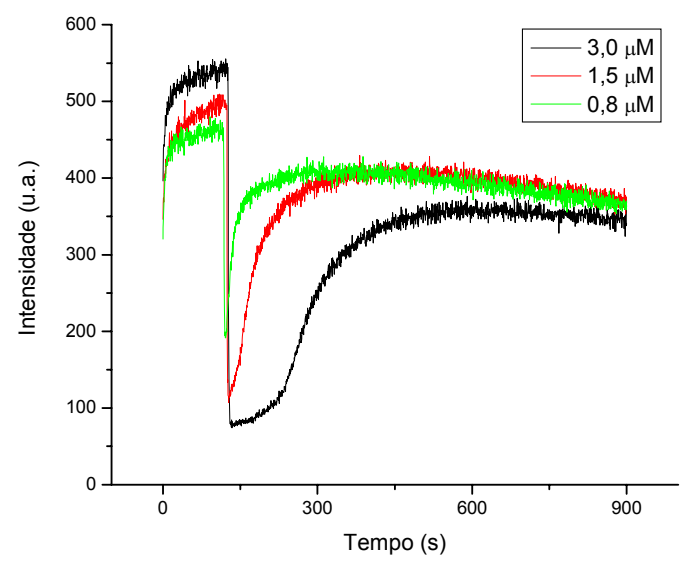

B

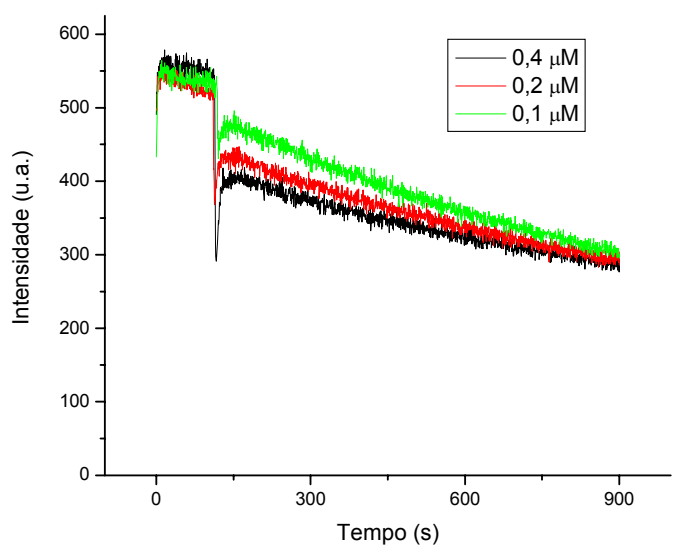

Figura 26: Cinética de decaimento do sistema luminol/ $\mathrm{H}_{2} \mathrm{O}_{2} /$ hemina frente à adição de A: F-9.3 e B: F-8.1 após $100 \mathrm{~s}$ de seu início

As curvas cinéticas obtidas com F-9.3 mostram um comportamento semelhante às curvas cinéticas obtidas com a infusão e os extratos da $B$. regnellii já discutidas 
anteriormente, e permitiram o cálculo de n (Figuras 18, 21, 26A e 27A). Já as curvas cinéticas obtidas com F-8.1 mostram um comportamento não convencional já discutido anteriormente, onde só foi possível o cálculo de $\mathrm{n}$ utilizando-se apenas três concentrações devido ao não retorno da intensidade de luz para concentrações mais altas (Figuras 26B e 27B).

A

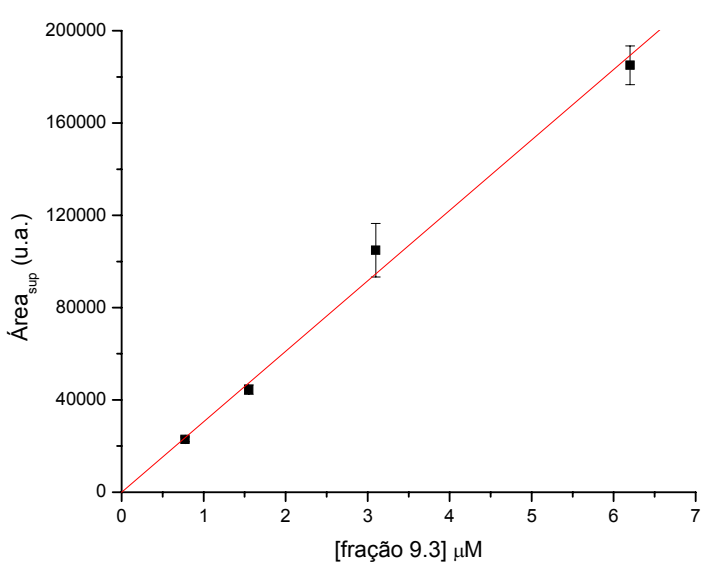

B

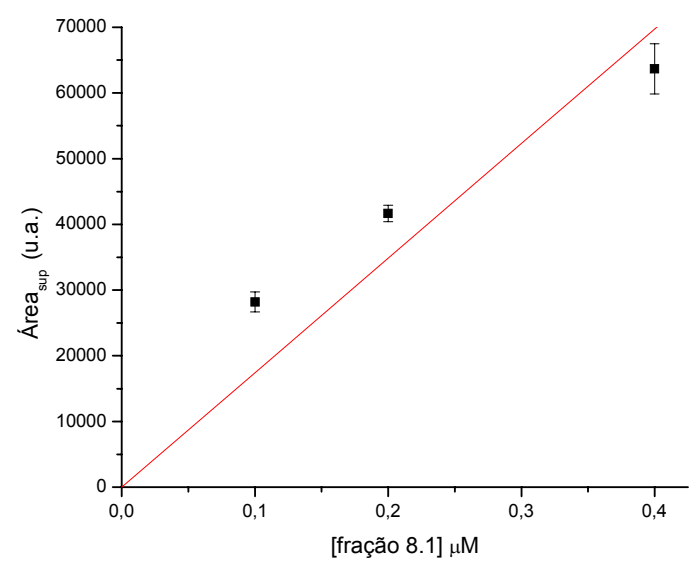

Figura 27: Correlação linear entre a concentração de A: F-9.3 e B: F-8.1 e a área de supressão.

De acordo com os gráficos de área de supressão versus concentração foram obtidos os valores de $\mathrm{n}$ para as substâncias isoladas, da qual F-9.3 apresentou maior atividade anti-radicalar $(n=0,71 \pm 0,02)$ que F-8.1 ( $n=0,4 \pm 0,25)$ frente ao ensaio luminol. 


\section{Discussão}

\section{Estudos da Atividade Anti-radicalar de Flavonóides e Compostos-Modelo}

A determinação da capacidade anti-radicalar de vários flavonóides e derivados análogos, utilizando-se o ensaio quimiluminescente com luminol/ $\mathrm{H}_{2} \mathrm{O}_{2} /$ hemina, levou à obtenção de valores desta capacidade $n$, obtidos em comparação com o padrão trolox $(n=2)$. A tabela 5 mostra os resultados destes estudos agregados a resultados obtidos anteriormente pelo grupo (Tabela 5). 17,51,52

Tabela 5: Atividade anti-radicalar expressa em termos de número de radicais seqüestrados por molécula de anti-radical e características estruturais de alguns flavonóides estudados

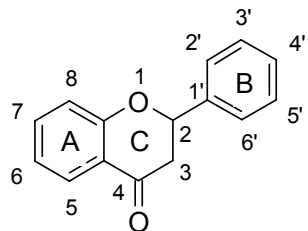

flavonóides<smiles>Oc1cc(O)c2c(c1)O[C@H](c1ccc(O)c(O)c1)[C@H](O)C2</smiles>

$(+)$-catequina<smiles>Oc1cc(O)c2c(c1)O[C@H](c1ccc(O)c(O)c1)[C@H](O)C2</smiles>

(-)-epicatequina

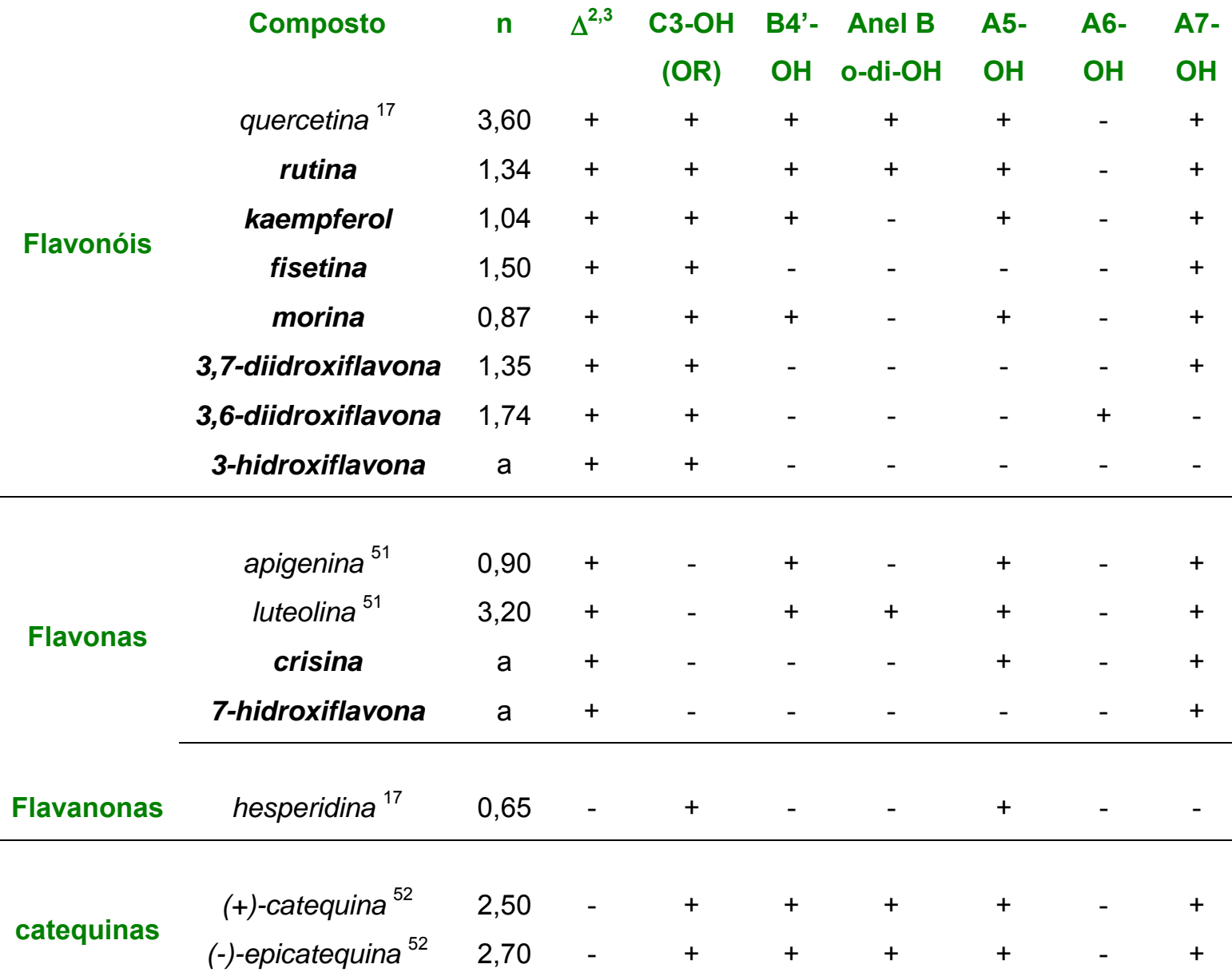


Para os flavonóis observa-se que a quercetina apresenta a maior atividade anti-radicalar. Tanto a fisetina como o kaempferol contém um grupo hidroxílico a menos em relação à quercetina, apresentando menor atividade. Estes resultados sugerem que os padrões de substituição dos anéis $A$ e $B$ contribuem para a atividade anti-radicalar. O fato de a rutina apresentar menor atividade que quercetina pode ser explicado pela ausência de uma hidroxila livre em C-3, indicando a importância deste grupo para a atividade anti-radicalar ou por uma diminuição da capacidade devido ao acúcar. ${ }^{53}$ A morina difere da quercetina unicamente no padrão de substituição do anel B, e apresenta a menor atividade dentre os flavonóis testados, indicando a importância do sistema orto-diidroxilado do anel $B$, porém em casos onde o anel $B$ não pode contribuir para a atividade anti-radicalar, certos substituintes no anel A podem estar aptos em compensar a eficácia da capacidade anti-radicalar. ${ }^{54}$ Resultados obtidos pelo grupo sugerem que no caso das flavonas testadas, a alta atividade obtida pela luteolina deve-se ao alto número de grupos hidroxílicos uma vez que não possui hidroxila em C-3. ${ }^{51}$ Por outro lado, 3,7 e 3,6-diidroxiflavonas apresentaram atividade anti-radicalar mais alta do que o esperado, pois essas duas substâncias não possuem sequer um grupo hidroxílico no anel $\mathrm{B}^{22}$ Entretanto, as catequinas foram mais ativas do que a maioria dos flavonóis testados, exceto a quercetina, apesar do anel $C$ não apresentar a função 4-oxo e nem a ligação dupla $\Delta^{2,3}$ (Tabela 5).

Nossos resultados sugerem que as características estruturais importantes para a atividade anti-radicalar são: (i) o sistema orto-diidroxilado do anel $\mathrm{B}$ e (ii) o número de grupos hidroxílicos livres. Outros trabalhos da literatura sugerem que a presença de função oxo e de ligação dupla no anel $C$ também tem influência. ${ }^{53}$ Porém, nossos resultados para as catequinas sugerem uma menor importância da constituição do anel C.

Os diferentes aspectos das curvas cinéticas de inibição observados com os anti-radicais flavonóides e derivados fenólicos estudados podem ser entendidos com base na sua reatividade em relação ao seqüestro das espécies radicalares formados no sistema luminol/hemina/ $\mathrm{H}_{2} \mathrm{O}_{2}$ (Esquema 3). Dos compostos estudados nesse trabalho, trolox, kaempferol e morina (Figura 1A') apresentam-se como antiradicais $(\mathrm{AOH})$ altamente reativos e são capazes de seqüestrar eficientemente os radicais formados por hemina e $\mathrm{H}_{2} \mathrm{O}_{2}$, inibindo desta maneira completamente a emissão do sistema. Somente quando o anti-radical está completamente esgotado ocorre a continuação da reação radicalar a qual leva à formação do estado eletronicamente excitado do aminoftalato $\left(\mathrm{AP}^{2-}\right)$ e a emissão é restaurada. ${ }^{55-57}$ 


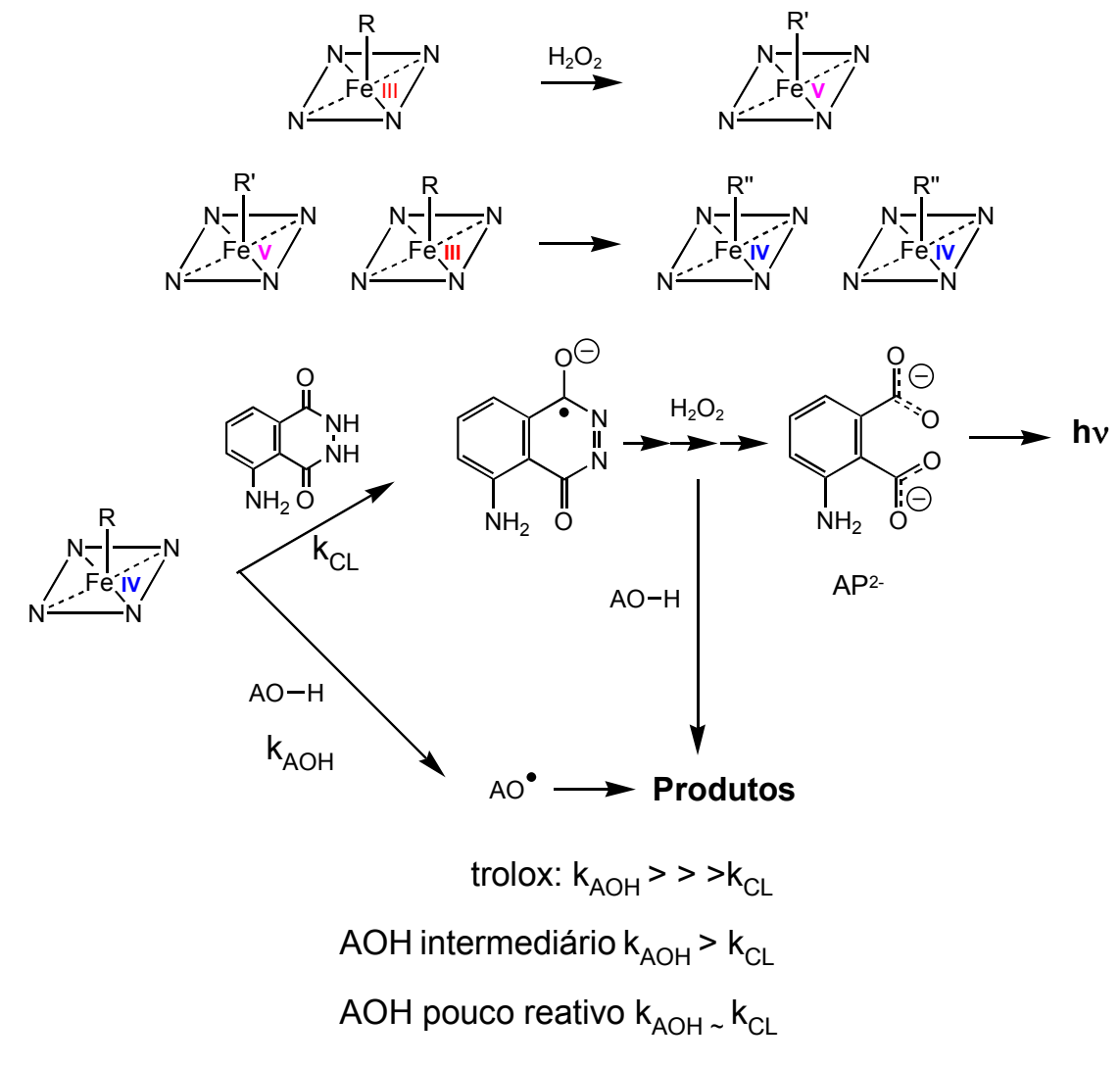

Esquema 3

Segundo esta abordagem, os flavonóides de reatividade intermediária são representados pela rutina, fisetina, 3,6- e 3,7-diidroxiflavona (Figura 1B). Adicionados em altas concentrações, estes antiradicais são capazes de suprimir quase que completamente a emissão, entretanto, na medida em que o anti-radical está sendo gasto ocorre uma retomada gradual da intensidade de emissão. (Figura 1B). Nessa condição ocorre uma concorrência entre o luminol e o anti-radical pelos radicais formados no sistema e ambos os processos possuem velocidades similares. Para estes antiradicais, é possível obter ainda a capacidade anti-radical utilizando-se o método das áreas de supressão. Deve-se mencionar que o uso deste método para estes compostos é essencial para a obtenção de resultados confiáveis e com o método de tempo de indução, normalmente utilizado na literatura não será possível determinar a capacidade anti-radical destes compostos. ${ }^{15}$

Os anti-radicais de baixa reatividade são constituídos pela crisina, 7hidroxiflavona e 3-hidroxiflavona. (Figura 1C). Para observação de inibição da emissão, estes compostos precisam ser utilizados em concentrações mais altas e mesmo assim a supressão da emissão é somente parcial. Devido à alta concentração de anti-radical este não está sendo totalmente gasto durante o tempo de ensaio e, por 
isso, a intensidade de emissão $\left(I_{0}\right)$ não é retomada. Dessa maneira, não é possível a determinação do potencial anti-radical destes compostos mesmo empregando-se o método da área de supressão.

Nos estudos com os compostos-modelo foram observados três comportamentos distintos nas curvas cinéticas obtidas pela adição do derivado fenólico à reação quimiluminescente de luminol com $\mathrm{H}_{2} \mathrm{O}_{2}$ catalizada por hemina: (i) supressão quase completa da emissão seguida por um aumento relativamente rápido da intensidade após esgotamento do composto anti-radicalar, possibilidade de cálculo de n; (ii) diminuição gradual da intensidade da emissão, dependendo da concentração do aditivo, sem a observação do retorno da emissão, possibilitando a obtenção do parâmetro de reatividade e (iii) aumento da intensidade de emissão após adição do composto fenólico - efeito amplificador de quimiluminescência. Os experimentos realizados com fenol como anti-radical frente ao ensaio quimiluminescente do luminol apresentam uma pequena diminuição da intensidade de luz dependendo da concentração utilizada, seguido de um decaimento e são bem diferentes das curvas cinéticas obtidas com trolox (Figura 1A e Figura 2A). As curvas cinéticas obtidas com catecol e resorcinol, apesar de não serem semelhantes, apresentam uma diminuição da intensidade de luz de acordo com as concentrações utilizadas seguidas por um retorno de luz até a intensidade normal por onde passaria a curva cinética sem adição de anti-radical, possibilitando o cálculo das áreas de supressão de acordo com as concentrações utilizadas, ocorrendo o mesmo com $p$-metoxifenol, $p$-aminofenol $p$ cianofenol cujas curvas cinéticas estão omitidas por mostrarem comportamento semelhante às curvas cinéticas obtidas com resorcinol (Figura 4A e B). $O$ efeito amplificador de quimiluminescência foi observado utilizando-se hidroquinona como aditivo, cujas curvas cinéticas apresentam uma diminuição da intensidade de luz seguida por um retorno de luz acima da intensidade normal por onde passaria a curva cinética sem adição de anti-radical, já as curvas cinéticas obtidas com pirogalol mostram apenas efeito amplificador de quimiluminescência, ou seja, nenhum efeito inibidor é observado (Figuras 2F e 8)

Para um melhor entendimento desses efeitos, seguem abaixo dois esquemas com os mecanismos simplificados da reação quimiluminescente de luminol e de inibição e amplificação da intensidade de luz pela substância anti-radicalar ( $A O H)$ adicionada ao sistema (Esquemas 4 e 5 ). 


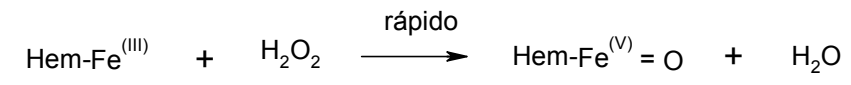

(II) $\mathrm{Hem}-\mathrm{Fe}^{(\mathrm{V})}=\mathrm{O}+\mathrm{Hem}-\mathrm{Fe}^{(\mathrm{III})} \longrightarrow\left(\mathrm{Hem}-\mathrm{Fe}^{(\mathrm{IV})}\right)_{2} \mathrm{O}$

(III)

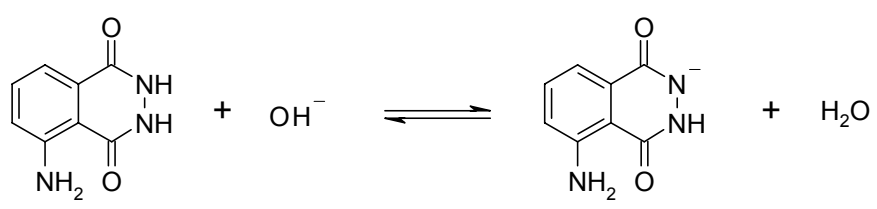

(IV)

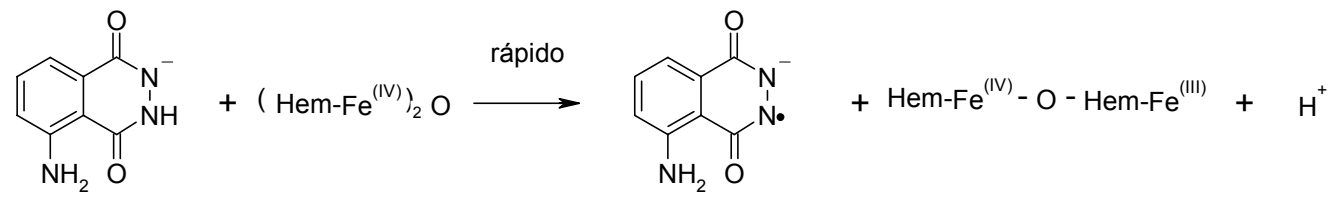

(V)<smiles>Nc1cccc2c(=O)[nH][nH]c(=O)c12</smiles>

(VI)

(VII)<smiles>Nc1cccc2c(=O)[n-][nH]c(=O)c12</smiles>

(VIII)<smiles>CC(C)C(=O)n1[nH]c(=O)c2cccc(N)c2c1=O</smiles>
$\left(\mathrm{Hem}-\mathrm{Fe}^{(I I I)}\right)_{2} \mathrm{O}+2 \mathrm{H}^{+}$

lento<smiles>Nc1cccc2c(=O)[n-][n-]c(=O)c12</smiles>

$\mathrm{Hem}-\mathrm{Fe}^{(\mathrm{III})}+\mathrm{H}_{2} \mathrm{O}$<smiles>[NH3+]c1cccc2c1C(=O)N=NC2=O</smiles>

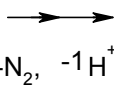<smiles>Nc1cccc(C(=O)[O-])c1C(=O)O</smiles><smiles>Nc1cccc(C(=O)O)c1C(=O)O</smiles><smiles>Nc1cccc(C(=O)[O-])c1C(=O)[O-]</smiles>

$+\quad h \vee 420 \mathrm{~nm}$

\section{Esquema 4}

O esquema 4 mostra os passos da reação de oxidação de luminol catalisados por hemina. Os passos I e II consistem na oxidação de Hem- $\mathrm{Fe}^{(\mathrm{III})}$ a $\mathrm{Hem}-\mathrm{Fe}^{(\mathrm{V})}=\mathrm{O}$ pelo peróxido de hidrogênio, com posterior comproporcionamento com Hem- $\mathrm{Fe}^{(\mathrm{III})}$ para a formação da espécie dimérica $\left(\mathrm{Hem}-\mathrm{Fe}^{(\mathrm{IV})}\right)_{2} \mathrm{O}$, a qual é, supostamente, responsável pela oxidação do luminol e iniciação da reação quimiluminescente (passo IV). O passo VI mostra o equilíbrio de reciclagem da espécie nativa da hemina $\left(\mathrm{Hem}-\mathrm{Fe}^{(I I I)}\right) .^{58}$ 
Após a oxidação do ânion luminol pelas espécies reativas de hemina nos passos IV e V, ocorre uma reação de disproporcionamento entre duas moléculas de luminol radical ânion levando a uma diazoquinona a qual, por uma série de reações no passo VIII é levada a um intermediário de alta energia, cuja decomposição resulta na formação de aminoftalato excitado (passo VIII). No passo IX o 3-aminoftalato no estado excitado singlete retorna ao estado fundamental resultando na emissão de fluorescência (Esquema 4).

No esquema 5 é mostrado o mecanismo de inibição da emissão de luz, onde a substância anti-radicalar $(\mathrm{AOH})$ pode competir com o luminol pelos intermediários ativos de hemina nos passos $\mathrm{X}$ e XI, ou reagir com o luminol radical ânion para formar o ânion luminol e um radical $\mathrm{AO}^{\circ}$, mais estável que o luminol radical ânion (passo XII). A estabilização dos radicais $\mathrm{AO}^{\circ}$ ocorre, ao menos para antioxidantes "bem comportados", principalmente pela interação de duas espécies $\mathrm{AO}^{*}$ através de reações de recombinação radicalar e/ ou disproporcionamento (passo XIII).

Inibição

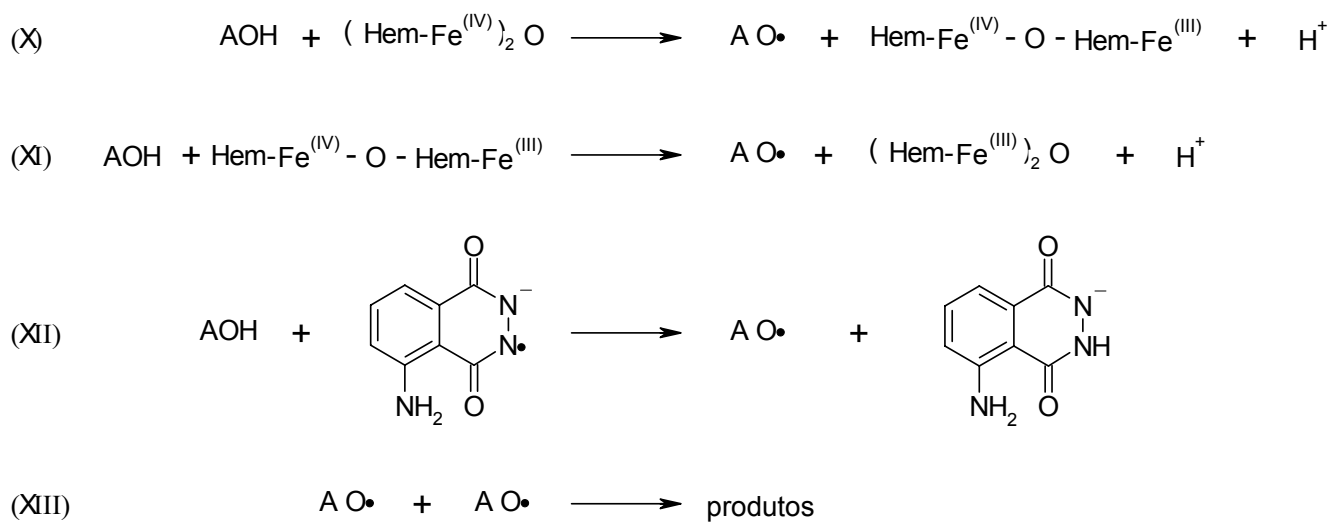

Amplificação

(XIV)

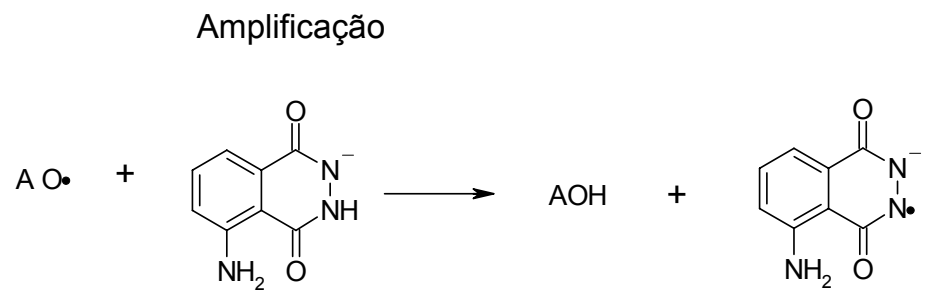

Esquema 5

Supondo-se que as reações de $\mathrm{AOH}$ com as espécies ativadas da hemina (Equema 5, passos $\mathrm{X}$ e $\mathrm{XI}$ ) sejam muito mais rápidas que as correspondentes transformações com luminol (Esquema 4, passos IV e V), a continuação da reação radicalar do luminol, a qual leva ultimamente à emissão de quimiluminescência, ocorre 
somente após o completo esgotamento do $\mathrm{AOH} .{ }^{17,55-57}$ Da mesma maneira, a inibição da emissão pode ser racionalizada pela interação de $\mathrm{AOH}$ com o radical ânion do luminol (Esquema 5, passo XII) caso esta reação seja muito mais rápida que o disproporcionamento desta espécie, levando à formação da diazoquinona (Esquema 1 , passo VII), passo chave para a formação de estados excitados. Não existem, até o momento, dados na literatura que permitam distinguir qual dos passos da transformação (Esquema 1, passos IV e $\mathrm{V}$ ou passo VII) é sujeito à inibição pelo oxidante. $^{17}$

Por outro lado, as transformações discutidas acima (Esquemas 4 e 5) podem também explicar a observada amplificação da emissão para alguns AOHs estudados. O primeiro mecanismo de amplificação possível é relacionado ao fato de que a reação do luminol ânion com a espécie $\left(\mathrm{Hem}-\mathrm{Fe}^{(\mathrm{IV})}\right)_{2} \mathrm{O}$ (passo IV) ser muito mais rápida do que a com Hem-Fe ${ }^{(\mathrm{IV})}-\mathrm{O}-\mathrm{Hem}-\mathrm{Fe}^{(\mathrm{III})}$ (passo $\mathrm{V}$ ), sendo que esta última reação deve ser o passo limitante da reação global. Como a espécie anti-radicalar $(\mathrm{AOH})$ reage muito mais rapidamente com Hem-Fe $\mathrm{I}^{(\mathrm{IV})}-\mathrm{O}-\mathrm{Hem}-\mathrm{Fe}^{(\mathrm{III})}$ (passo $\mathrm{XI}$ ) que o luminol (passo V), a presença do $\mathrm{AOH}$ pode resultar num aumento da velocidade de reciclagem de hemina, e com isso, pode ocorrer um aumento de velocidade da reação global e, consequentemente, um efeito de amplificação da emissão de luz. ${ }^{17}$

O segundo mecanismo de amplificação possível depende da reatividade do radical do antioxidante formado, $\mathrm{AO}^{\circ}$. Caso este radical seja reativo o suficiente para oxidar o ânion luminol, ele contribui para a continuação da seqüência de transformações que levam à emissão de luz, desta maneira, o seqüestro de espécies radicalares no sistema luminol $/ \mathrm{H}_{2} \mathrm{O}_{2} /$ hemina não leva à inibição da emissão. Além disso, em combinação com o primeiro mecanismo de amplificação descrito acima, pode ser observado neste caso um aumento da intensidade de emissão.

Deve-se destacar ainda que a observação de uma inibição ou amplificação na adição de um determinado composto $\mathrm{AOH}$ depende, além da reatividade intrínseca dos reagentes e espécies radicalares envolvidos, da concentração do $\mathrm{AOH}$ e dos reagentes do ensaio luminol.

A tabela 6 mostra todos os compostos-modelo estudados frente ao ensaio quimiluminescente do luminol. O cálculo do número de radicais seqüestrados por molécula de $\mathrm{AOH}(\mathrm{n})$, em relação ao trolox, só foi possível para catecol, resorcinol, $p$ metóxifenol e $p$-cianofenol devido ao tipo de curvas cinéticas obtidas com essas substâncias conforme discutido anteriormente. Entretanto, as curvas cinéticas obtidas com fenol, resorcinol, floroglucinol, $p$-fluorofenol, $p$-bromofenol, $p$-iodofenol e $p$ nitrofenol, possibilitaram o cálculo do fator de inibição normalizado $\left(I_{0}-1 / I_{0}\right)$, o que 
resultou num gráfico da dependência desse fator com a concentração do aditivo, consequentemente nos valores de reatividade relativa. Além disso, o estudo desses compostos ainda resultou na observação do efeito de amplificação para as curvas cinéticas obtidas com hidroquinona e pirogalol em certos intervalos de concentrações (Tabela 6).

Tabela 6: Capacidade Anti-Radicalar (n), Reatividade Relativa e Efeito Amplificador dos CompostosModelo Estudados com o Sistema Luminol / Hemina $\mathrm{H}_{2} \mathrm{O}_{2}$ e Capacidade Anti-radicalar (n) obtida com DPPH.

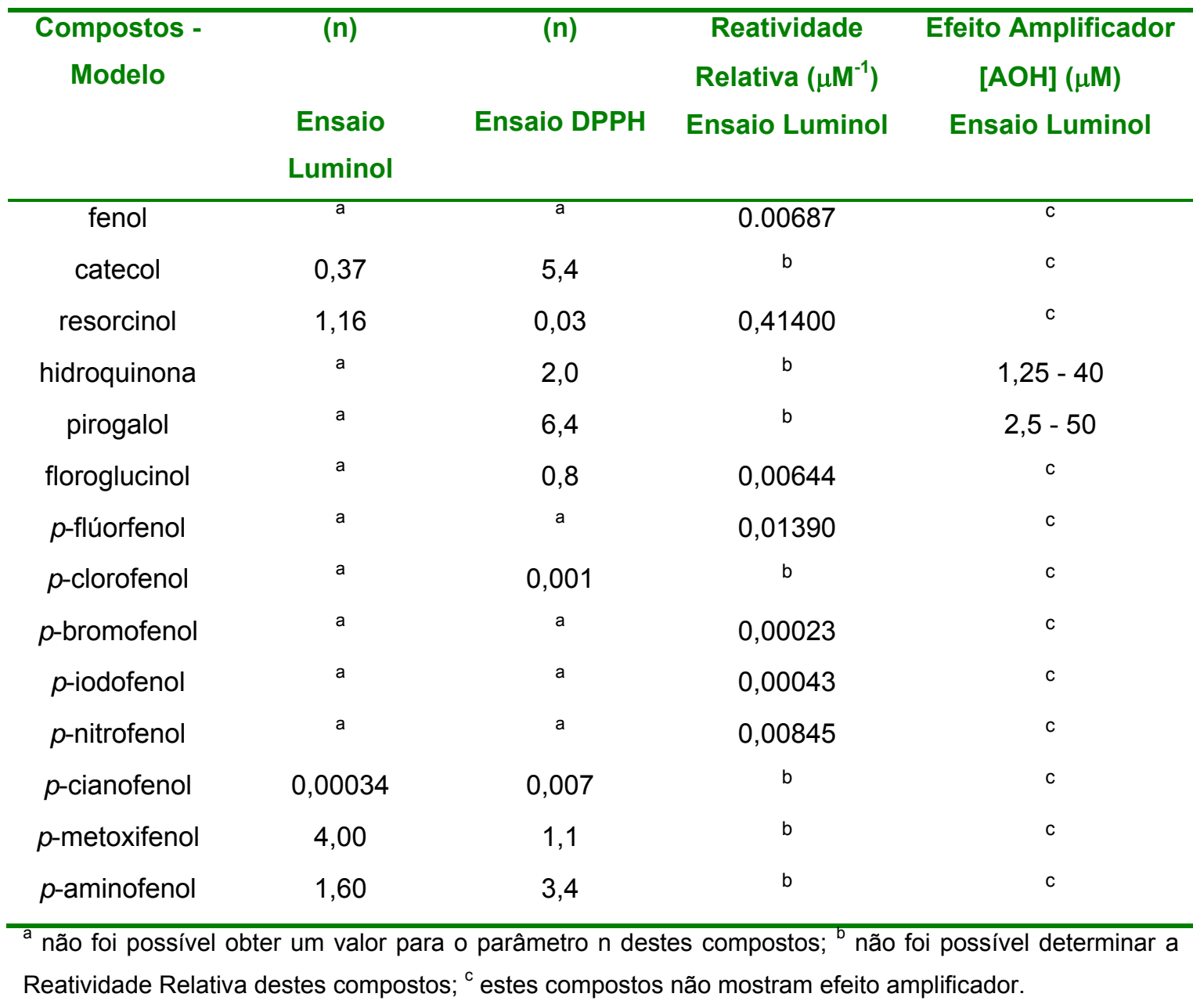

O derivado $p$-metoxifenol obteve maior atividade anti-radicalar frente ao sistema luminol/hemina/ $\mathrm{H}_{2} \mathrm{O}_{2}(\mathrm{n}=4,00)$ que $p$-aminofenol $(n=1,60)$ seguido pelos derivados resorcinol $(n=1,16)$, catecol $(n=0,37)$ e $p$-cianofenol $(n=0,00034)$. $O$ resultado obtido é muito interessante devido à alta capacidade anti-radicalar observada para $p$-metoxifenol, onde nesse ensaio, a estabilidade do radical fenoxila pode ser mais favorecida pelo grupo metoxilico que pelo grupo amino. Já entre os 
derivados diidroxilados, observa-se um resultado obtido para valores de $\mathrm{n}$ oposto ao obtido por Heijnen et al. para a atividade seqüestradora de peroxinitrito onde Heijnen et al observou maior capacidade para catecol que resorcinol. ${ }^{59}$ Ainda é possível observar que não foi possível obter valores de $\mathrm{n}$ para os derivados halogenados e com o nitrofenol.

Os resultados obtidos com o ensaio de DPPH sugerem a maior importância do sistema orto-diidroxilado que o sistema meta-diidroxilado nesse ensaio devido à alta capacidade anti-radicalar obtida com pirogalol $(n=6,4)$ e catecol $(n=5,4)$. Apesar de apresentar três hidroxilas livres, o floroglucinol $(n=0,8)$ obteve baixa atividade antiradicalar juntamente com resorcinol $(n=0,8)$ que possui um sistema meta-diidroxilado (Tabela 6). Hidroquinona $(n=2)$ apresentou maior capacidade anti-radicalar que resorcinol, talvez pela melhor estabilização do radical fenoxila por um sistema paradihidroxilado. Além disso, $p$-aminofenol $(n=3,4)$ apresentou maior atividade antiradicalar no ensaio com DPPH que $p$-metoxifenol $(n=1,1)$, o que sugere que esses derivados fenólicos possuem comportamento bem diferente frente a sistemas diferentes. Da mesma forma como observado com o sistema luminol, $p$-cianofenol apresentou baixa atividade anti-radicalar frente ao ensaio com DPPH. Entre os derivados halogenados só foi possível obter valor de $n$ para p-clorofenol (Tabela 6 ).

Heijnen et al. reportaram uma boa correlação entre $\sigma$ de Hammett de substituintes fenólicos, entre eles catecol e resorcinol, e a inibição de oxidação de diidrorodamina por peroxinitrito, e com os valores de energia do HOMO $\left(E_{\text {HOMO }}\right){ }^{60} \mathrm{Na}$ tentativa de verificar uma relação entre $\sigma$ de Hammett com os resultados obtidos para os compostos-modelo estudados foi obtida a figura 28. 
A

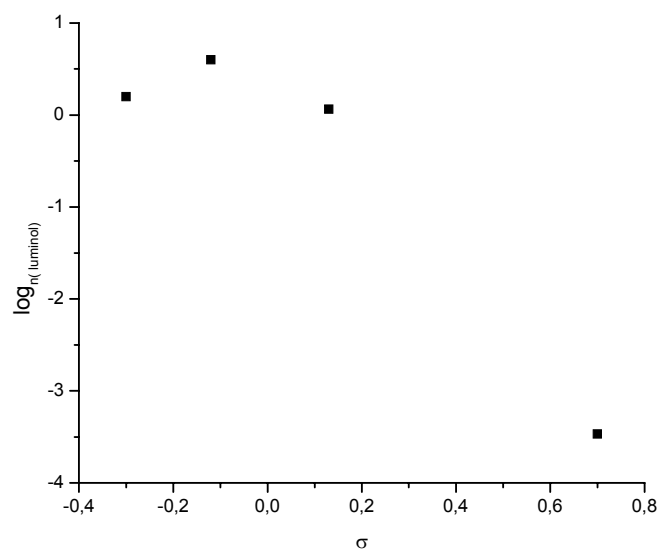

B

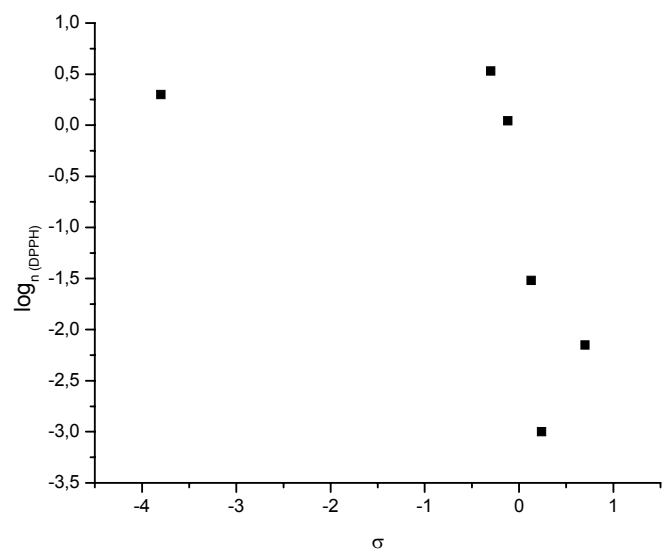

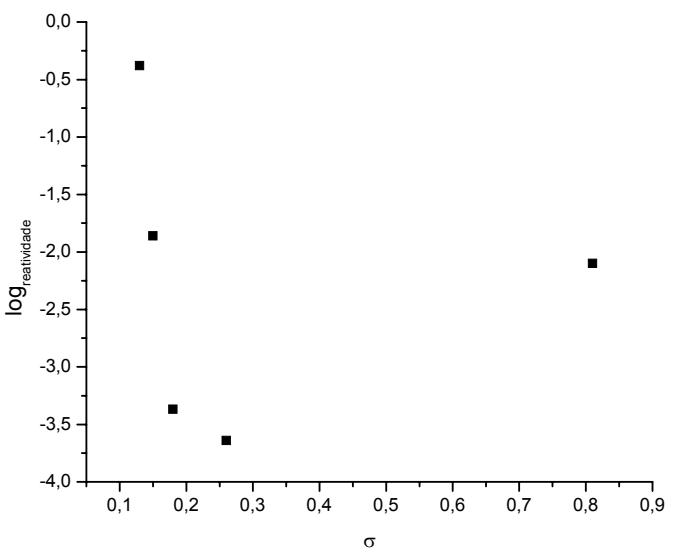

Figura 28: Correlação entre valores experimentais obtidos com os ensaios anti-radical e as constantes de substituintes de Hammett. A: Capacidade anti-radical do ensaio luminol; B: Capacidade anti-radical do ensaio DPPH; C: Reatividade anti-radical do ensaio luminol.

Através da figura 28 é possível observar que não existe correlação entre os resultados experimentais obtidos da capacidade anti-radical com o ensaio luminol e o ensaio DPPH e os valores de substituinte de Hammett. Da mesma maneira, os parâmetros de reatividade (ensaio luminol) não se correlacionam com os valores de $\sigma$. Os resultados obtidos até o momento não são suficientes para um esclarecimento da relação estrutura - atividade frente ao sistema luminol, do efeito de amplificação e das reatividades relativas. 


\section{Ensaio Fitoquímico Monitorado de Espécies de Baccharis}

Através do estudo fitoquímico monitorado pela atividade anti-radicalar realizado com a fase em acetato de etila das folhas de Baccharis regnellii, foi possível isolar duas substâncias majoritárias, sendo uma inédita (Esquema 6). A substância denominada preliminarmente de F-9.3 foi isolada de Baccharis articulata por De Oliveira et al. ${ }^{61}$ Com o objetivo de determinação estrutural, foi obtido o espectro de Ressonância Magnética Nuclear de ${ }^{1} \mathrm{H}\left(\mathrm{RMN}{ }^{1} \mathrm{H}\right)$ e ${ }^{13} \mathrm{C}\left(\mathrm{RMN}{ }^{13} \mathrm{C}\right)$ em piridina para F9.3 (em anexo Figuras tal), cujos sinais foram comparados com os obtidos por De Oliveira et al . ${ }^{61}$

O espectro de $\mathrm{RMN}{ }^{13} \mathrm{C}$ mostra um sinal em $\delta 167,3$ (C-9) que pode indicar a presença de uma carbonila de éster $\alpha-\beta$ insaturado juntamente com a presença de sinais em $\delta 146,3$ e 114,6 (C-8 e C-7) característicos de carbonos olefínicos. É possível observar também sinais entre $\delta$ 107,1 e 132,7 (C-1, C-2, C-5, C-6, C-1'C-2'e C-6') que podem indicar carbonos aromáticos e ainda sinais em $\delta$ 147,7, 150, 6 e 153,7 (C-3, C-4, C-3'e C-5') que sugerem a presença de carbonos aromáticos ligados a oxigênio. Além disso, um sinal em $\delta 56,4$ (C-3'/C-5'OMe ) sugere a presença de um grupo metoxílico. O sinal relativo a C-4' não pode ser observado provavelmente devido a sobreposição deste com o sinal do solvente, no caso piridina (Tabela 7).

$\mathrm{O}$ espectro de RMN ${ }^{1} \mathrm{H}$ indica a presença de prótons olefínicos $(\mathrm{H}-8 \mathrm{e} \mathrm{H}-7)$ na posição trans devido aos sinais em $\delta$ 6,68 e 8,03 ambos dubletos com J = 15,7 Hz. Além disso, um singleto $\left(\mathrm{H}-3^{\prime} / \mathrm{H}-5^{\prime} \mathrm{OMe}, 6 \mathrm{H}\right)$ em $\delta 3,72$ indica a presença de dois grupos metoxílicos. Sinais em $\delta 6,88,7,62$ e em 7,23, referentes a H-6', H-2, H-5 e H-6, respectivamente, dão boa indicativa da presença de dois núcleos aromáticos. A presença de resíduo de açúcar é sugerida pela presença de um sinal em $\delta 5,84$ característico de próton anomérico. A configuração $\beta$ do açúcar é indicada pela constante de acoplamento entre H-2" e H-1", cujo valor é J = $6 \mathrm{~Hz}$ (Tabela 7). 


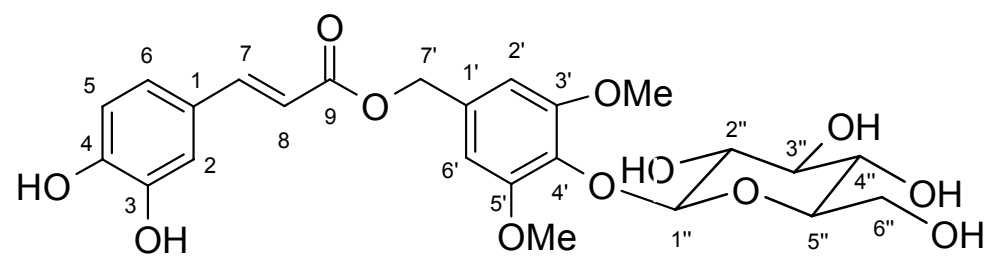

Tabela 7: Sinais de $\mathrm{RMN}{ }^{13} \mathrm{C}$ e ${ }^{1} \mathrm{H}$ obtidos e relatados para F-9.3 em piridina- $\mathrm{d}_{5}$.

\begin{tabular}{|c|c|c|c|c|}
\hline Carbono & $\begin{array}{c}{ }^{13} \mathrm{C} \text { (ppm) } \\
\text { obtido }\end{array}$ & $\begin{array}{c}{ }^{13} \mathrm{C}(\mathrm{ppm}){ }^{61} \\
\text { relatado }\end{array}$ & $\begin{array}{c}{ }^{1} \mathrm{H} \text { (ppm) } \\
\text { obtido }\end{array}$ & $\begin{array}{c}{ }^{7} \mathrm{H}(\mathrm{ppm})^{61} \\
\text { relatado }\end{array}$ \\
\hline 1 & 126,7 & 127,0 & - & - \\
\hline 2 & 115,7 & 116,6 & $7,62(\mathrm{~s})$ & $7,70(\mathrm{~s})$ \\
\hline 3 & 147,7 & 148,0 & - & - \\
\hline 4 & 150,6 & 151,0 & - & - \\
\hline 5 & 116,7 & 117,0 & $7,23(\mathrm{~m})$ & $7,20(m)$ \\
\hline 6 & 122,1 & 123,0 & $7,23(\mathrm{~m})$ & $7,20(\mathrm{~m})$ \\
\hline 7 & 146,3 & 147,0 & $8,03(\mathrm{~d}, \mathrm{~J}=15,7 \mathrm{~Hz})$ & $8,20(\mathrm{~d}, \mathrm{~J}=15,8 \mathrm{~Hz})$ \\
\hline 8 & 114,6 & 115,4 & $6,68(\mathrm{~d}, \mathrm{~J}=15,7 \mathrm{~Hz})$ & $6,70(\mathrm{~d}, \mathrm{~J}=15,8 \mathrm{~Hz})$ \\
\hline 9 & 167,3 & 168,0 & - & - \\
\hline $1^{\prime}$ & 132,7 & 133,0 & - & - \\
\hline $2^{\prime}$ & 107,1 & 108,0 & $6,88(\mathrm{~s})$ & $6,90(\mathrm{~s})$ \\
\hline $3^{\prime}$ & 153,7 & 154,0 & - & - \\
\hline $4^{\prime}$ & - & 136,0 & - & - \\
\hline 5 & 153,7 & 154,0 & - & - \\
\hline $6^{\prime}$ & 107,1 & 108,0 & $6,88(\mathrm{~s})$ & $6,90(\mathrm{~s})$ \\
\hline $7^{\prime}$ & 66,3 & 67,0 & $5,32(\mathrm{~s})$ & $5,30(\mathrm{~s})$ \\
\hline $1 "$ & 104,7 & 105,8 & $5,84(\mathrm{~d}, \mathrm{~J}=6,0 \mathrm{~Hz})$ & $5,80(\mathrm{~d}, \mathrm{~J}=7,0 \mathrm{~Hz})$ \\
\hline 2" & 76,0 & 76,8 & $4,34(m)$ & $4,38(m)$ \\
\hline 3" & 78,7 & 79,4 & $4,34(m)$ & $4,38(m)$ \\
\hline $4 "$ & 71,4 & 72,4 & $4,34(\mathrm{~m})$ & $4,38(m)$ \\
\hline $5 "$ & 78,3 & 79,1 & $4,34(m)$ & $3,90(\mathrm{~m})$ \\
\hline $6 "$ & 62,4 & 63,4 & $4,34(m)$ & $4,38(m)$ \\
\hline $\mathrm{C}-3^{\prime} / \mathrm{C}-5^{\prime} \mathrm{OMe}$ & 56,4 & 57,3 & $3,72(\mathrm{~s})$ & $3,80(\mathrm{~s})$ \\
\hline
\end{tabular}

Para a substância inédita isolada, denominada preliminarmente de F-8.1, a determinação estrutural baseou-se na análise dos dados de espectros de Infravermelho (IV), de massas, de RMN de ${ }^{1} \mathrm{H}$ e ${ }^{13} \mathrm{C}$, além de técnicas bidimensionais como HMQC (Heteronuclear Multiple Quantum Coherence Spectroscopy) e HMBC (Heteronuclear Multiple Bond Connectivity) (em anexo Figuras tal). 
O espectro no IV mostra uma banda larga em $3410,9 \mathrm{~cm}^{-1}$ característica de grupos hidroxílicos e uma banda em $1704,8 \mathrm{~cm}^{-1}$ característica de grupos ésteres (Figura tal).

A substância F-8.1 apresentou um pico de íon quasi-molecular no espectro de massas em $m / z 545,1633[\mathrm{M}+\mathrm{Na}]^{+}$o que sugere a fórmula molecular $\mathrm{C}_{25} \mathrm{H}_{30} \mathrm{O}_{12}$. Além disso, observa-se um sinal em $\mathrm{m} / \mathrm{z} 540,0$ referente a um aduto com água [M + $\left.\mathrm{H}_{2} \mathrm{O}\right]$, um em $\mathrm{m} / \mathrm{z} 541$ referente à $\left[\mathrm{M}+\mathrm{H}_{2} \mathrm{O}+\mathrm{H}\right]$ e um em $\mathrm{m} / \mathrm{z} 546$ referente à $[\mathrm{M}+\mathrm{Na}$ $+\mathrm{H}]$ (Figura tal).

Através do espectro de massas é sugerida a seguinte estrutura para F-8.1 bem como os sinais obtidos nos $\mathrm{RMN}{ }^{13} \mathrm{C}$ e ${ }^{1} \mathrm{H}$ são mostrados (Tabela 8).

Os espectros de $\mathrm{RMN}{ }^{13} \mathrm{C}$ e ${ }^{1} \mathrm{H}$ obtidos para $\mathrm{F}-8.1$ apresentaram sinais semelhantes aos obtidos com F-9.3, ou seja, sinal referente a carbonila de éster $\alpha-\beta$ insaturado, sinais de núcleos aromáticos com carbonos ligados a hidrogênio e oxigênio, sinais que sugerem a presença de grupos metoxílicos, sinais referentes a prótons olefínicos em trans e ainda, sinais referentes a um resíduo de açúcar com configuração $\beta$. Porém, esta substância apresenta um grupo metoxílico a mais em relação à substância anterior, pela observação do singleto em $\delta 3,77$, no espectro de RMN de ${ }^{1} \mathrm{H}$, e pelo sinal em $\delta 55,6$ no espectro de $\mathrm{RMN}$ de ${ }^{13} \mathrm{C}$.

A elucidação final da estrutura é confirmada pelo espectro 2D heteronuclear HMBC que mostra correlação entre os hidrogênios metoxílicos $(\delta 3,77)$ com C-5' e C3 ' de núcleo aromático $(\delta 153,6)$, correlações entre prótons trans olefínicos H-7 e H-8 $(\delta 6,76$ e $\delta 8,03)$ com C-1 $(\delta 126,1)$ e principalmente a correlação entre os hidrogênios metoxílicos OMe-3 $(\delta 3,80)$ e C-3, o que difere da estrutura da substância F-9.3 que apresenta uma hidroxila nessa mesma posição (Figura 29).

Através da análise dos espectros de massas e de $\mathrm{RMN}{ }^{13} \mathrm{C}$ e ${ }^{1} \mathrm{H}$ é sugerida a seguinte estrutura para F-8.1: 


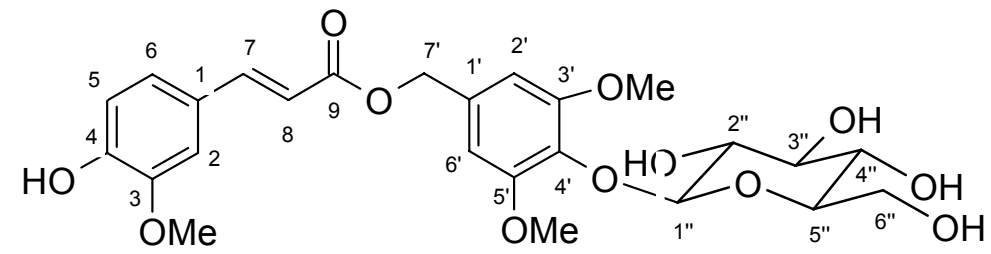

Tabela 8: Sinais de $\mathrm{RMN}{ }^{13} \mathrm{C}$ e ${ }^{1} \mathrm{H}$ e as correlações obtidos para F-8.1 em piridina- $\mathrm{d}_{5}$.

\begin{tabular}{|c|c|c|c|}
\hline Carbono & ${ }^{13} \mathrm{C}(\mathrm{ppm})$ & ${ }^{1} \mathrm{H}(\mathrm{ppm})$ & HMBC (ppm) \\
\hline 1 & 126,1 & - & \\
\hline 2 & 111,2 & $7,35(\mathrm{~d}, \mathrm{~J}=1,5 \mathrm{~Hz})$ & C-6, C-7, C-3, C-4 \\
\hline 3 & 148,7 & - & \\
\hline 4 & 151,0 & - & \\
\hline 5 & 116,6 & $7,22(\mathrm{~m})$ & $C-1, C-6, C-3, C-4$ \\
\hline 6 & 122,8 & $7,28(\mathrm{dd}, \mathrm{J}=1,5$ e $8,2 \mathrm{~Hz})$ & C-2, C-7, C-4 \\
\hline 7 & 145,8 & $8,03(\mathrm{~d}, \mathrm{~J}=15,8 \mathrm{~Hz})$ & $\mathrm{C}-2, \mathrm{C}-8, \mathrm{C}-6, \mathrm{C}-1, \mathrm{C}-9$ \\
\hline 8 & 114,6 & $6,76(d, J=15,8 \mathrm{~Hz})$ & C-1, C-9, C-7 \\
\hline 9 & 167,1 & - & \\
\hline 1' & 132,5 & - & \\
\hline 2' & 106,9 & $6,94(\mathrm{~s})$ & C-6', C-1', C-3', C-4' \\
\hline $3^{\prime}$ & 153,6 & - & \\
\hline $4^{\prime}$ & 130,5 & - & \\
\hline 5 & 153,6 & - & \\
\hline $6^{\prime}$ & 106,9 & $6,94(\mathrm{~s})$ & C-2', C-1', C-3', C-4' \\
\hline $7^{\prime}$ & 66,2 & $5,38(s)$ & C-9, C-2', C6', C-1' \\
\hline $1 "$ & 104,5 & $5,85(\mathrm{~d}, \mathrm{~J}=6,3 \mathrm{~Hz})$ & \\
\hline 2" & 75,8 & $4,37(\mathrm{~m})$ & \\
\hline 3" & 78,5 & $4,37(\mathrm{~m})$ & \\
\hline $4 "$ & 71,3 & $4,37(\mathrm{~m})$ & \\
\hline $5 "$ & 78,1 & $4,37(\mathrm{~m})$ & \\
\hline $6 "$ & 62,3 & $4,37(\mathrm{~m})$ & \\
\hline $\mathrm{C}-3 \mathrm{OMe}$ & 55,6 & $3,80(\mathrm{~s})$ & $C-3$ \\
\hline C-3'/C-5'OMe & 56,3 & 3,77 (s) & C-5', C-3' \\
\hline
\end{tabular}




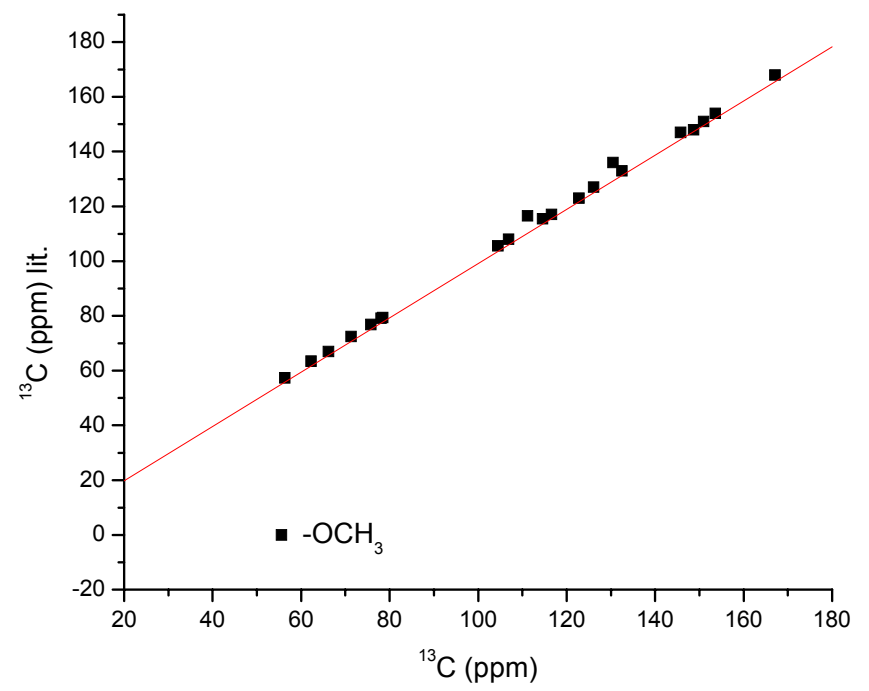

Figura 29: Correlação linear entre os sinais de $\mathrm{RMN}{ }^{13} \mathrm{C}$ obtidos da literatura para F-9.3 e os sinais obtidos pelo grupo para F-8.1.

A Figura 29 mostra uma correlação linear entre os sinais de $\mathrm{RMN}{ }^{13} \mathrm{C}$ relatados por De Oliveira et al para F-8.1 e os sinais de RMN ${ }^{13} \mathrm{C}$ obtidos para F-9.3, onde fica claro que a única diferença é o grupo metoxílico presente na substância inédita.

Essa metoxila diferencial presente na substância inédita ainda pode ser confirmada com a análise dos cromatogramas obtidos para as duas frações onde se observa que o pico da F-9.3 aparece com um menor tempo de retenção que o pico da F-8.1 devido a maior polaridade (Figura 24). Além disso, a F-9.3 apresentou uma maior atividade anti-radicalar frente ao ensaio luminol que F-8.1, devido a este padrão de substituição do anel aromático.

A partir das estruturas das substâncias isoladas F-9.3 e F-8.1 elucidadas, é possível atribuir os nomes para as mesmas. A F-9.3 refere-se a substância já relatada na literatura cujo nome é cafeato de 4'-O- $\beta$-D-glucopiranosil-3',5'-dimetóxibenzoíla e F8.1 é ferulato de 4'-O- $\beta$-D-glucopiranosil-3',5'-dimetóxibenzoíla.

Após as substâncias devidamente caracterizadas, é possível discutir o fracionamento cromatográfico da fase em acetato de etila das folhas de Baccharis regnellii monitorado pela atividade anti-radicalar (Esquema 6). O valor de TRAP obtido para a fase em acetato de etila indica que são necessários $0,80 \mathrm{mg} / \mathrm{L}$ desse extrato para causar o mesmo efeito de $1 \mu \mathrm{M}$ de trolox. Se os valores de $\mathrm{n}$ encontrados para $\mathrm{F}$ 8.1 e F-9.3 foram 0,4 e 0,7 respectivamente, em comparação com o padrão trolox, cujo valor de n é 2, significa que é necessário $5 \mu \mathrm{M}(2,60 \mathrm{mg} / \mathrm{L})$ de F-8.1 e 2,86 $\mu \mathrm{M}$ $(1,45 \mathrm{mg} / \mathrm{L})$ de F-9.3 para causar o efeito de $1 \mu \mathrm{M}$ de trolox. Com isso, é possível 
observar que o extrato é mais eficiente que as substâncias isoladas. Esses resultados obtidos podem ser explicados por um efeito sinérgico dessas substâncias, bem como pela presença de outros constituintes não isolados que apresentem forte atividade anti-radicalar. 


\section{Conclusão}

Os resultados obtidos nesse trabalho da determinação da capacidade antiradical de flavonóides utilizando-se o ensaio quimiluminescente com luminol demonstram a utilidade deste ensaio, sendo que com o uso dele é possível obter valores confiáveis também para substâncias que possuem baixa reatividade antiradicalar. Porém, com os derivados estudados não foi possível obter tendências claras de relações estrutura atividade.

A tentativa de elucidar o princípio da relação estrutura do anti-radical com a sua atividade ou capacidade, utilizando-se como compostos-modelo fenóis substituídos, não foi até o momento bem sucedida. Não foi observada uma tendência lógica entre o padrão de substituição dos fenóis utilizados e a sua capacidade ou reatividade. Além disso, resultados obtidos com o ensaio DPPH mostraram diferenças significativas com aqueles do ensaio luminol. Porém, também as capacidades anti-radicalares determinadas com este último ensaio não podem ser correlacionadas com os valores de substituintes de Hammett.

Os resultados obtidos até o momento indicam que há a necessidade de mais estudos sistemáticos, utilizando-se ensaios da capacidade e reatividade bem estabelecidos e entendidos, para poder estabelecer uma correlação entre a estrutura de flavonóides e sua capacidade e reatividade antioxidante.

Finalmente, através do estudo fitoquímico monitorado pela atividade antiradicalar de extratos e fases das folhas de Baccharis regnelli foi possível identificar a fase com maior atividade anti-radical (apesar das baixas diferenças entre os valores de TRAP obtidos entre as fases estudadas). Desta fase foram isoladas duas substâncias (uma inédita) que mostram considerável atividade anti-radical. 


\section{Materiais e Métodos}

\section{Reagentes e Soluções}

Luminol (5-amino-2,3-dihidroftalazino-1,4-diona) foi obtido da Merck (Darmstadt, Alemanha), uma solução estoque $(10 \mathrm{mM})$ foi preparada em $\mathrm{NaOH} 1 \mathrm{M} \mathrm{e}$ mantido a $4{ }^{\circ} \mathrm{C}$ por no máximo dez dias. A concentração final de luminol é determinada espectrofotometricamente em $347 \mathrm{~nm}\left(\varepsilon=7600 \mathrm{M}^{-1} . \mathrm{cm}^{-1}\right){ }^{62}$ Peróxido de Hidrogênio (Peróxidos do Brasil - São Paulo, Brasil) foi obtido na forma de uma solução aquosa $60 \%$ v/v não estabilizada. A concentração final após a diluição com água desmineralizada (18 M $\Omega$, Milli-Q, Millipore) foi determinada espectrofotometricamente como descrito por Cotton and Dunford. ${ }^{63}$. Hemina (cloridrato de ferriprotoporfinira IX) foi adquirida da Sigma (St. Louis, EUA). Uma solução estoque (8 $\mu \mathrm{M})$ foi preparada dissolvendo-se 2,5 mg de hemina em $5 \mathrm{~mL}$ de $\mathrm{NaOH} 1 \mathrm{M}$ e diluindo 1:100 com NaOH $1 \mathrm{M}$. A concentração final foi determinada espectrofotometricamente em $385 \mathrm{~nm}(\varepsilon=$ $\left.58400 \mathrm{M}^{-1} \mathrm{~cm}^{-1}\right){ }^{64}$

Trolox (ácido 6-hidroxi-2,5,7,8-tetrametilcroman-2-carboxilico) foi obtido da Aldrich (Milwaukee, EUA), e foi utilizado como anti-radical padrão sem purificação. Fisetina, kaempferol, rutina, morina da Sigma (St. Louis, EUA), 3,6-dihidroxiflavona e 3,7-dihidroxiflavona da Aldrich, e 7-hidroxiflavona, 3-hidroxiflavona e crisina da Acros Organics e foram utilizadas sem purificação adicional. p-Metoxifenol, p-nitrofenol, catecol e p-cianofenol foram obtidos da Acros Organics. Floroglucinol, p-bromofenol, p-iodofenol e $p$-aminofenol foram obtidos Aldrich (Milwaukee, EUA). Fenol, pirogalol, resorcinol, hidroquinona e $p$-clorofenol foram obtidos da Reagen, Mallinckrodt, Synth, B. Herzog e Merck (Darmstadt, Alemanha), respectivamente. O p-metoxifenol (PF: 50 $2{ }^{0} \mathrm{C}$, lit. $\left.{ }^{65}: 54-5\right)$, p-nitrofenol (PF: $110-3{ }^{\circ} \mathrm{C}$, lit. ${ }^{65}: 113$ - 4), p-bromofenol (PF: 64 - 6 ${ }^{0} \mathrm{C}$, lit. ${ }^{65}$ : 64), pirogalol (PF: $133-4{ }^{\circ} \mathrm{C}$, lit. ${ }^{65}$ : 136) e resorcinol (PF: $109-12^{0} \mathrm{C}$, lit. ${ }^{65}$ 111) foram recristalizados de éter etílico, etanol com gotas de acetona, clorofórmio, mistura de tolueno e etanol 1:1 e mistura de tolueno e éter etílico 1:1, respectivamente. O catecol (PF: $100-3^{0} \mathrm{C}$, lit. ${ }^{65}$ : 105) e o p-aminofenol (PF: $182-3^{\circ} \mathrm{C}$, lit. $\left.{ }^{65}: 190\right)$ foram purificados por sublimação. O p-cianofenol (PF: $108-12{ }^{\circ} \mathrm{C}$, lit. ${ }^{65}$ : 113), o p-fluorofenol (PF: $40-3{ }^{0} \mathrm{C}$ PF: $40-6$, lit. ${ }^{63}$ ) e o p-clorofenol (PF: $39-41{ }^{0} \mathrm{C}$, lit. ${ }^{65}: 43$ ) foram utilizados sem purificação adicional. A hidroquinona (PF: $172-5^{0} \mathrm{C}$, lit. $^{65}$ : 176) e o floroglucinol (PF: $218-21{ }^{\circ} \mathrm{C}$, lit. ${ }^{65}: 217$ - 19) foram recristalizados de água. O fenol (PF: $40-2^{0} \mathrm{C}$, lit. ${ }^{65}: 40,9$ ) e o $p$-iodofenol (PF: $92-4{ }^{\circ} \mathrm{C}$, lit. ${ }^{65}: 94$ ) foram recristalizados 
de éter de petróleo. As soluções estoque dos compostos anti-radicais são preparadas imediatamente antes do uso através da dissolução da quantidade adequada de sólido em uma solução aquosa de $\mathrm{NaOH} 10 \mathrm{mM}$ saturada com nitrogênio. As soluções são mantidas sob refrigeração e na ausência de luz.

$D P P H$ (2,2-difenil-1-picrilhidrazil), foi adquirido da Sigma - Aldrich,. As soluções estoque dos compostos-modelo, para esse ensaio, foram preparadas em etanol (Synth) previamente tratado com $\mathrm{Mg}^{0}$ e $\mathrm{I}_{2}$ e mantidas sob refrigeração e na ausência de luz. A solução estoque de $D P P H(\sim 1,6 \mathrm{mM})$ foi preparada também com etanol previamente purificado e foi filtrada com filtro Milli-Q. A concentração da solução de DPPH foi determinada em cada dia de experimento utilizando-se $\varepsilon_{515}=1,09.10^{4} \mathrm{M}^{-}$ ${ }^{1} . \mathrm{cm}^{-1} .66$

O material vegetal (Baccharis dracunculifolia, trimera, regnellii, sp e microdonta) foi coletado em Campos do Jordão, na Colônia da Universidade Presbiteriana Mackenzie em setembro de 2005. As folhas foram secas ao ar livre e depois moídas. As infusões das espécies de Baccharis foram preparadas com 2,5g do material vegetal em $50 \mathrm{~mL}$ de água fervente durante vinte minutos. A infusão foi filtrada, saturada com nitrogênio e diluída até as concentrações necessárias. ${ }^{67}$ Uma exsicata (Baccharis regnellii) foi depositada no Herbário da Prefeitura Municipal de São Paulo, cujo número do tombo é 8759. Primeiramente, as partes aéreas secas e pulverizadas de $B$. regnellii, foram lavadas com hexano a fim de extrair os componentes apolares, como os ácidos graxos. Após esse procedimento inicial, o resíduo vegetal foi tratado com metanol para que fossem extraídas substâncias mais polares, resultando no extrato metanólico bruto. O extrato metanólico bruto seco foi ressuspendido em metanol/água 9:1 e submetido à partição seqüencial com hexano, diclorometano, acetato de etila e n-butanol, resultando nas respectivas fases.

Para a realização do ensaio do luminol, as soluções estoque dos extratos obtidos são preparadas imediatamente antes do uso através da dissolução da quantidade adequada de sólido em uma solução aquosa de $\mathrm{NaOH} 10 \mathrm{mM}$ saturada com nitrogênio. As soluções são mantidas sob refrigeração e na ausência de luz.

Por apresentar o potencial anti-radicalar mais alto, ou seja, o menor valor de $\operatorname{TRAP}(82,5 \mathrm{mg} / \mathrm{L})$, a fase em acetato de etila foi escolhida para ensaio fitoquímico monitorado pela atividade anti-radicalar, resultando no isolamento de duas substâncias majoritárias nessa fase (Esquema 6). Para a obtenção dos espectros de Ressonância Magnética Nuclear de ${ }^{1} \mathrm{H}$ e ${ }^{13} \mathrm{C}$, as frações F-8.1 e F-9.3 foram dissolvidas em piridina$d_{5}$. 
F-9.3- RMN ${ }^{1} \mathrm{H} \delta: 3,72$ (s, 6H, C-3'/C-5'OMe); 4,34 (m, 5H, C-2" até C-6"); 5,32 (s, 1H C-7'); 5,84(d, J = 6,0 Hz, 1H, C-7'); 6,68 (d, J = 15,7 Hz, 1H, C-8); 6,88 (s, 2H, C-2' e C6'); 7,23 (m, 2H, C-5 e C-6); 7,62 (s, 1H, C-2); 8,03 (d, J = 15,7 Hz, 1H, C-7).

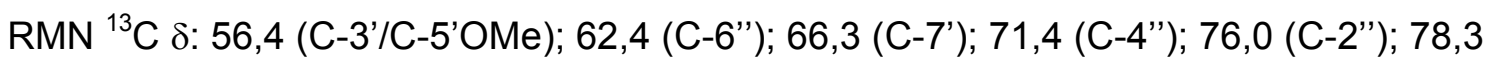
(C-5”); 78,7 (C-3"'); 104,7 (C-1"); 107,1 (C-2'e C-6'); 114,6 (C-8); 115,7 (C-2); 116,7 (C-5); 122,1 (C-6); 126,7 (C-1); 132,7 (C-1'); 146,3 (C-7); 147,7 (C-3); 150,6 (C-4); 153,7 (C-3'e C-5'); 167,3 (C-9).

F-8.1- RMN ${ }^{1} \mathrm{H} \delta: 3,77$ (s, 6H, C-3'/C-5'OMe); 3,80 (s, 3H, C-3OMe); 4,37 (m, $5 \mathrm{H}, \mathrm{C}-2$ " até C-6"); 4,38 (s $1 \mathrm{H}, \mathrm{C}-7$ '); 5,85 (d, J = 6,3 Hz, $1 \mathrm{H}, \mathrm{C}-1$ "); 6,76 (d, J = 15,8 $\mathrm{Hz}, \mathrm{C}-8$ ); 6,94 (s, 2H, C-2'e C-6); 7,22 (m, 1H, C-5); 7,28 (dd, J = 1,5 e 8,2 Hz, 1H, C6); 7,35 (d, J = 1,5 Hz, 1H, C-2); 8,03 (d, J = 15, 8Hz, 1H, C-7). RMN ${ }^{13} \mathrm{C} \delta: 55,6$ (C3OMe); 56,3 (C-3'/C-5'OMe); 62,3 (C-6”); 66,2 (C-7'); 71,3 (C-4"); 75,8 (C-2”); 78,1 (C5”); 78,5 (C-3"); 104,5 (C-1"); 106,9 (C-2'e C-6'); 114,6 (C-8); 111,2 (C-2); 116,6 (C-5); 122,8 (C-6); 126,1 (C-1); 132,5 (C-1'); 145,8 (C-7); 148,7 (C-3); 151,0 (C-4); 153,6 (C3'e C-5'); 167,1 (C-9).

A fase móvel utilizada em CLAE (Cromatografia Líquida de Alta Eficiência) foi constituída por uma solução aquosa de $\mathrm{H}_{3} \mathrm{PO}_{4} 50 \mathrm{mM}$ (solução A) e acetonitrila (solução B) com eluição isocrática 95\% A / 5\% B, 0-5 min.; gradiente linear de 95\% A / $5 \%$ B para 50\% A / 50\% B, 5-55 min.; eluição isocrática 50\% A / 50\% B, 55-65 min.; gradiente linear 50\% A / 50\% B para 95\% A / 5\% B, 65-67 min.; este gradiente é mantido por $6 \min ^{49}$ 
Material Seco

Extração exaustiva com :

1. Hexano,

2. Metanol

\section{Extrato Metanólico}

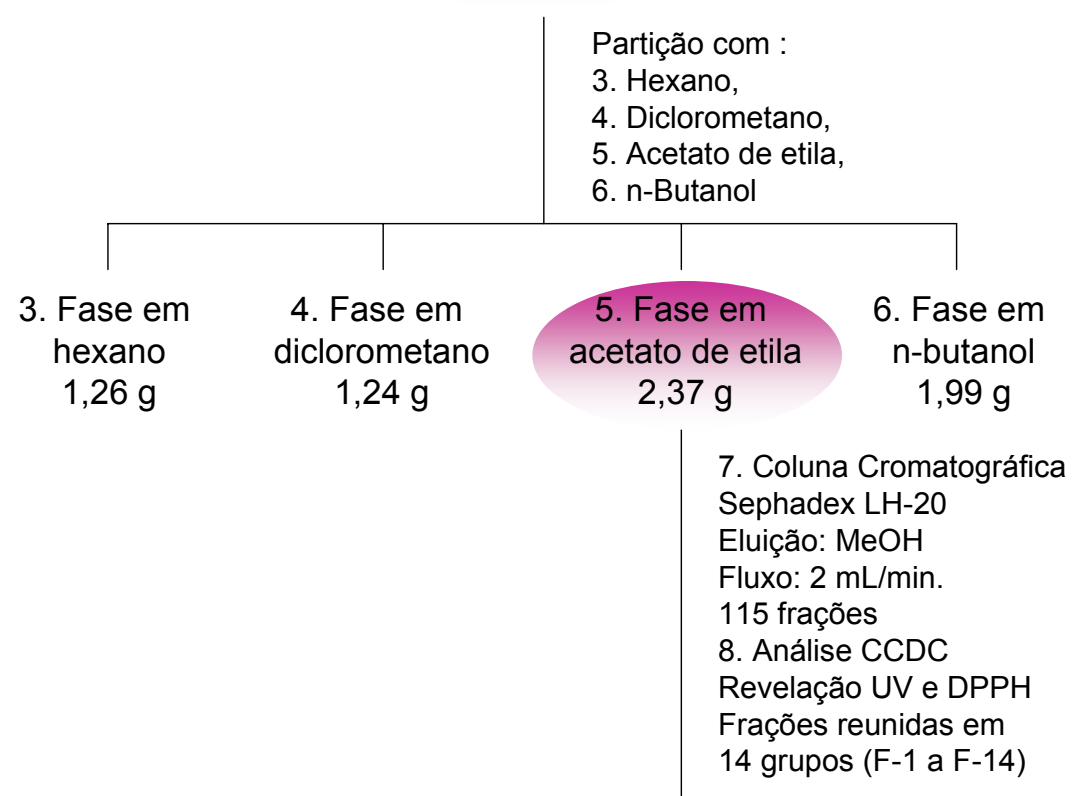

$\mathrm{F}-1$ a F-14

9. Análise por RMN de ${ }^{1} \mathrm{H}$

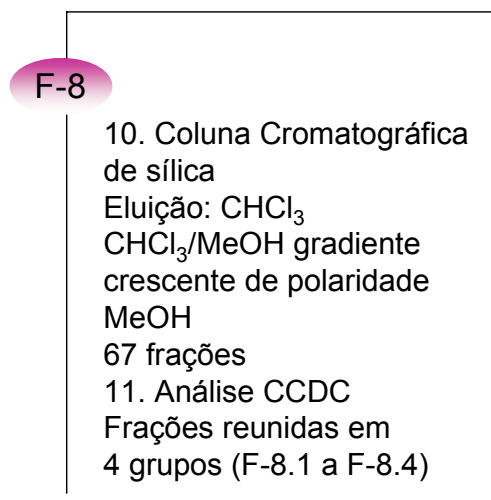

\section{F-8.1 $\rightarrow$ Substância}

Esquema 6: Fluxograma de ensaio fitoquímico monitorado resultando em duas substâncias isoladas. substâncias ou fases que foram submetidas à determinação da capacidade anti-radicalar.

\section{Instrumentação}

Os ensaios antiradicais foram realizados em dois espectrofluorímetros. Um Hitachi F-4500 (tensão da fotomultiplicadora: $700 \mathrm{~V}$, fenda: $10 \mathrm{~nm}$, comprimento de onda: $420 \mathrm{~nm}$ ) e um Varian Cary Eclipse (tensão da fotomultiplicadora: $750 \mathrm{~V}$, fenda: 
$20 \mathrm{~nm}$, comprimento de onda: $420 \mathrm{~nm}$ ). Ensaios espectrofotométricos foram conduzidos em um espectrofotômetro Shimadzu Multispec 1500 UV-Visível.

As curvas cinéticas com DPPH foram obtidas em um espectrofotômetro Shimadzu UV-2401 PC em $515 \mathrm{~nm}$. Inicialmente foi utilizado também um espectrofotômetro Shimadzu Multispec 1500 UV-Visível.

Os cromatogramas foram obtidos utilizando-se uma coluna $\mathrm{C}_{18}$ (Phenomenex) Luna $5 \mu, 250$ x 4,6 mm e em dois cromatógrafos diferentes. Um Shimadzu LC - 10 A, detector SPD - 10 A, UV. vis. e um Waters bombas 515, detector PDA - 996.

Os espectros de RMN ${ }^{1} \mathrm{H}$ e ${ }^{13} \mathrm{C}$ foram registrados em um espectrômetro Bruker modelo DRX-500 (500 MHz) e em um espectrômetro Bruker DPX-300 (300 MHz). Os espectros de infravermelho e de massas foram registrados em um espectrofotômetro FTIR Bomem MB 100 e LC-MS Bruker Daltonics Micro TOF, respectivamente.

\section{Procedimento de Ensaio Anti-radical.}

Em uma cela de quartzo para fluorescência munida de agitação magnética e termostatizada a $25^{\circ} \mathrm{C} \pm 0,6$ são adicionados $20 \mu \mathrm{L}$ de solução de luminol $10 \mathrm{mM}$ e 20 $\mu \mathrm{L}$ hemina $8 \mu \mathrm{M}$ a $1920 \mu \mathrm{L}$ de tampão fosfato $\mathrm{pH} 11,6 \mu=0,1 \mathrm{M}$. A reação quimiluminescente é iniciada pela adição de $20 \mu \mathrm{L}$ de uma solução de peróxido de hidrogênio $1 \mathrm{mM}$. A intensidade de emissão é registrada em $420 \mathrm{~nm}$. Após cem segundos de reação, são adicionados $20 \mu \mathrm{L}$ de uma solução da amostra anti-radical de concentração adequada com a sala escura para poder continuar a leitura. A mistura final de reação contém hemina $80 \mathrm{nM}$, luminol $0,1 \mathrm{mM}$ e peróxido de hidrogênio $10 \mu \mathrm{M}$ em $2 \mathrm{~mL}$ de volume final. A cinética de reação é registrada por quinze minutos.

\section{Procedimento de Ensaio Anti-radical com DPPH.}

Em uma cela de quartzo para absorção munida de agitação magnética são adicionados $150 \mu \mathrm{L}$ de solução de anti-radical e $150 \mu \mathrm{L}$ DPPH 1 mM a $2700 \mu \mathrm{L}$ de etanol. A mistura final de reação contém cerca de $78 \mu \mathrm{M}$ de DPPH e a concentração adequada da amostra de anti-radical. A cinética de reação foi registrada durante trinta minutos e monitorada em $515 \mathrm{~nm}$. 


\section{Quantificação da Capacidade Anti-radicalar}

\section{Ensaio Luminol}

Considerando uma emissão luminosa cuja intensidade varia com o tempo, em um tempo $t$, o número de fótons emitido por segundo será $N(t)$. A luz total emitida $(L)$ em uma reação quimiluminescente será proporcional à intensidade de emissão (I)e é dada pela Equação 1.

$$
\mathrm{L}=\int_{0}^{\infty} \mathrm{N}(\mathrm{t}) \mathrm{dt}=\int_{0}^{\infty} \mathrm{I} \mathrm{dt}
$$

A área sob a curva de decaimento de quimiluminescência da reação padrão é proporcional à concentração total de espécies reativas presentes no meio de reação. Compostos seqüestradores de radical irão consumir estas espécies, resultando na diminuição da intensidade de emissão. Desta forma, a diferença entre as áreas obtidas com e sem a presença do anti-radical representa o número de espécies reativas consumidas pelo anti-radical (Figura 30). O valor obtido deve ser proporcional à concentração de anti-radical adicionado ao sistema quimiluminescente.
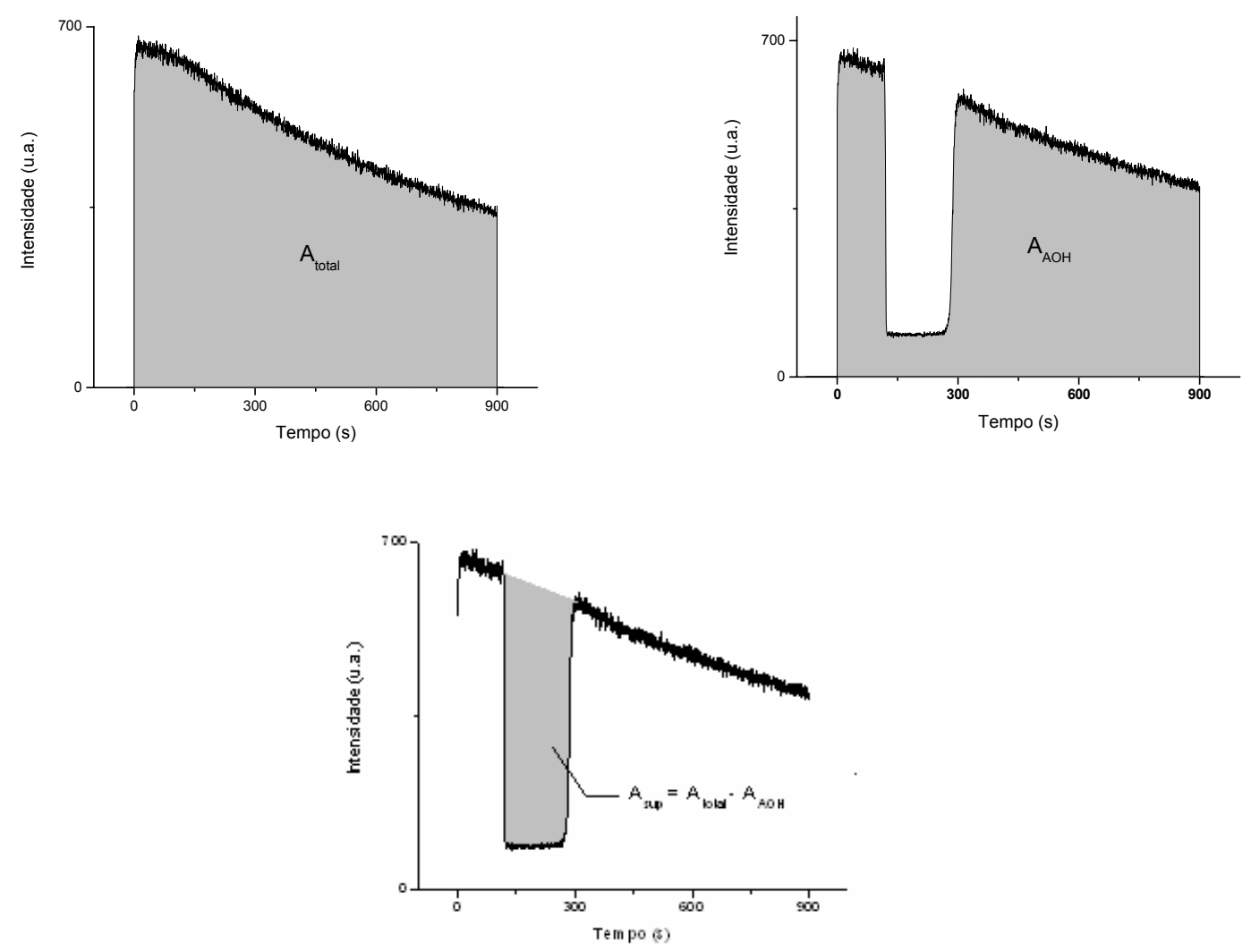

Figura 30: Determinação da área de supressão $\left(A_{\text {sup }}\right)$ pela diferença das áreas de emissão obtidas na presença $\left(\mathrm{A}_{\mathrm{AOH}}\right)$ e na ausência (Atotal) do anti-radical $(\mathrm{AOH})$.

O coeficiente angular obtido do ajuste da correlação entre a concentração de trolox e a área de supressão $\left(\alpha_{T}\right)$ é proporcional, por definição, a $2 .^{68-70}$ ou seja, uma 
molécula de trolox pode seqüestrar dois radicais. O coeficiente angular obtido da amostra $\left(\alpha_{\mathrm{a}}\right)$ através do cálculo das áreas de supressão é utilizado para calcular o número de radicais seqüestrados por molécula de anti-radical (n), no caso a amostra (Figura 28).

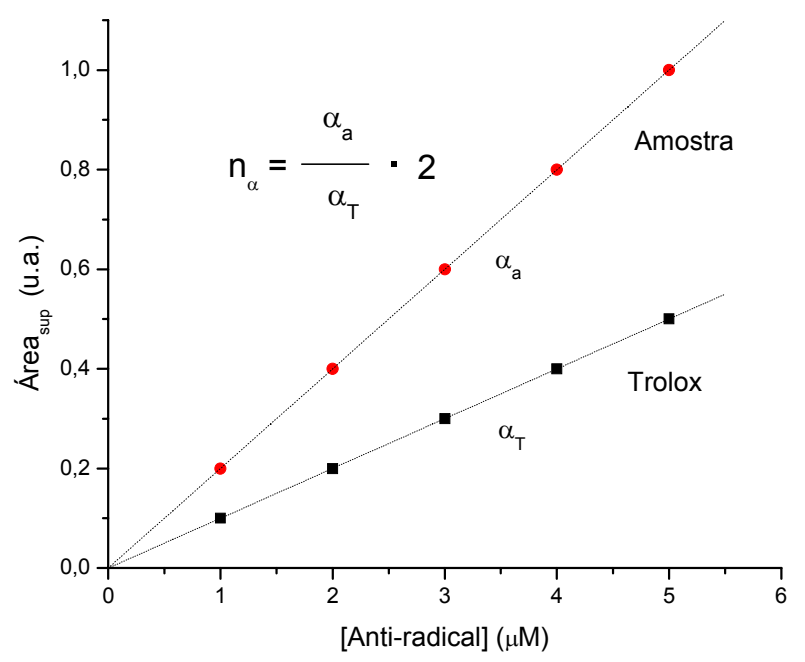

Figura 31: Correlação linear entre área de supressão e a concentração do anti-radical em $\mu \mathrm{M}$ para o cálculo do número de radicais seqüestrado por molécula de anti-radical (n).

Misturas complexas, como produtos naturais e extratos de alimentos, também podem ter sua atividade anti-radical avaliada através de uma curva de calibração. Os resultados são expressos na forma da concentração $(\mathrm{mg} / \mathrm{L})$ com a mesma atividade de $1 \mu \mathrm{M}$ de Trolox (Figura 32). O valor numérico é inversamente proporcional à capacidade anti-radical.

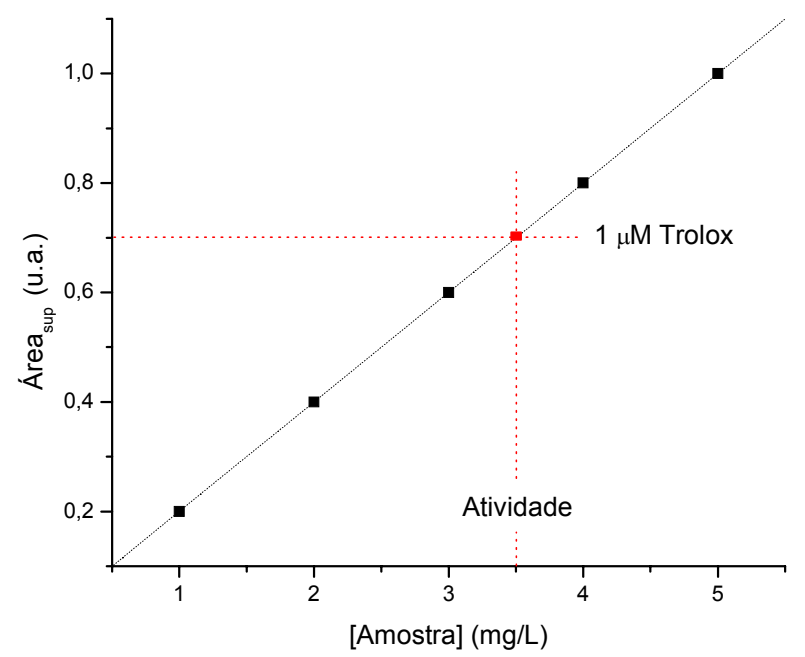

Figura 32: Correlação linear entre a área e a concentração da amostra em mg/L para o cálculo do Potencial Anti-radical Total (TRAP). O valor de área obtida com $1 \mu \mathrm{M}$ de Trolox corresponde à atividade em mg/L da amostra. Quanto menor o valor de TRAP, maior a atividade anti-radical. 


\section{Ensaio DPPH}

O ensaio antioxidante é baseado na medida da perda da cor da solução de DPPH em $515 \mathrm{~nm}$ após a reação de um composto anti-radicalar, monitorada espectrofotometricamente. Com a adição do composto anti-radicalar na solução etanólica de DPPH, observa-se um decréscimo do valor da absorbância inicial de acordo com a concentração utilizada. A quantificação da capacidade anti-radicalar pode ser feita de duas maneiras: (i) obtenção do valor da capacidade anti-radicalar $(\mathrm{n})$ em comparação com o padrão trolox, de maneira análoga à feita no ensaio luminol (Figura 28A); (ii) obtenção de um valor absoluto para a capacidade anti-radicalar $\left(\mathrm{n}^{*}\right)$ pela quantidade de radicais DPPH seqüestrados, determinado pelo decréscimo da absorbância (Figura 28 B).

A

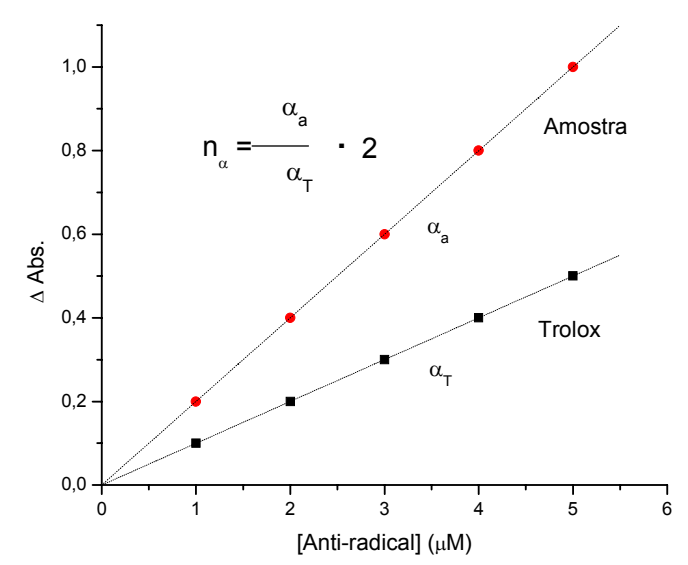

B

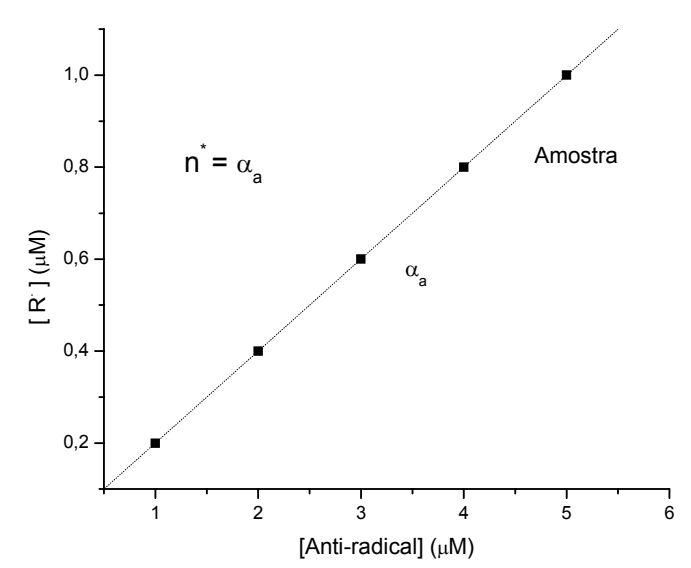

Figura 33: Correlação linear entre a concentração do anti-radical e A: $\Delta$ Abs.e B: [R ] para o cálculo de A: n e B: $n^{*}$.

\section{Análise Estatística}

Os valores são expressos como média \pm desvio padrão da amostra, obtidos a partir de ao menos três resultados experimentais. Os cálculos de desvio padrão para valores de $n$ e TRAP foram realizados utilizando-se os valores de inclinação do ajuste linear do padrão trolox e da amostra $\left(\alpha^{\mathrm{t}} \mathrm{e} \alpha^{\mathrm{a}}\right)$, bem como seus erros $\left(\sigma_{\alpha}{ }^{\mathrm{t}} \mathrm{e} \sigma_{\alpha}{ }^{\mathrm{a}}\right)$ através da equação Todos os cálculos e ajustes foram realizados utilizando o software Microcal Origin 6.1 (2001).

$$
\sigma_{n}=\frac{1}{\alpha^{t}} \sqrt{\left(\sigma_{\alpha}{ }^{a}\right)+\left(\frac{\left(\alpha^{a}\right)^{2}\left(\sigma_{\alpha}{ }^{t}\right)^{2}}{\left(\alpha^{t}\right)^{2}}\right)^{2}}
$$

$$
\sigma_{\text {TRAP }}=\frac{1}{\alpha^{a}} \sqrt{\left(\sigma_{\alpha}{ }^{t}\right)+\left(\frac{\left(\alpha^{\mathrm{t}}\right)^{2}\left(\sigma_{\alpha}^{\mathrm{a}}\right)^{2}}{\left(\alpha^{\mathrm{a}}\right)^{2}}\right)^{2}}
$$




\section{Anexos}

Anexo 1: Espectro de RMN ${ }^{13} \mathrm{C}$ de F-9.3.

Anexo 2: Espectro expandido de RMN ${ }^{13} \mathrm{C}$ de F-9.3.

Anexo 3: Espectro expandido de $\mathrm{RMN}{ }^{13} \mathrm{C}$ de F-9.3.

Anexo 4: Espectro de RMN ${ }^{1} \mathrm{H}$ de F-9.3.

Anexo 5: Espectro expandido de RMN ${ }^{1} \mathrm{H}$ de F-9.3.

Anexo 6: Espectro expandido de RMN ${ }^{1} \mathrm{H}$ de F-9.3.

Anexo 7: Espectro expandido de RMN ${ }^{1} \mathrm{H}$ de F-9.3.

Anexo 8: Espectro de massas de F-8.1.

Anexo 9: Espectro de infravermelho de F-8.1.

Anexo 10: Espectro de ${ }^{1} \mathrm{H}$ de F-8.1.

Anexo 11: Espectro expandido de ${ }^{1} \mathrm{H}$ de F-8.1.

Anexo 12: Espectro expandido de ${ }^{1} \mathrm{H}$ de F-8.1.

Anexo 13: Espectro expandido de ${ }^{1} \mathrm{H}$ de F-8.1.

Anexo 14: Espectro de ${ }^{13} \mathrm{C}$ de F-8.1.

Anexo 15: Espectro expandido de ${ }^{13} \mathrm{C}$ de F-8.1.

Anexo 16: Espectro expandido de ${ }^{13} \mathrm{C}$ de F-8.1.

Anexo 17: Espectro expandido de ${ }^{13} \mathrm{C}$ de F-8.1.

Anexo 18: Espectro de HMQC de F-8.1.

Anexo 19: Espectro expandido de HMQC de F-8.1.

Anexo 20: Espectro expandido de HMQC de F-8.1.

Anexo 21: Espectro expandido de HMQC de F-8.1.

Anexo 22: Espectro de HMBC de F-8.1.

Anexo 23: Espectro expandido de HMBC de F-8.1.

Anexo 24: Espectro expandido de HMBC de F-8.1.

Anexo 25: Espectro expandido de HMBC de F-8.1.

Anexo 26: Espectro expandido de HMBC de F-8.1.

Anexo 27: Espectro expandido de HMBC de F-8.1.

Anexo 28: Espectro expandido de HMBC de F-8.1. 


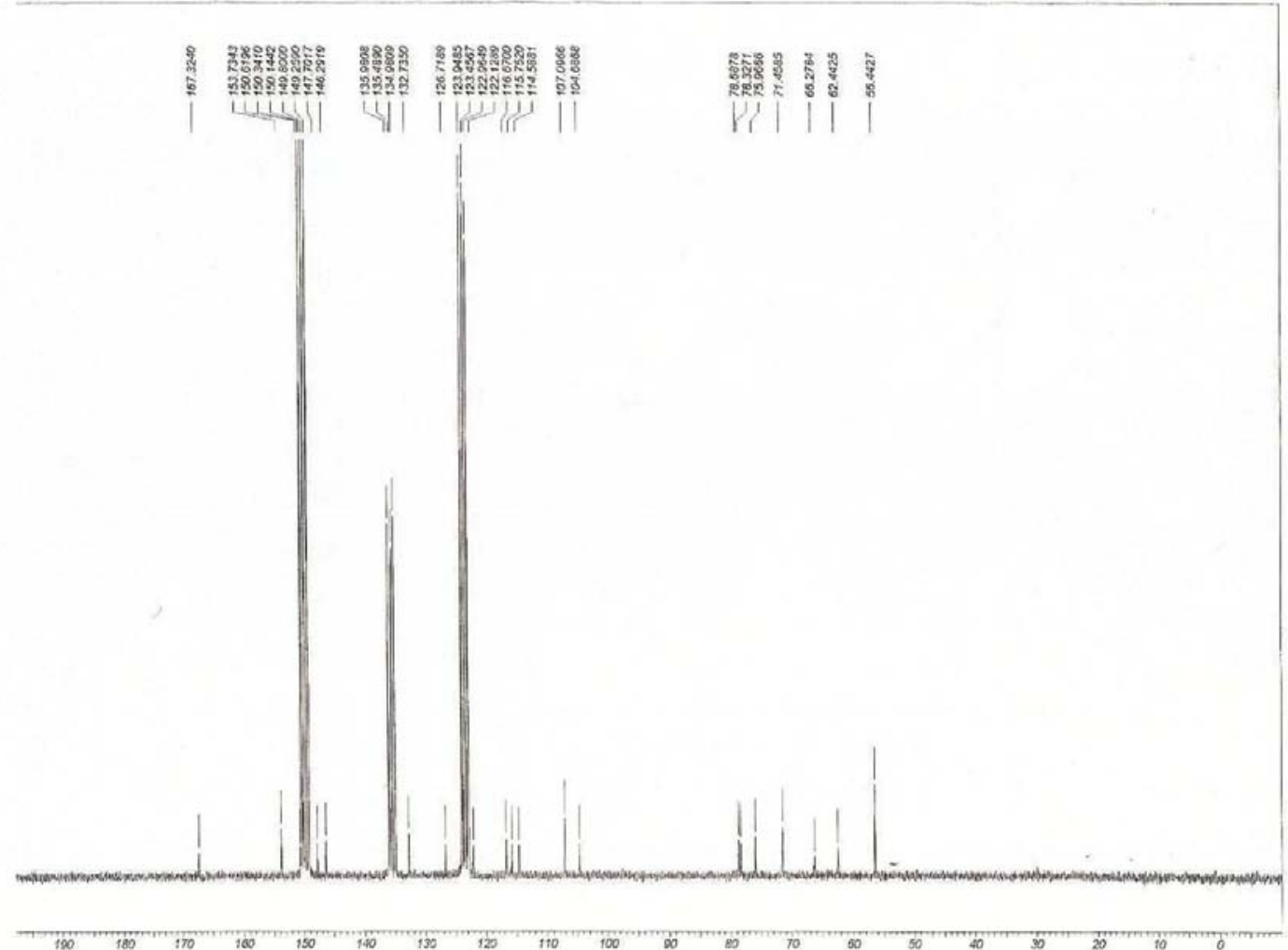

Anexo 1: Espectro de RMN ${ }^{13} \mathrm{C}$ de F-9.3. 


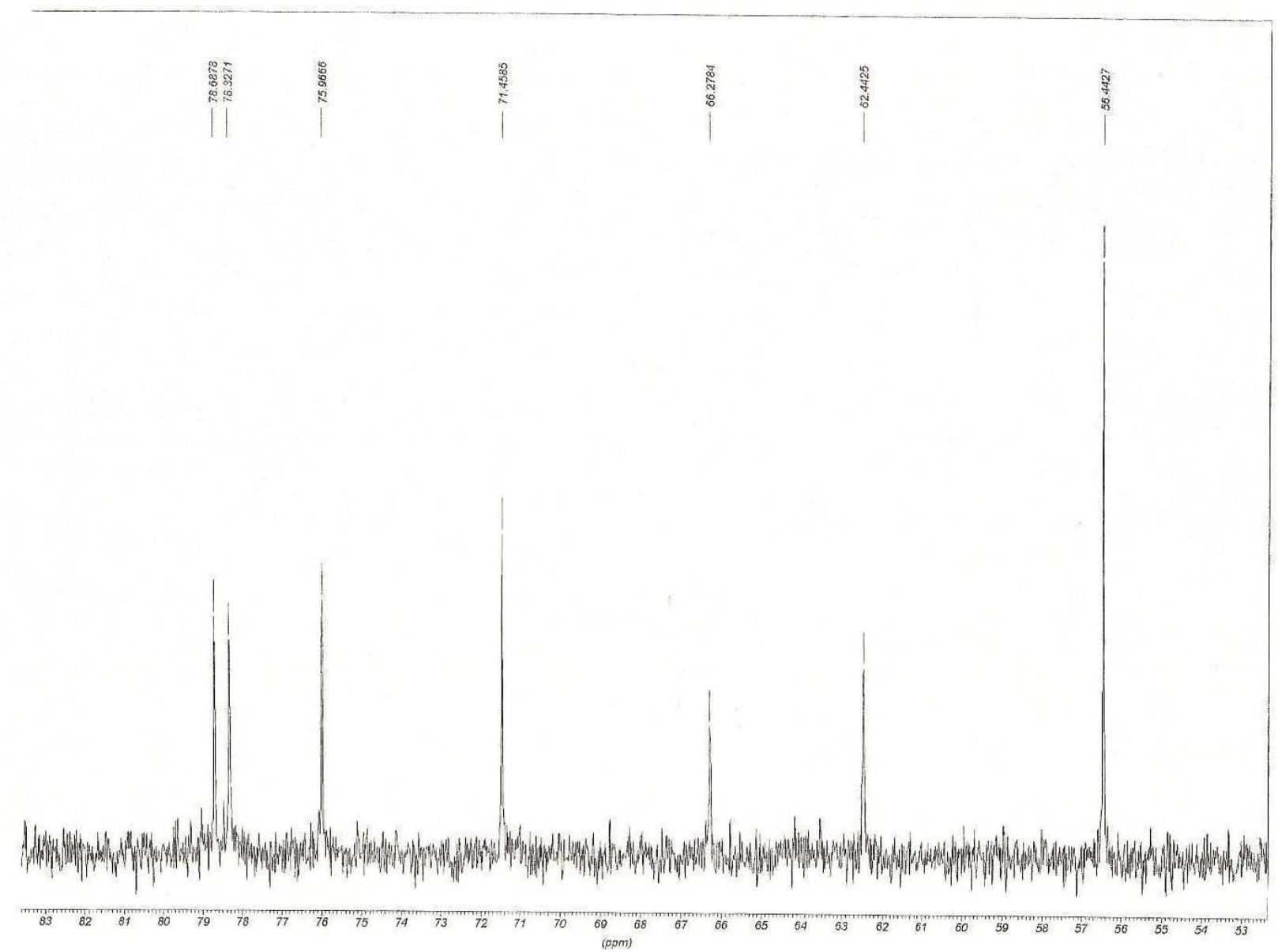

Anexo 2: Espectro expandido de RMN ${ }^{13} \mathrm{C}$ de F-9.3. 


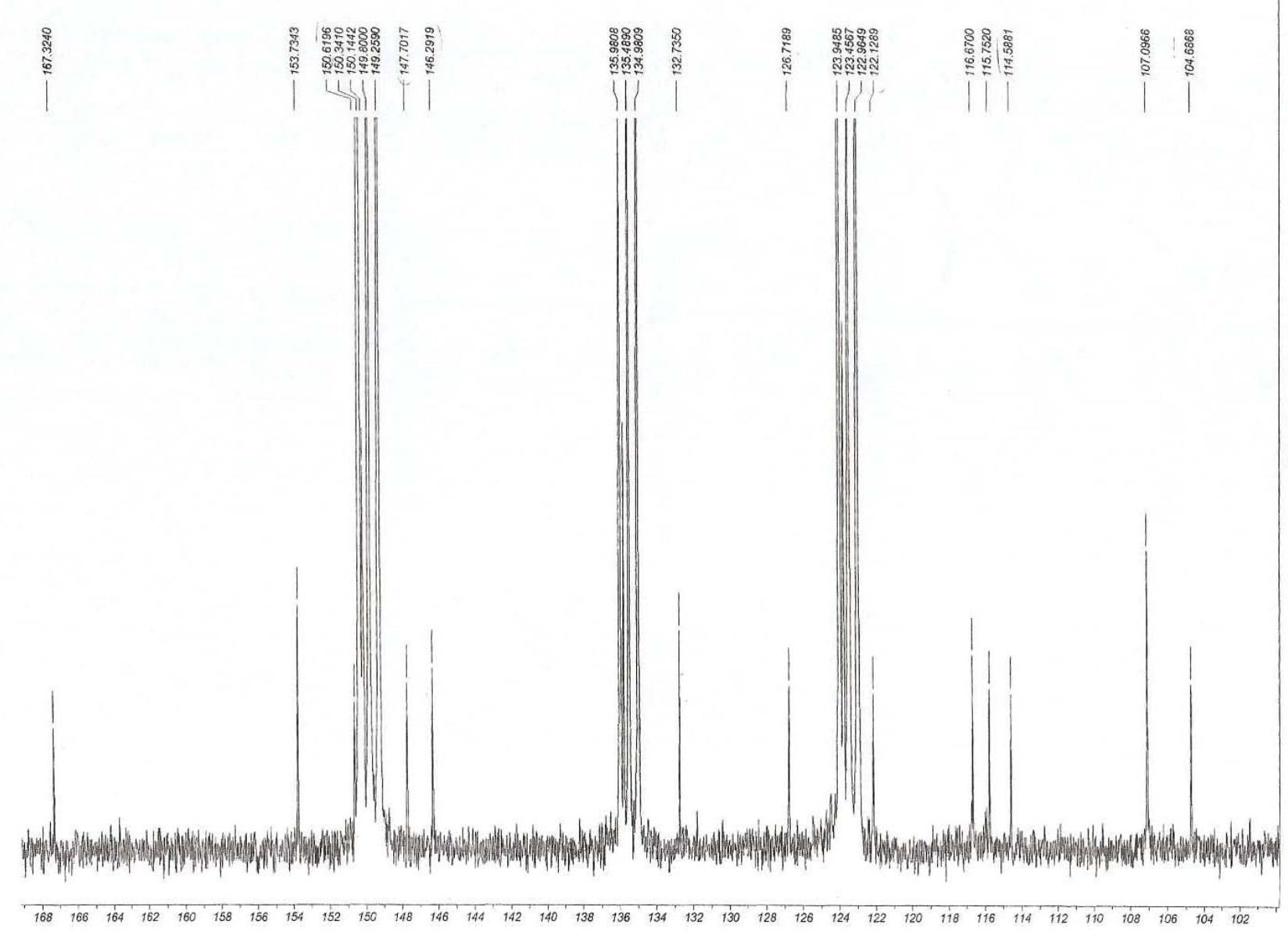

Anexo 3: Espectro expandido de $\mathrm{RMN}{ }^{13} \mathrm{C}$ de F-9.3. 


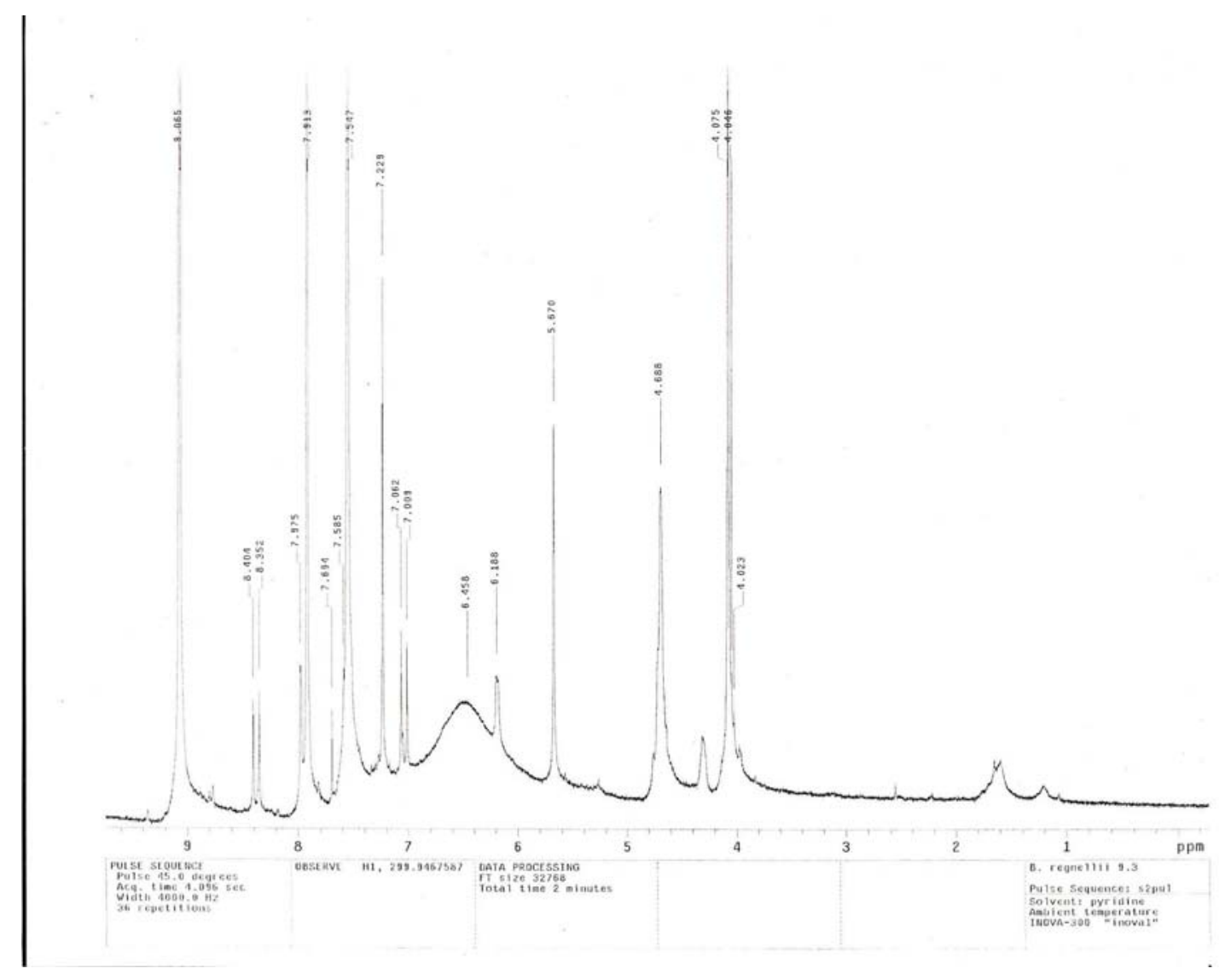

Anexo 4: Espectro de RMN ${ }^{1} \mathrm{H}$ de F-9.3. 


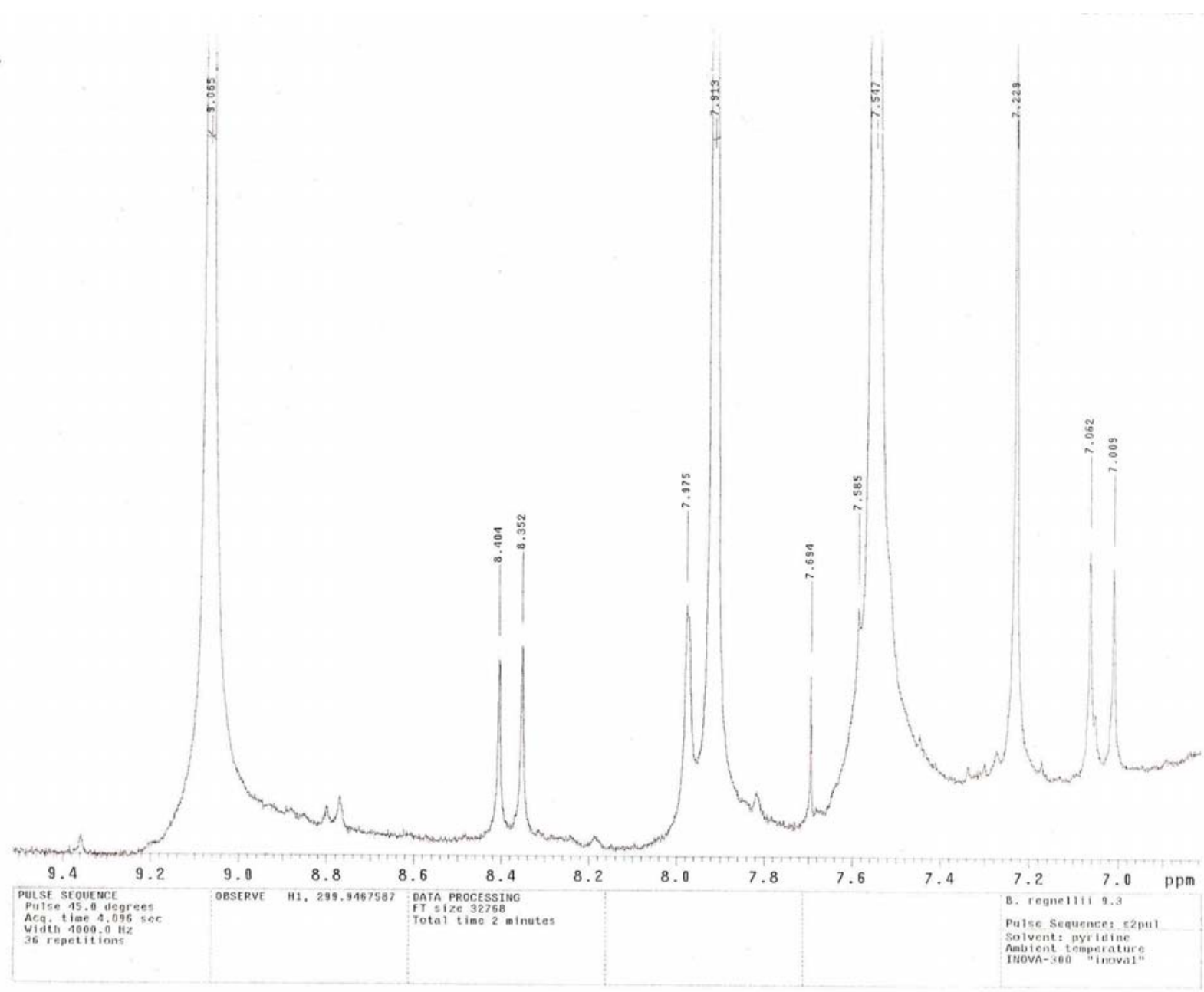

Anexo 5: Espectro expandido de $\mathrm{RMN}{ }^{1} \mathrm{H}$ de F-9.3. 


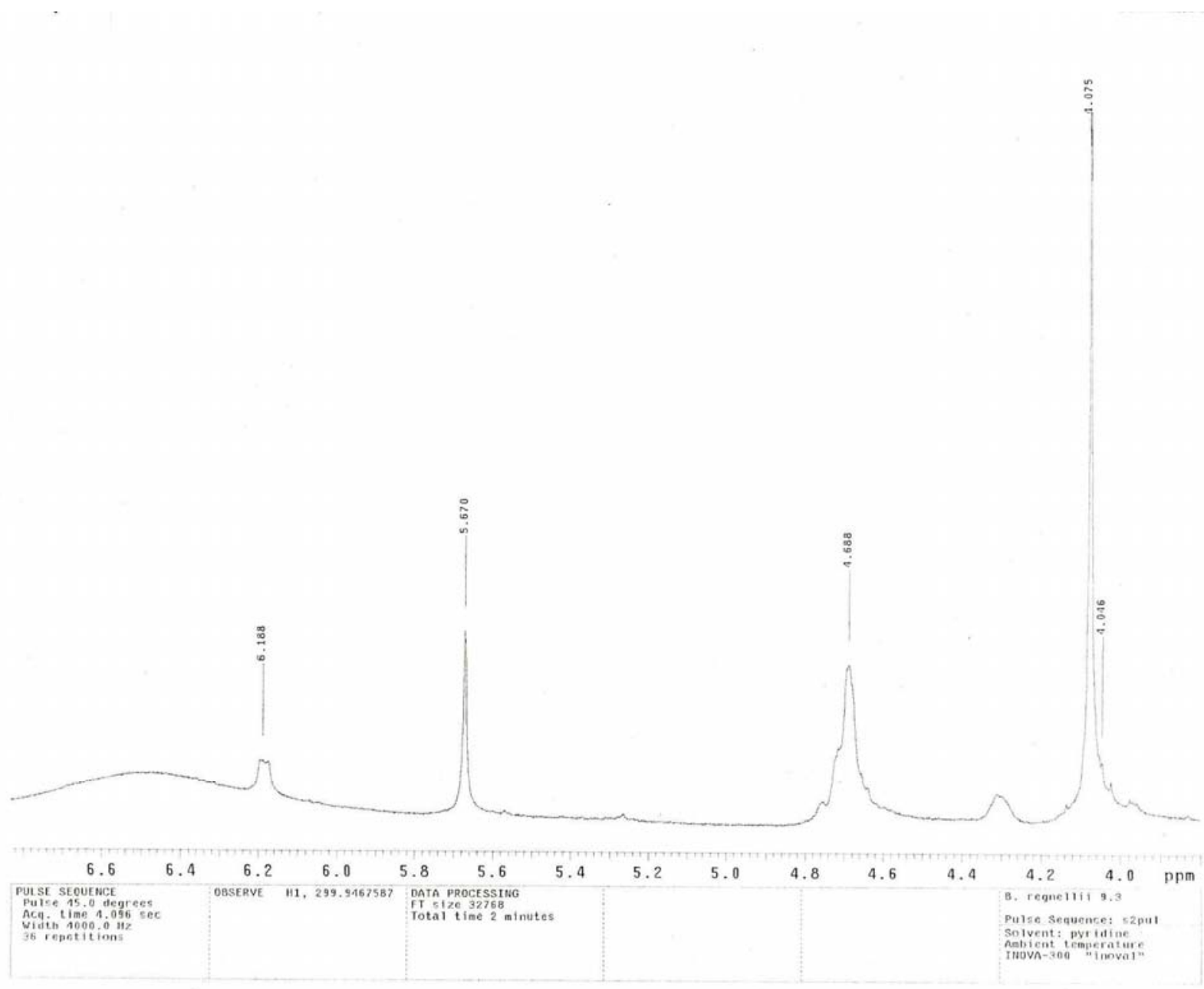

Anexo 6: Espectro expandido de $\mathrm{RMN}^{1} \mathrm{H}$ de F-9.3. 


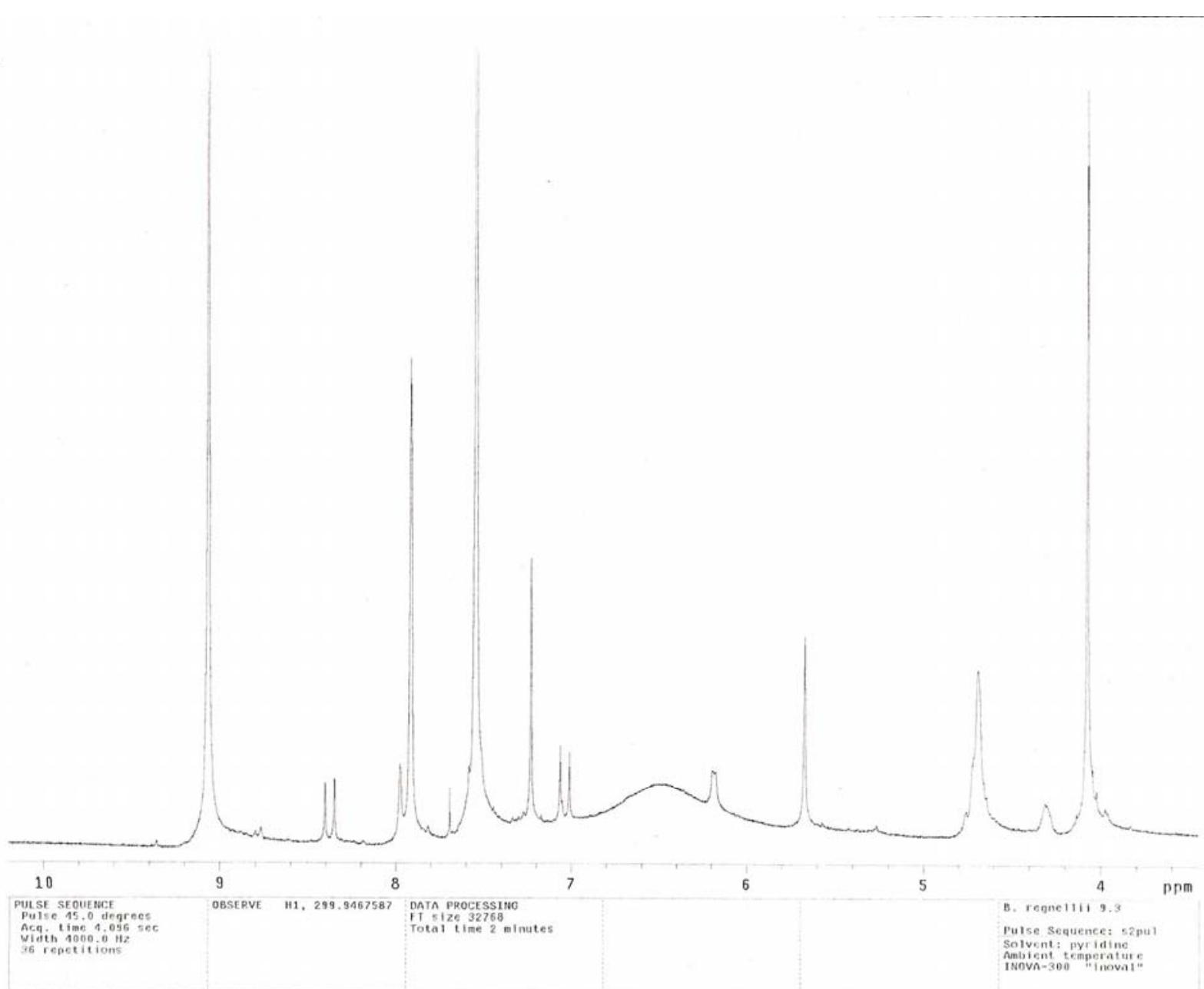

Anexo 7: Espectro expandido de $\mathrm{RMN}{ }^{1} \mathrm{H}$ de F-9.3. 

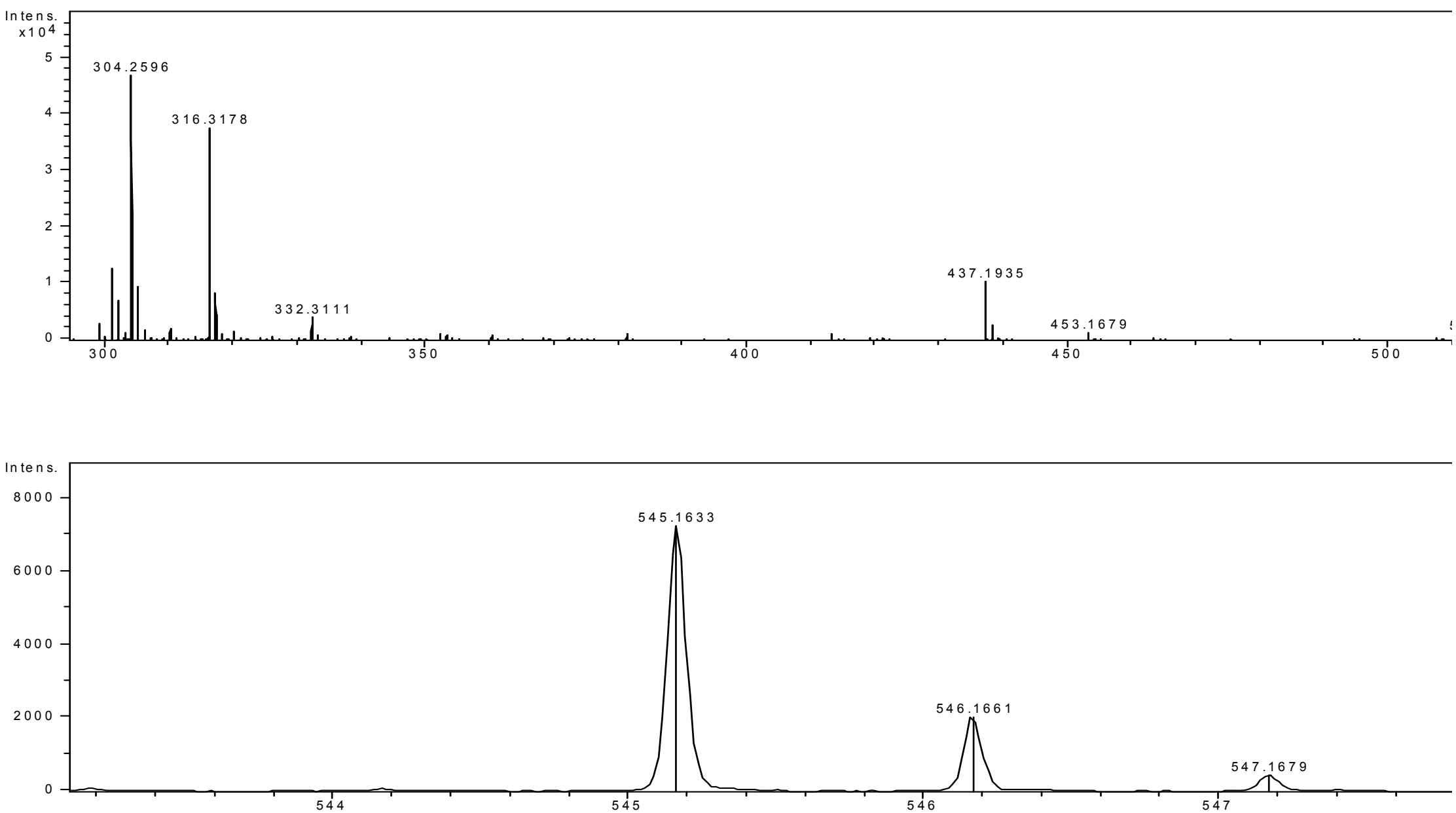

Anexo 8: Espectros de massas de F-8.1. 


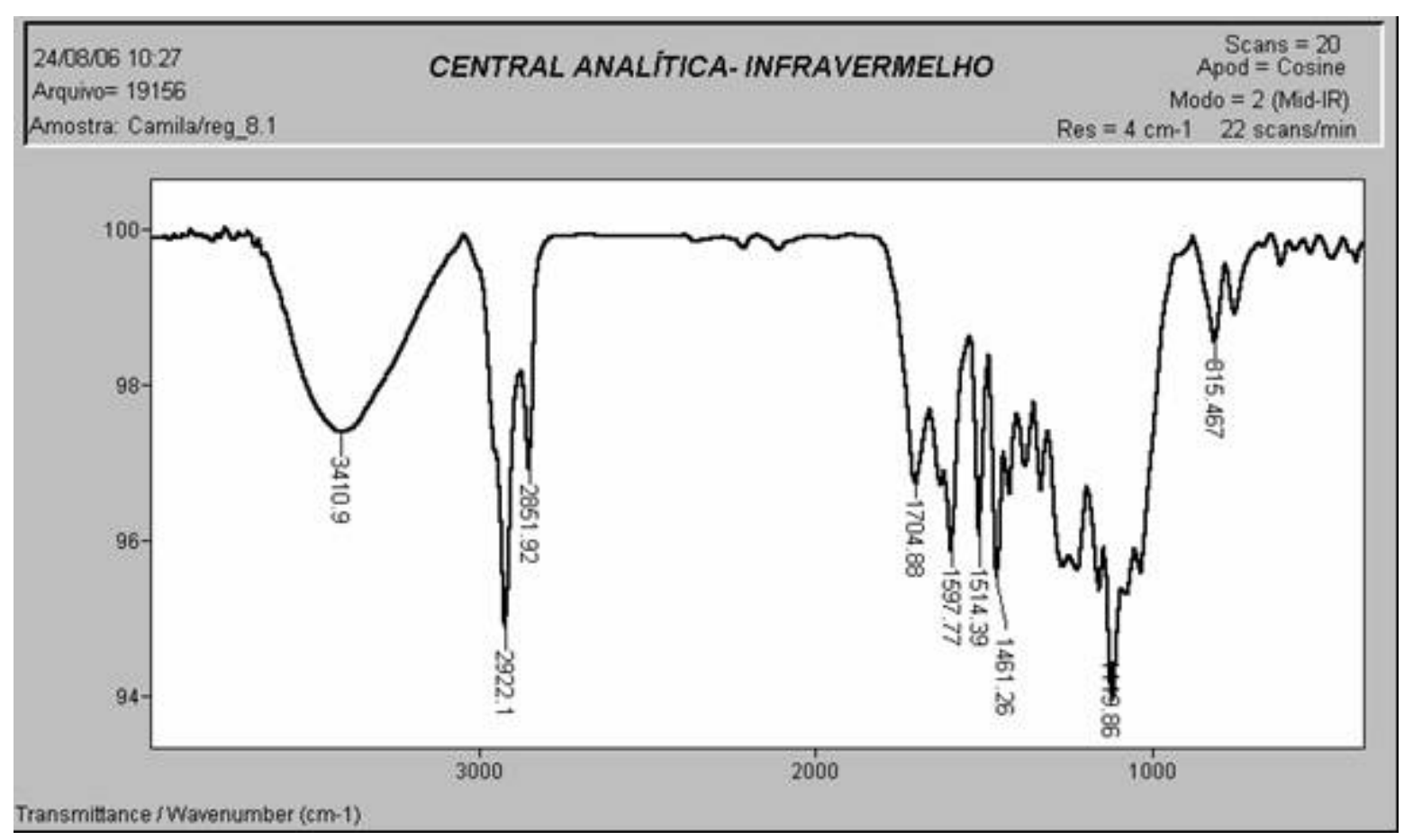

Anexo 9: Espectro de Infravermelho de F-8.1. 


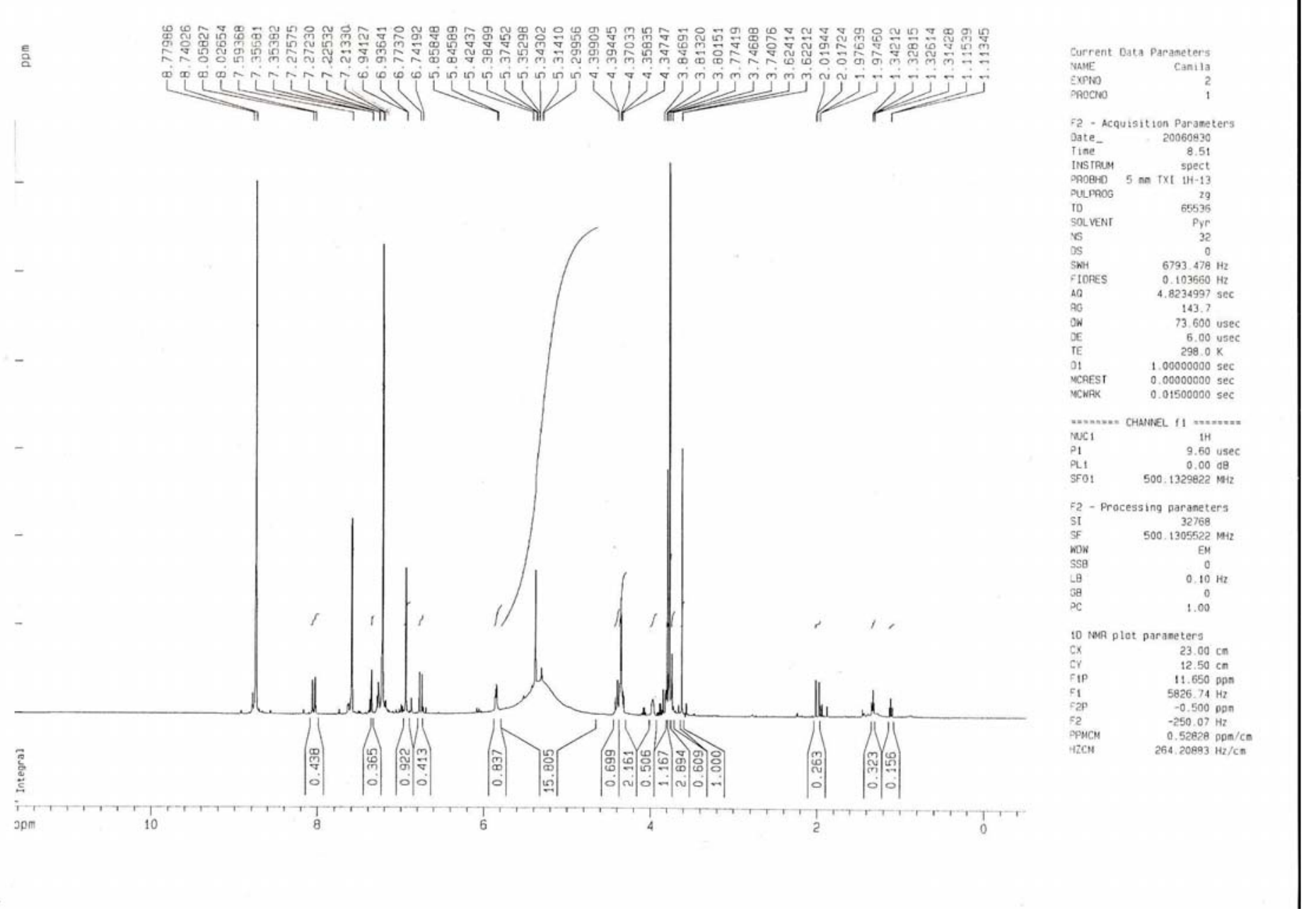

Anexo 10: Espectro de RMN ${ }^{1} \mathrm{H}$ de F-8.1. 


$$
\text { "W. }
$$




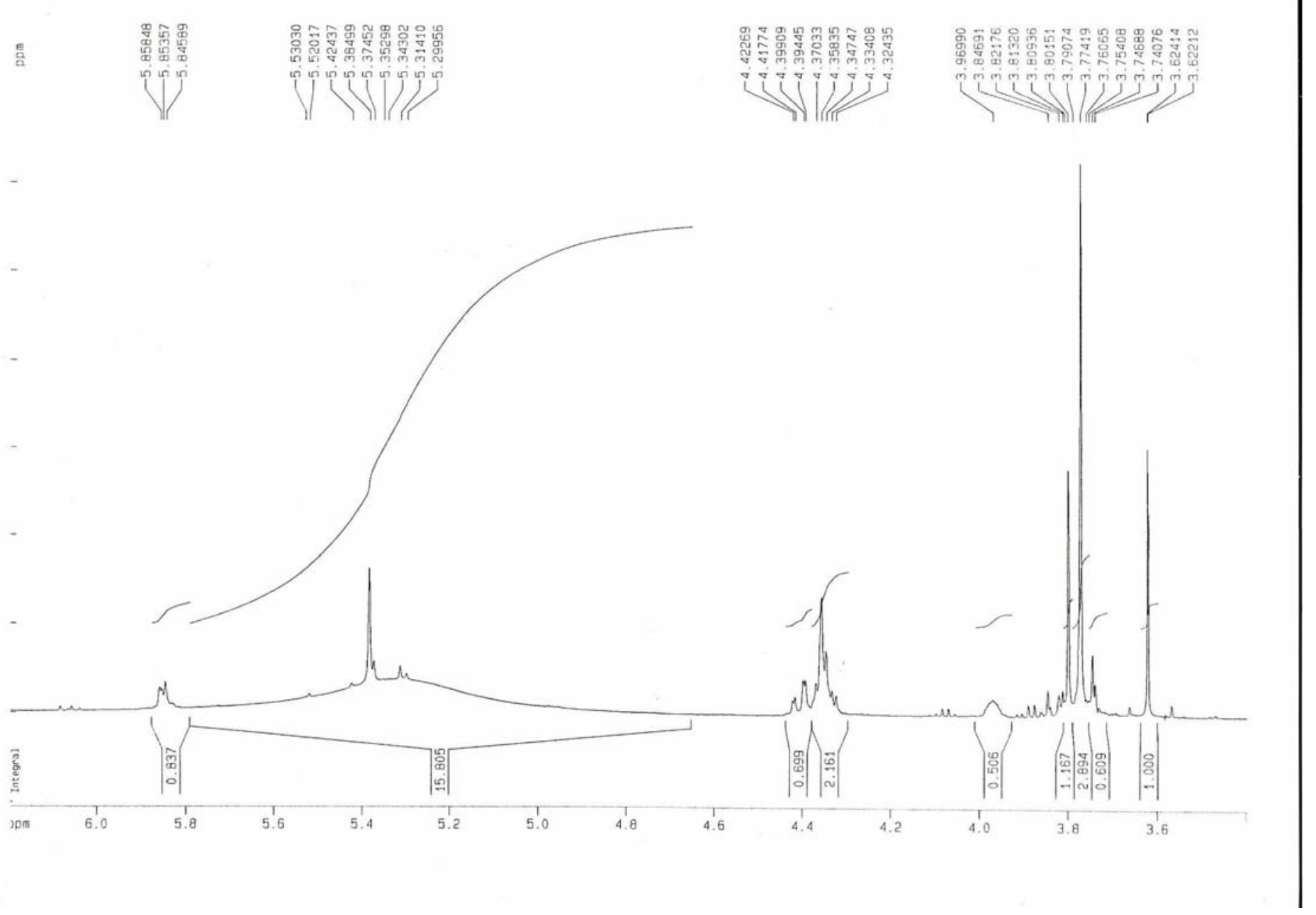

Anexo 12: Espectro expandido de RMN ${ }^{1} \mathrm{H}$ de F-8.1. 


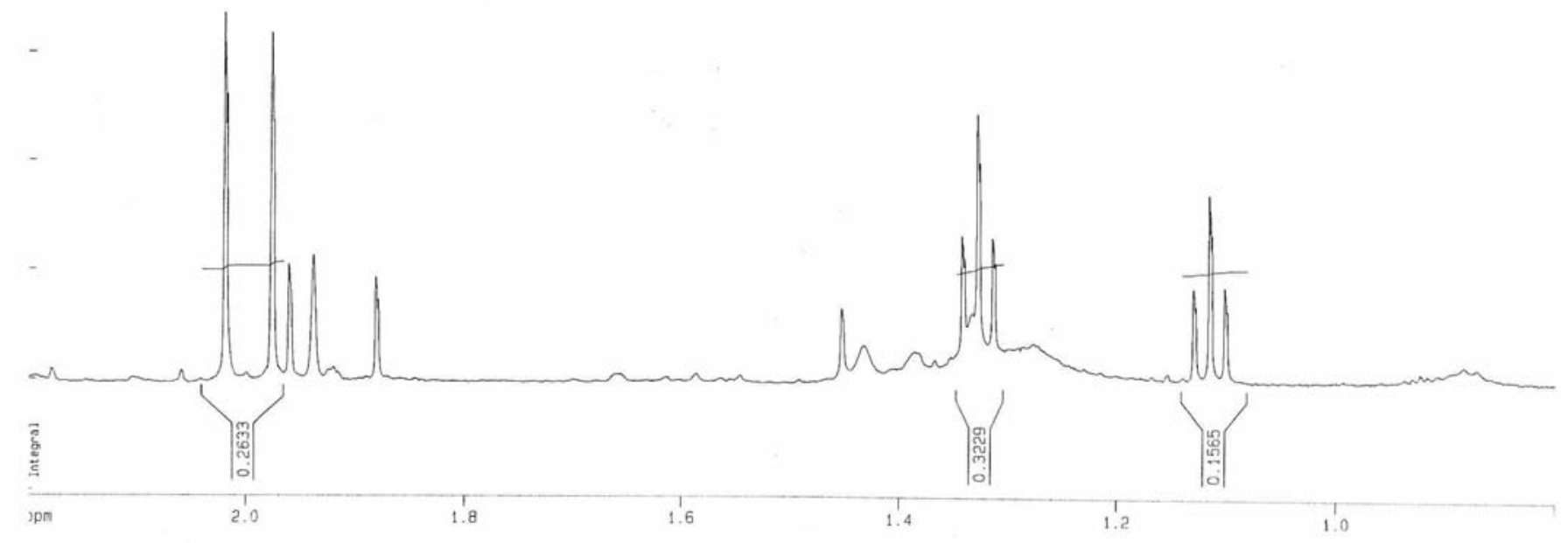

Anexo 13: Espectro expandido de RMN ${ }^{1} \mathrm{H}$ de F-8.1. 

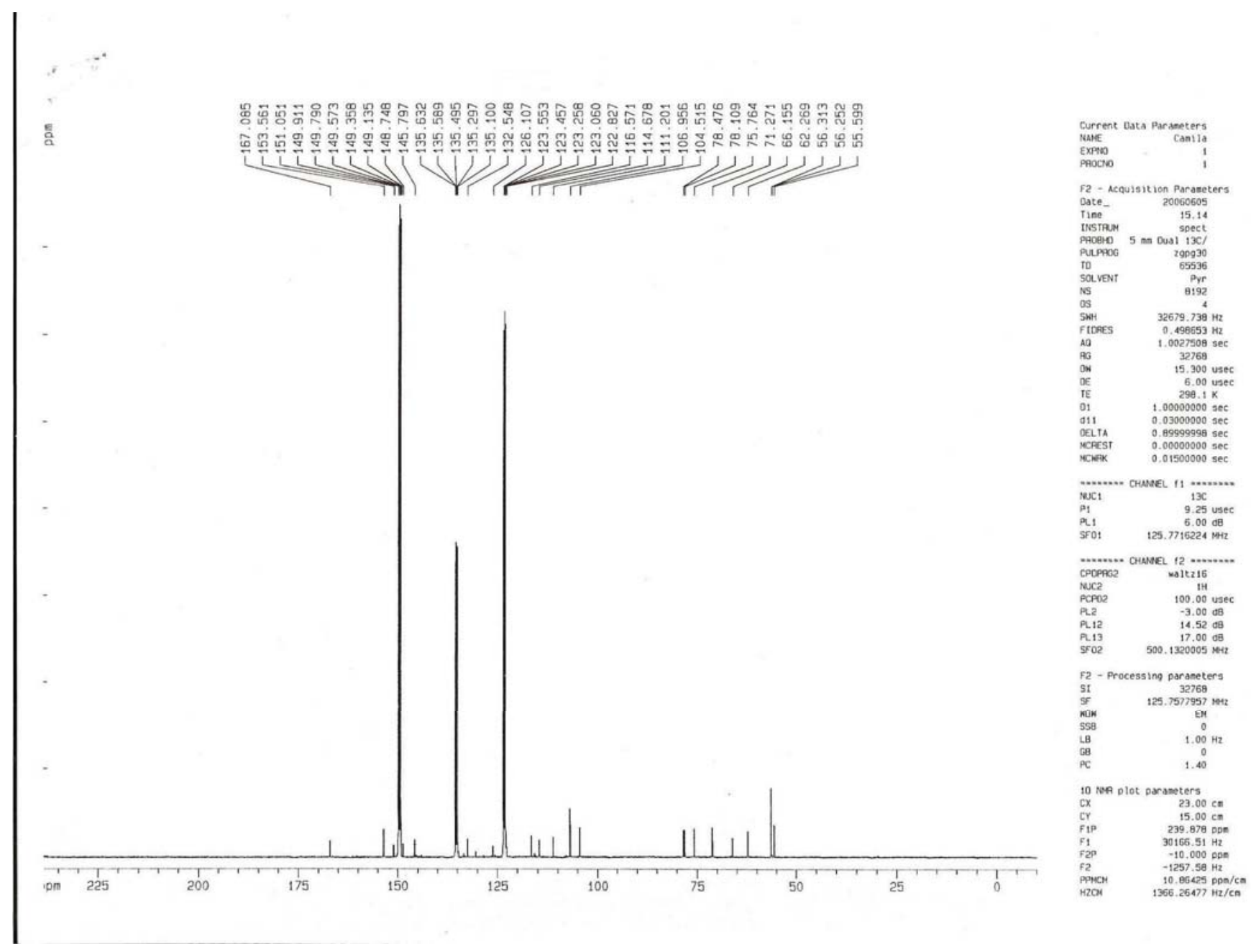

Anexo 14: Espectro de RMN ${ }^{13} \mathrm{C}$ de F-8.1. 


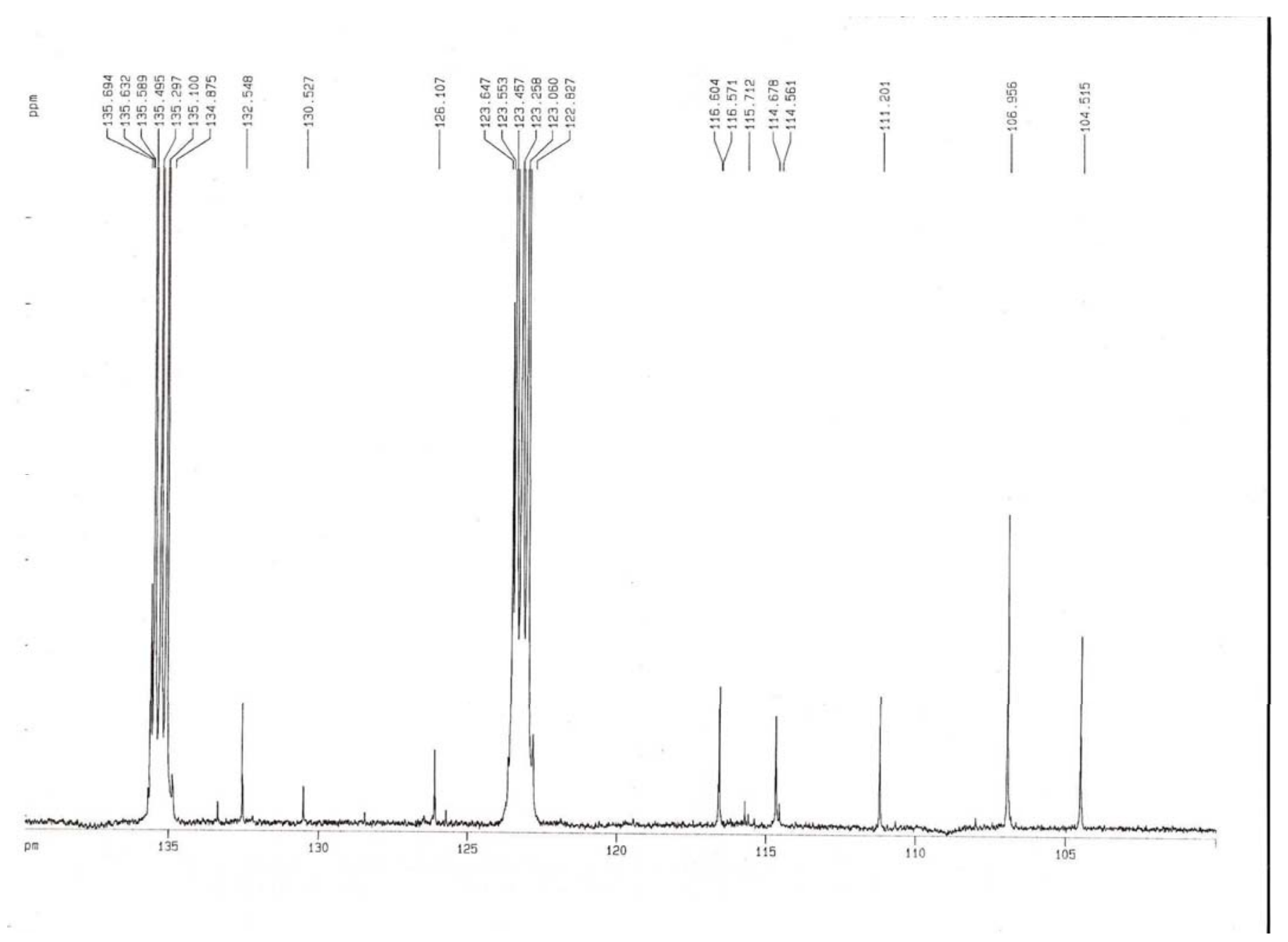

Anexo 15: Espectro expandido de $\mathrm{RMN}{ }^{13} \mathrm{C}$ de F-8.1. 


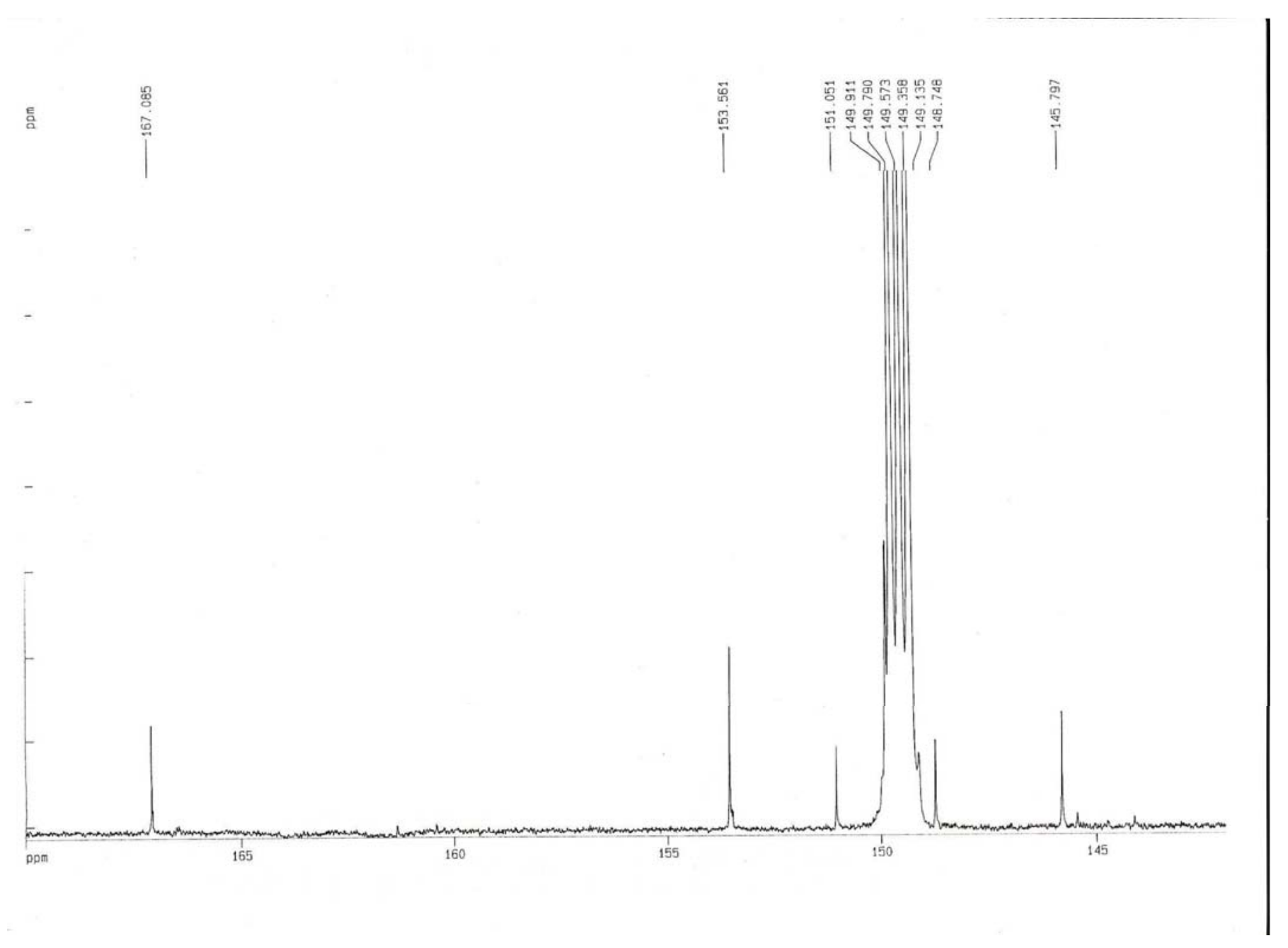

Anexo 16: Espectro expandido de $\mathrm{RMN}{ }^{13} \mathrm{C}$ de $\mathrm{F}-8.1$ 


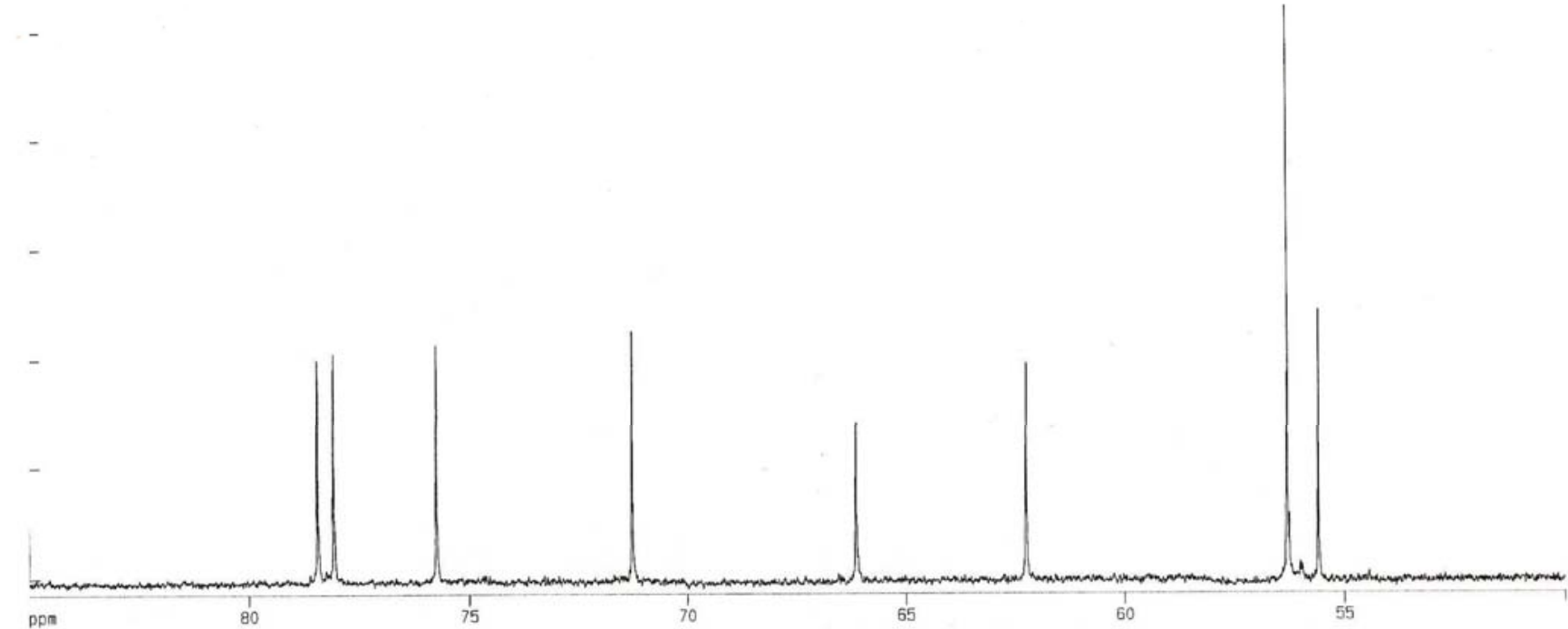

Anexo 17: Espectro expandido de RMN ${ }^{13} \mathrm{C}$ de F-8.1. 

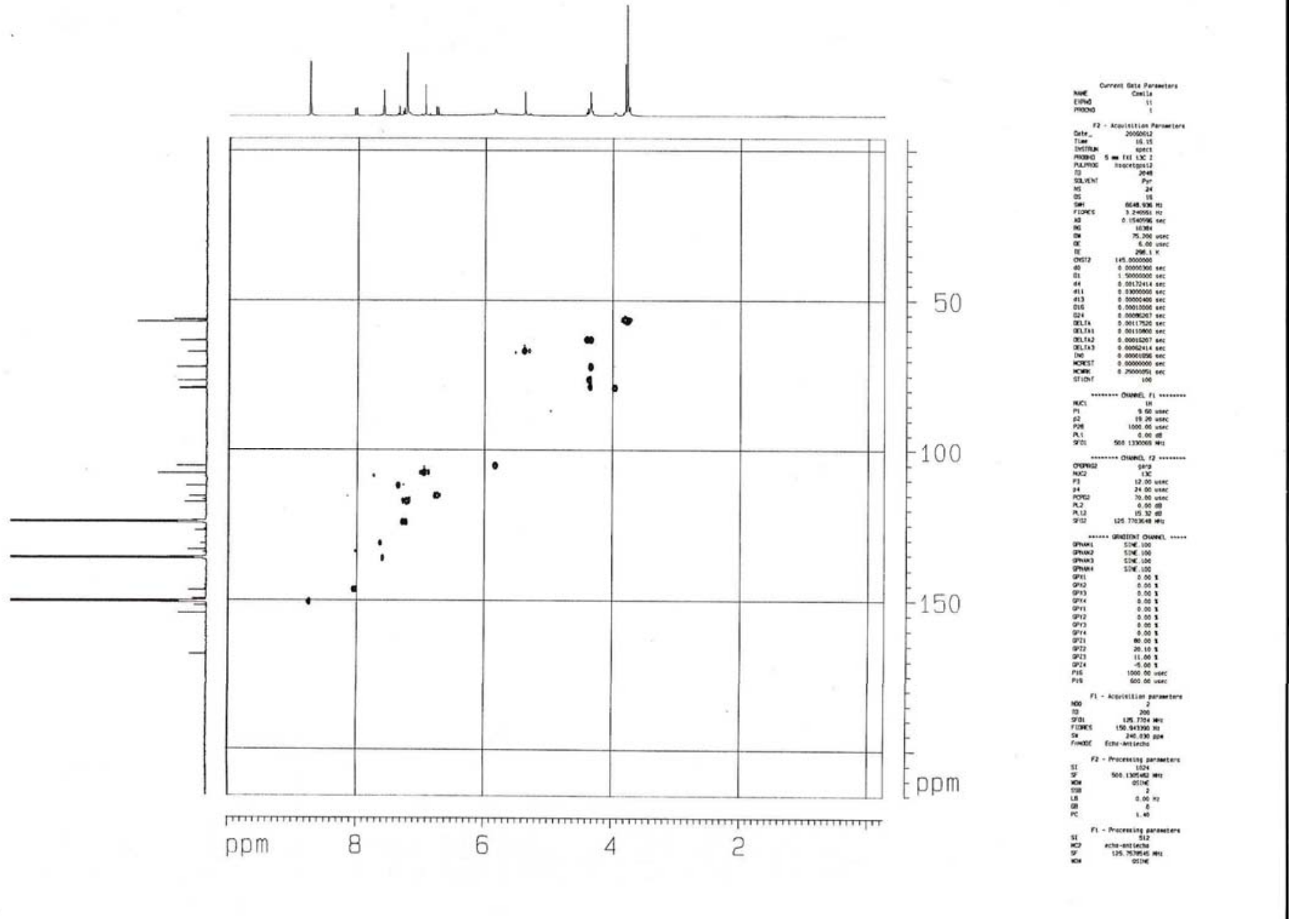

Anexo 18: Espectro de HMQC de F-8.1. 

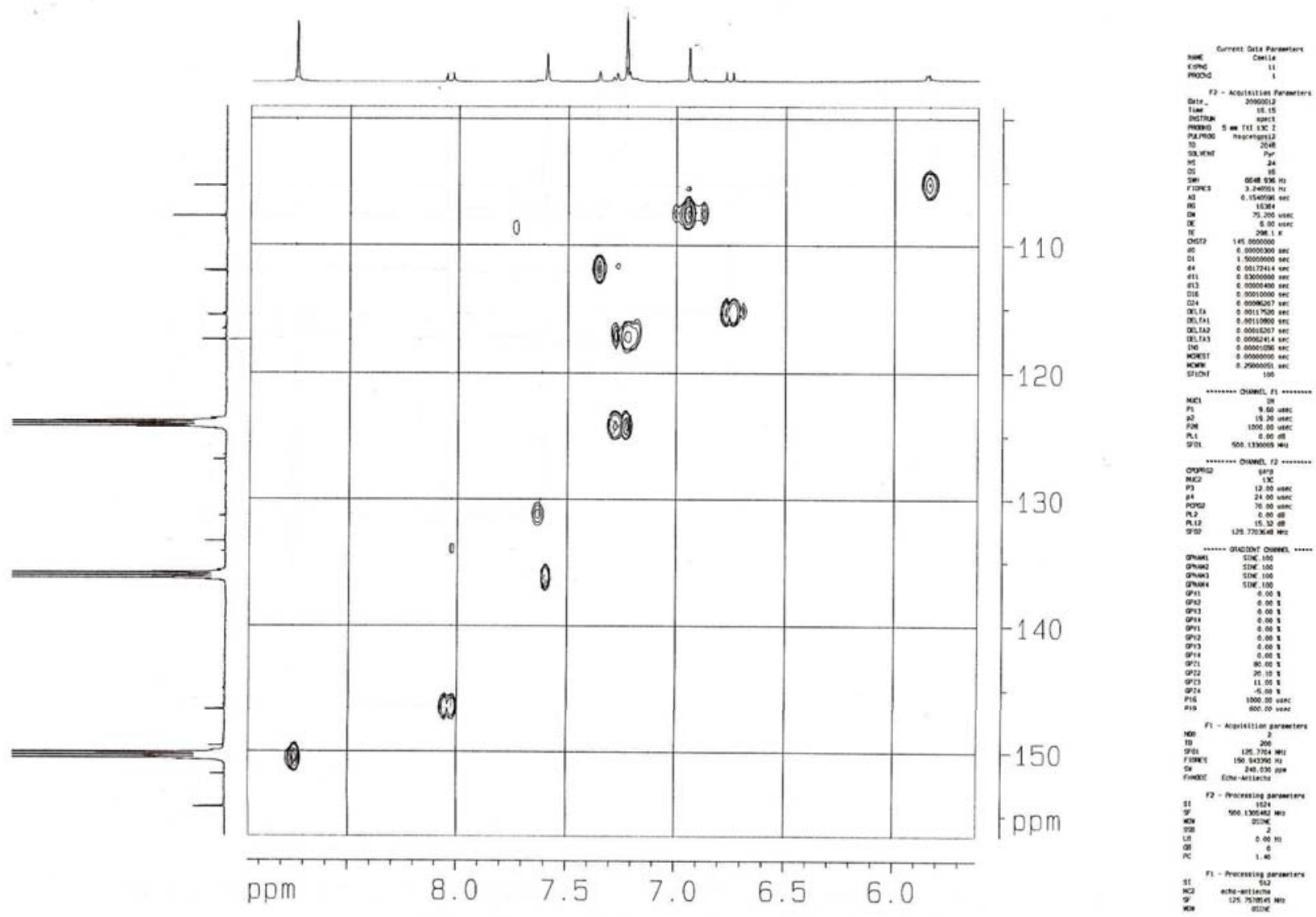

Anexo 19: Espectro expandido de HMQC de F-8.1. 

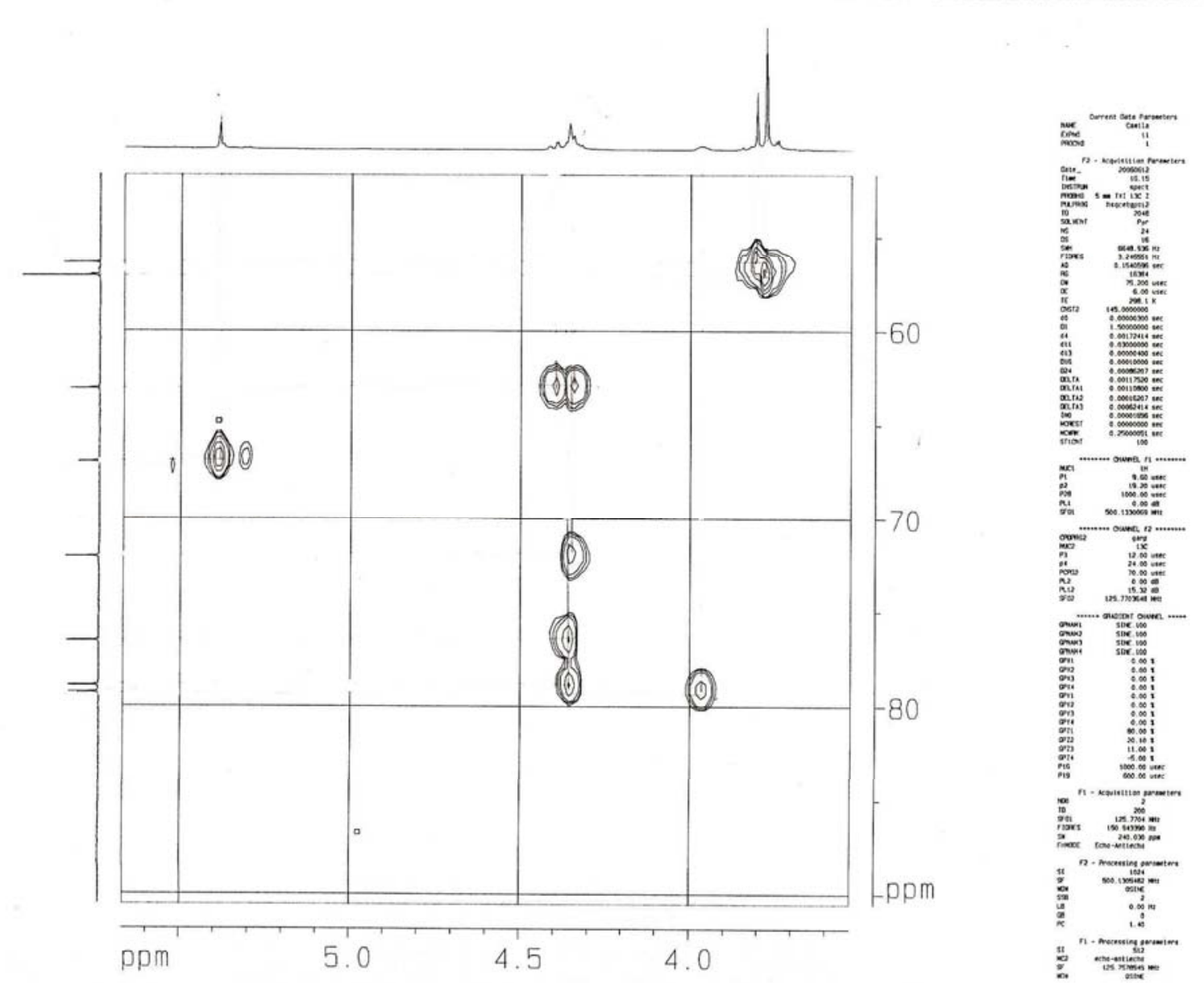

Anexo 20: Espectro expandido de HMQC de F-8.1. 

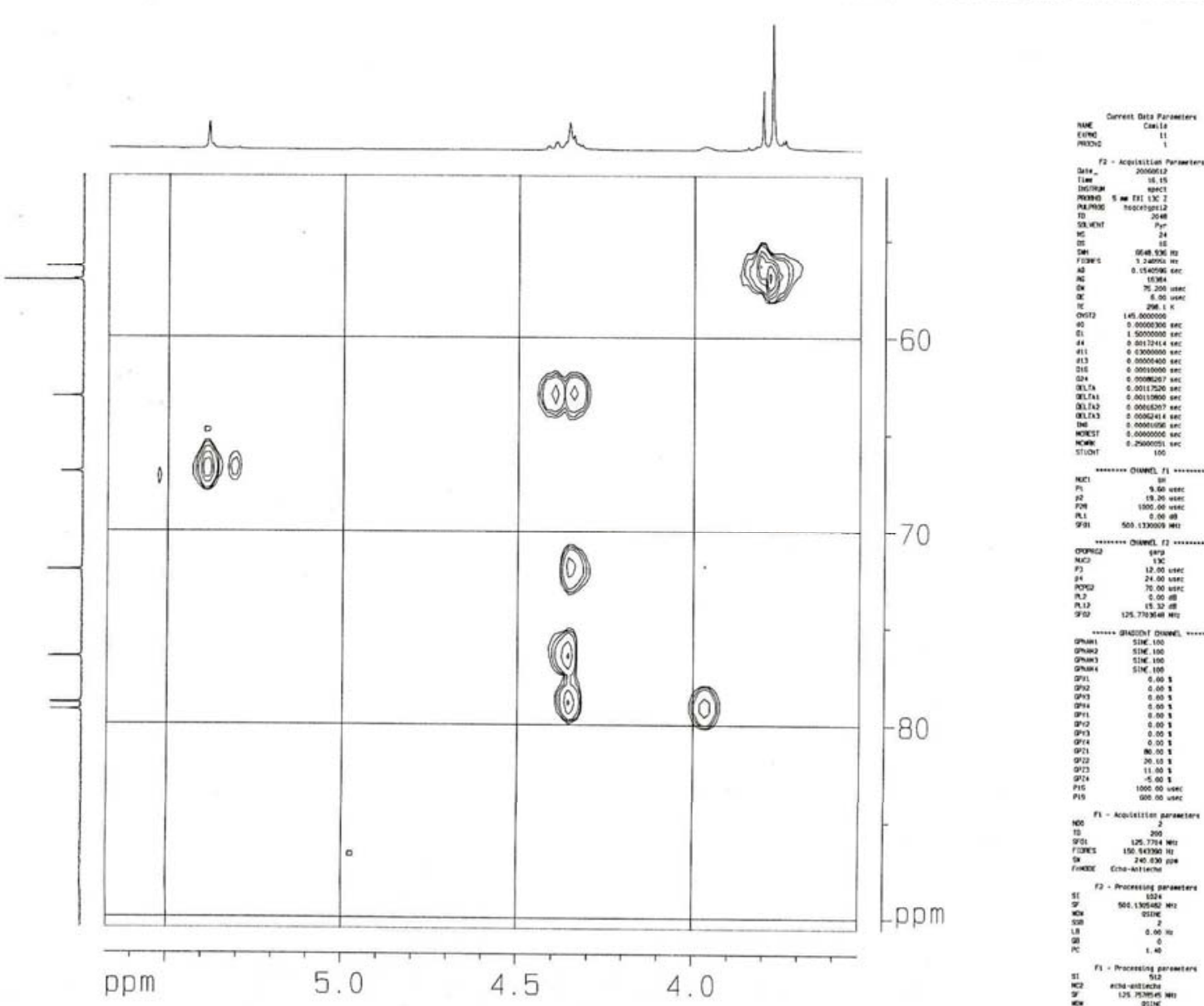

Anexo 21: Espectro expandido de HMQC de F-8.1. 

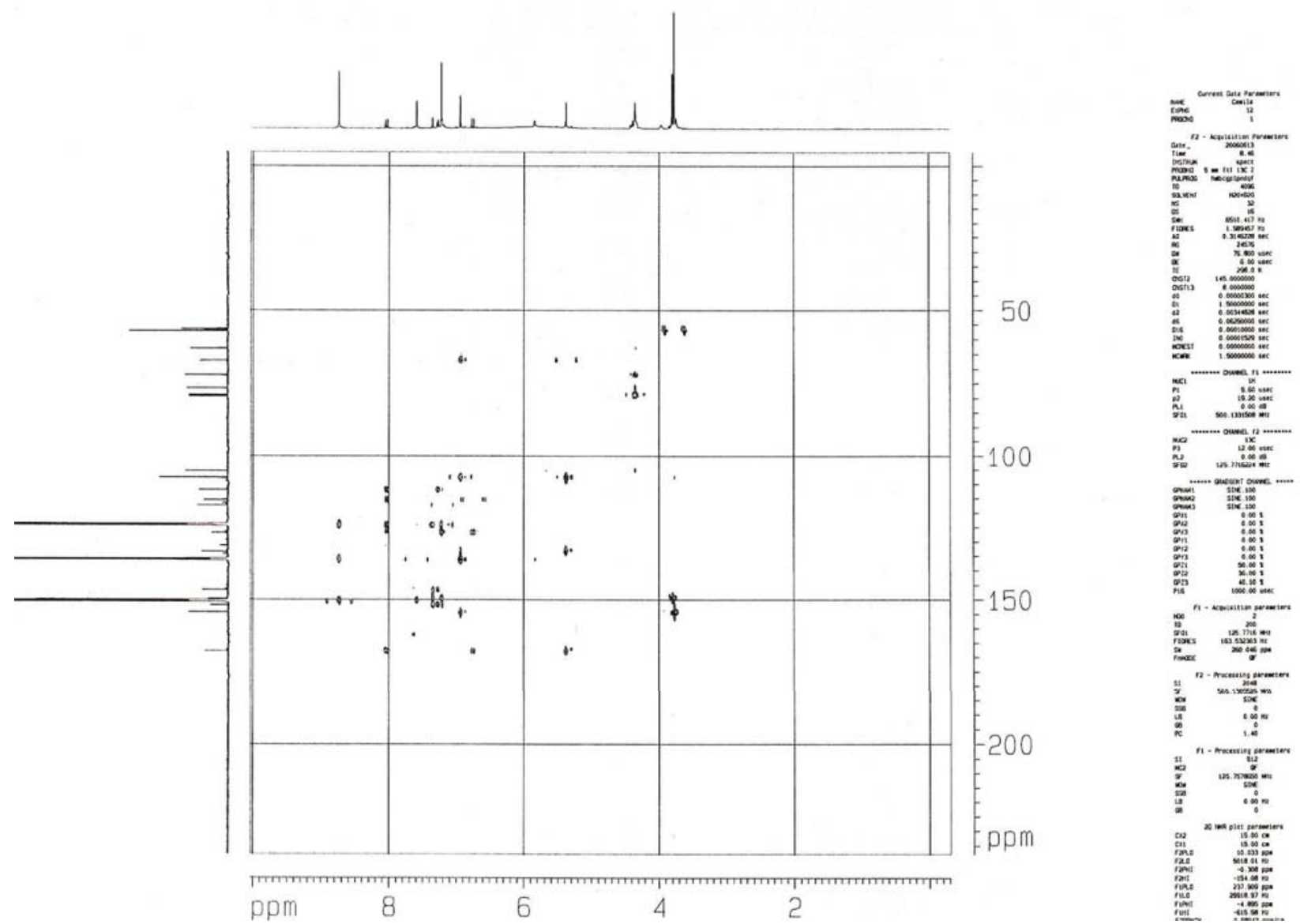

Anexo 22: Espectro de HMBC de F-8.1. 

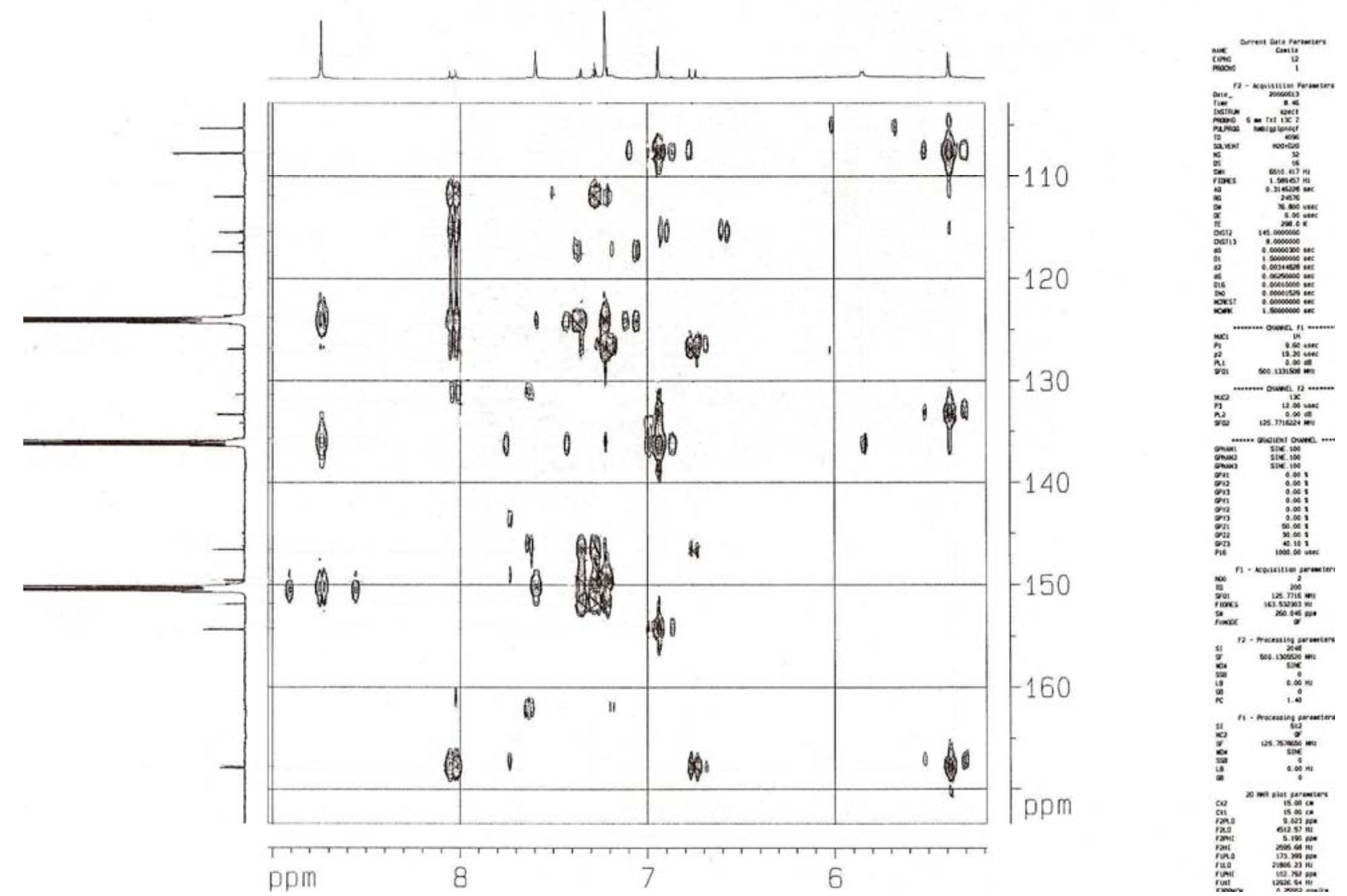

Anexo 23: Espectro expandido de HMBC de F-8.1. 

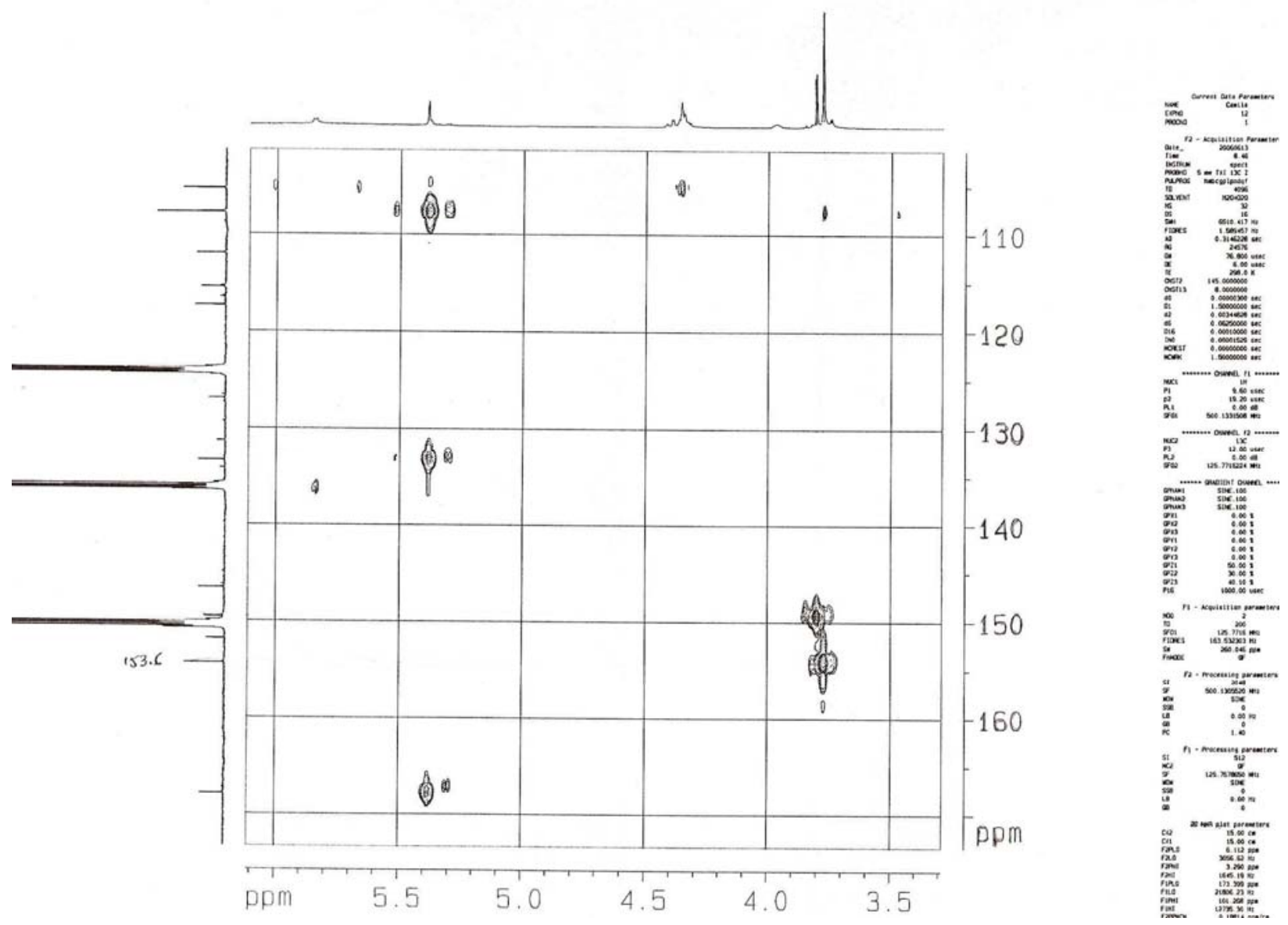

Anexo 24: Espectro expandido de HMBC de F-8.1. 

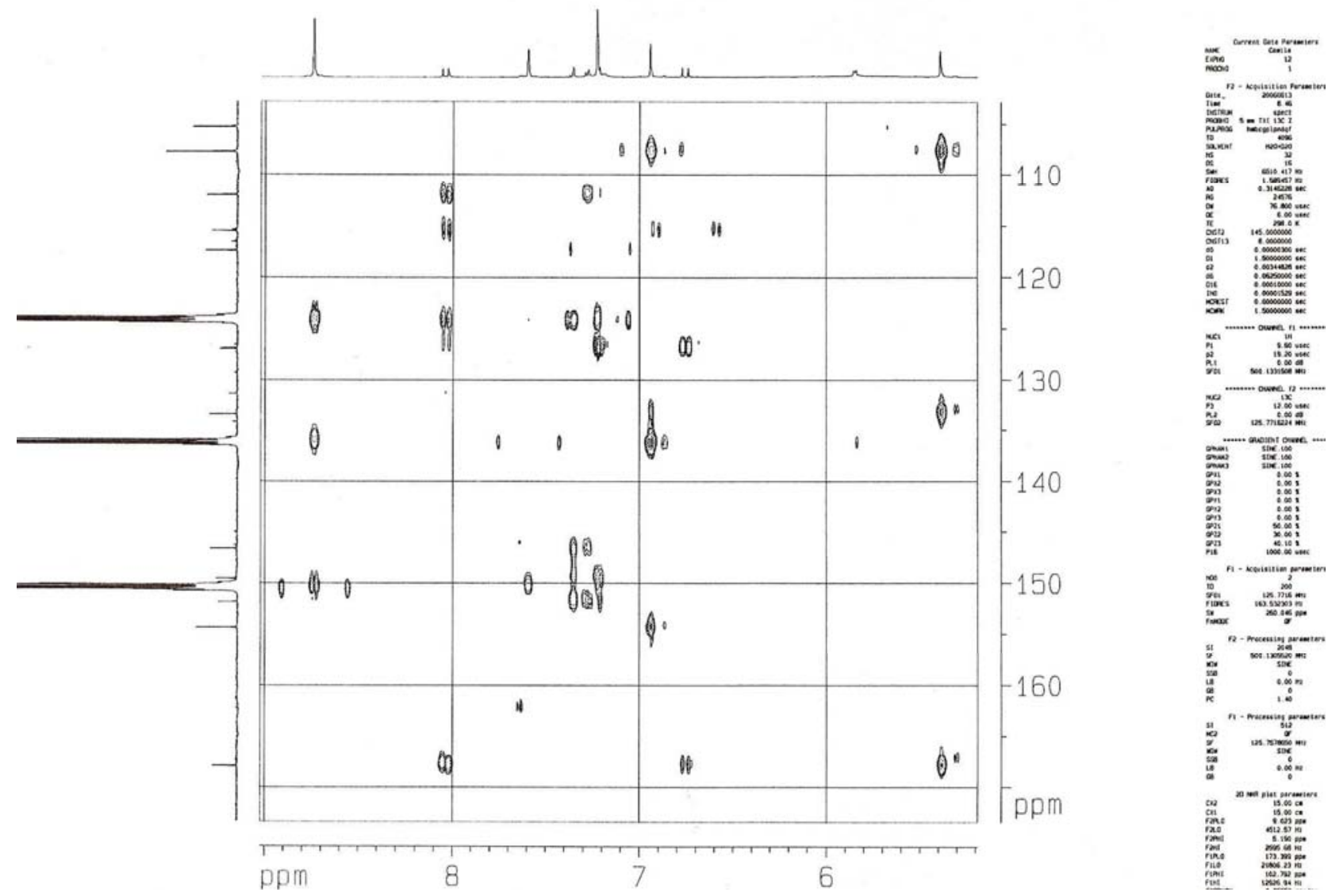

Anexo 25: Espectro expandido de HMBC de F-8.1. 

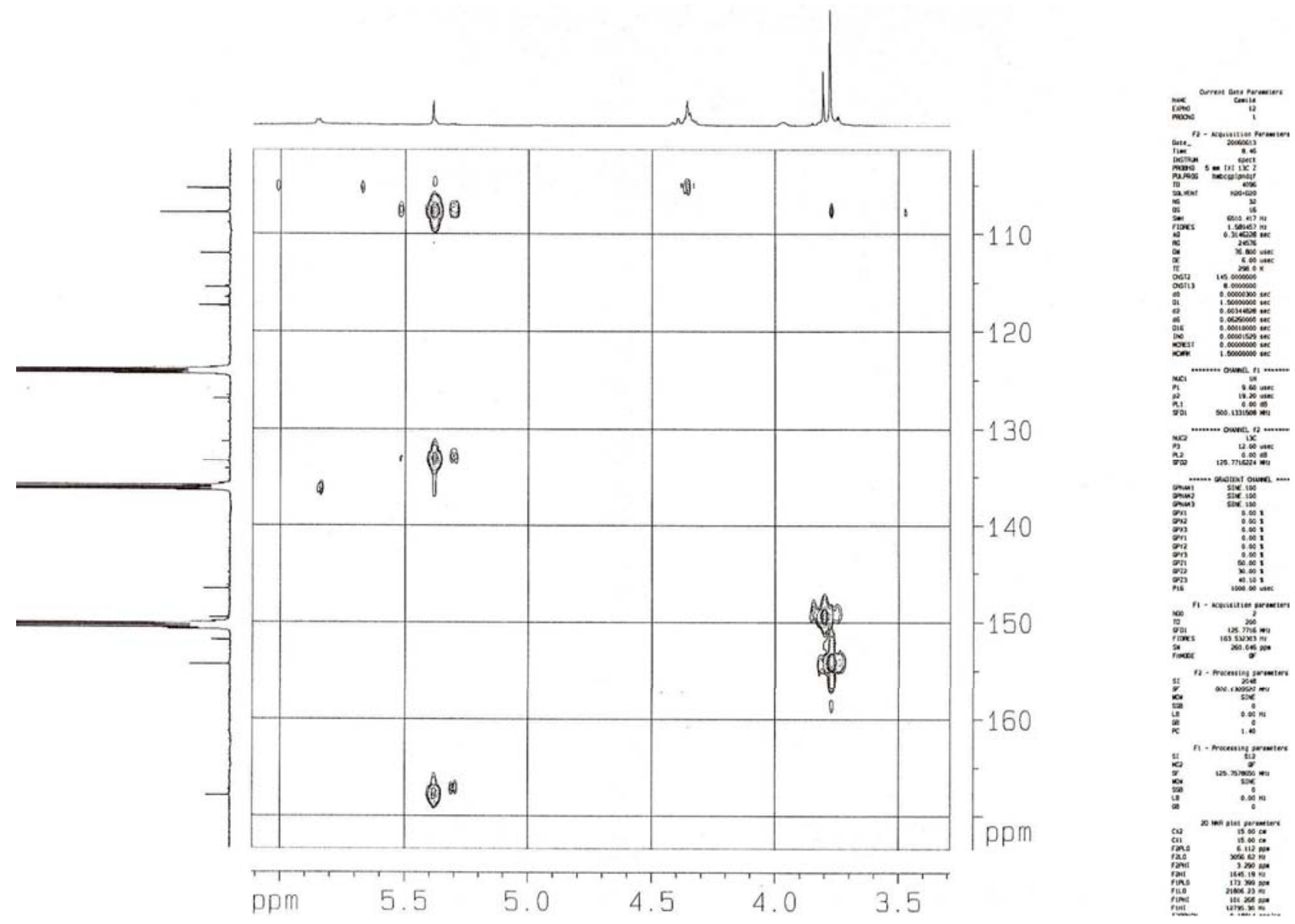

Anexo 26: Espectro expandido de HMQC de F-8.1. 

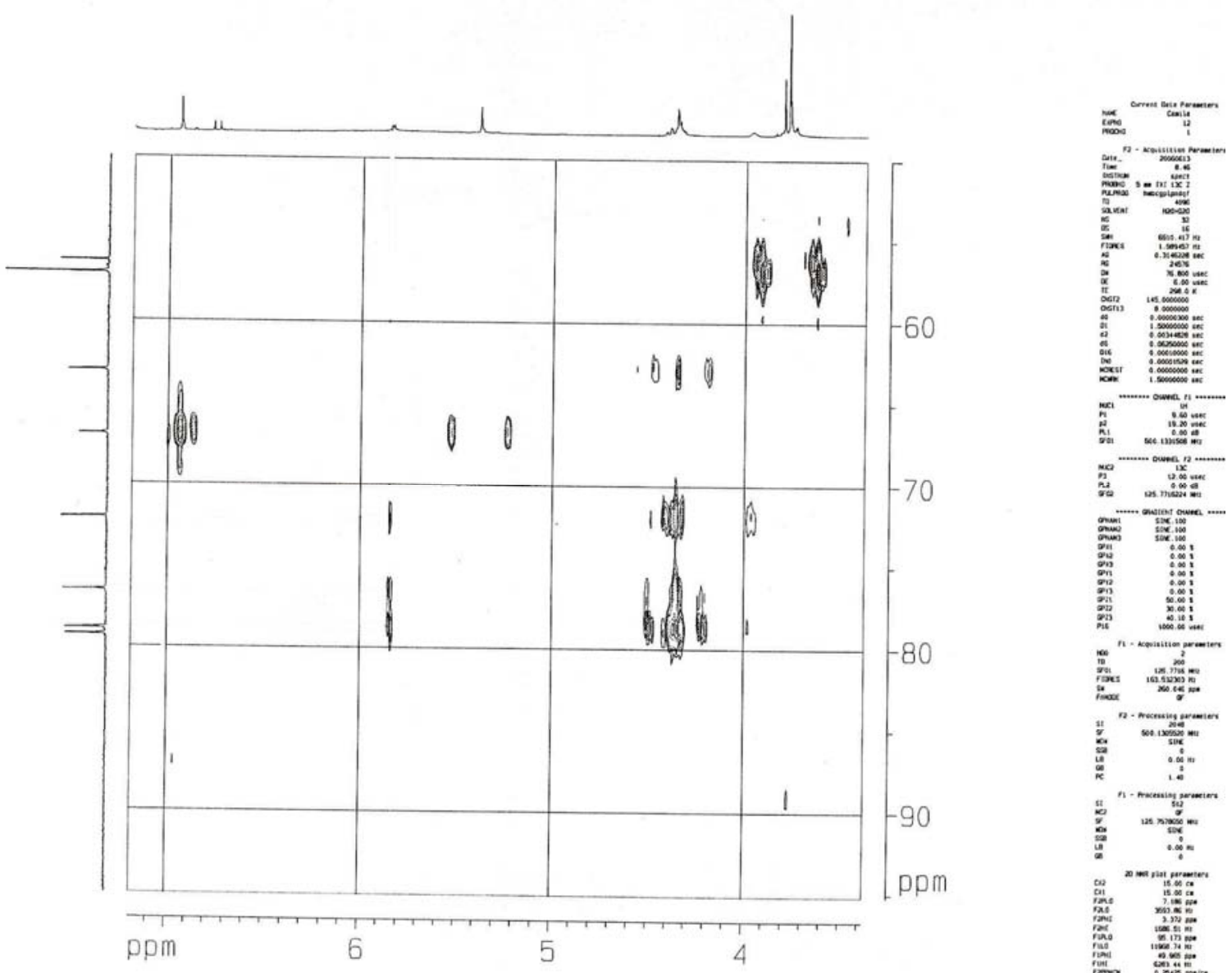

Anexo 27: Espectro expandido de HMBC de F-8.1. 

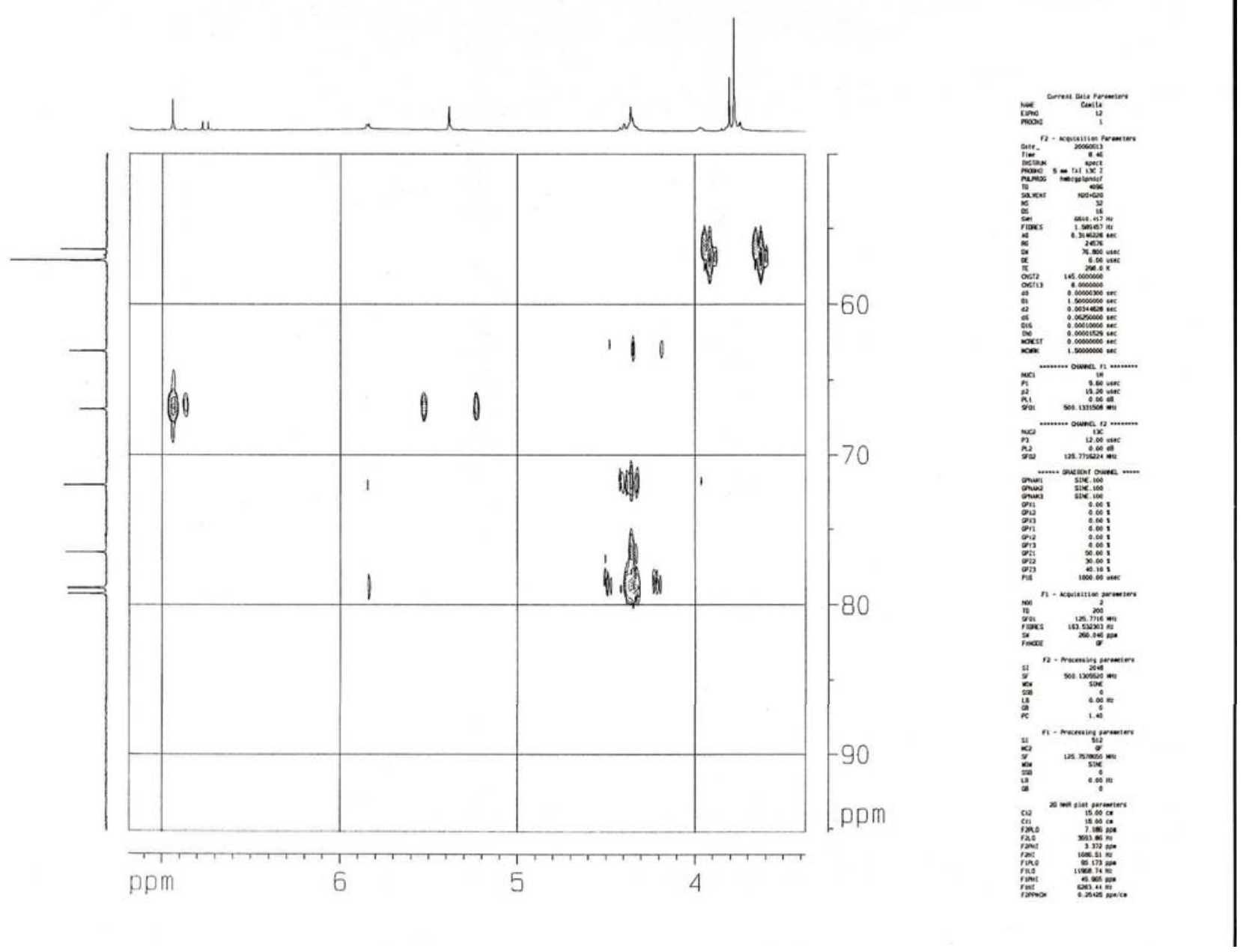

Anexo 28: Espectro expandido de HMBC de F-8.1. 


\section{Referências Bibliográficas}

${ }^{1}$ Pietta, P.; J. Nat. Prod.; 63; 1035-1042 (2000).

${ }^{2}$ Potterat, O.; Current Org. Chem.; 1; 415-440 (1997).

${ }^{3}$ Halliwell, B.; Gutteridge, J. M. C.; Free Rad. Biol. Med.; 18; 125-126 (1995).

${ }^{4}$ Halliwell, B.; Guteridge, J.M.C. \& Cross, E.E.; J. Lab. Clin. Med.; 119; 598-620 (1992).

${ }^{5}$ Max, J.L.; Science; 235; 529-531 (1987).

${ }^{6}$ Sies, H. \& Groot, H.; Toxicol. Lett.; 64/65; 546-551 (1992).

${ }^{7}$ Abuja, P. M. \& Albertini, R.; Clinica Chimica Acta; 306, 1-17 (2001).

${ }^{8}$ Halliwell, B. Biochem. Pharmacol.; 49; $1341-1354$ (1995).

${ }^{9}$ Prior, R. L.; Cao, G.: Comparation of Different Analytical Methods. Free Radical Biol. Med. 27; 1173-1181; (1999).

${ }^{10}$ Re, R.; Pellegrin, N.; Proteggente, A.; Pannala, A.; Ang, M.; Rice-Evans, C.; Free Rad. Biol. Med.; 26, 1231-1237 (1999).

${ }^{11}$ Brand-Williams, W.; Cuvelier, M. E.; Berset, C.; Lebensm.-Wiss. u.-Technol.; 28, 2530; (1995).

${ }^{12}$ Wayner, D. D. M.; Burton, G. W.; Ingold, K. U.; Barclay, L. R. C. \& Locke, S. J. ; Biochim. Biophys. Acta; 924, 408-419 (1987).

${ }^{13}$ Ghiselli, A.; Serafini, M.; Maiani, G.; Azzini, E. \& Ferro-Luzzi, A.; Free Rad. Biol. Med.; 18, 29-36 (1995).

${ }^{14}$ Barreiros, A. L. B. S.; David, J. M. \& David, J. P.; Quim. Nova; 29, 113-123 (2006).

${ }^{15}$ Lisse, E.; Salim-Hanna; Pascual,C. \& Del Castillo, M. D.; Free Rad. Biol. Med.; 18, 153-158 (1995).

${ }^{16}$ Whitehead T. P.; Thorpe, G. H. G. \& Maxwell, S. R. J.; Anal. Chem. Acta, 266, 265277 (1992).

17 Bastos, E. L.; Romoff, P.; Eckert, C. R. \& Baader, W. J.; J. Agric. Food Chem. 51; 7481-7488 (2003).

${ }^{18}$ van Beek, T. A.; Bombardelli, E.; Morazzoni, P.; Peterlongo, F. Fitoterapia, LXIX, 195-244 (1998). 
${ }^{19}$ Gottlieb, O. R.; Kaplan, M. A. C.; Borin, M. R. M. B. Biodiversidade: Um enfoque químico-biológico; UFRJ: Rio de Janeiro, RJ, 1996.

${ }^{20}$ Simões, C. M. O.; Science; 235, 529-531 (1987).

${ }^{21}$ Prior, R. L.; Cao, G.; Free Rad. Biol. \& Med.; 27; 1173-1181 (1999).

${ }^{22}$ Burda, S.; Oleszek, W. J. Agric. Food Chem.; 49, 2774-2779 (2001).

${ }^{23}$ Lemanska, K.; Szymuslak, H.; Tyrakowska, B.; Zielinski, R.; Soffers, A. E. M. F.; Rietjens, I. M. C. M.; Free Rad. Biol. \& Med.; 31; 869-881 (2001).

${ }^{24}$ Malagarriga Heras, R. D. P.; Mem. Soc. Cienc. Nat.; 23; 129 (1976).

${ }^{25}$ Dupont, P.; Bull. Soc. Bretogne ; 41; 141 (1966).

${ }^{26}$ Verdi, L. G.; Brighente, I. M.; Pizzolatti, M.G.; Quím. Nova; 28; 85-94; (2005).

${ }^{27}$ Emerenciano, V. P.; Militão, J. P. S . L. T.; Campos, C. C.; Romoff, P.; Kaplan, M. A. C.; Zambon, M. \& Brandt, A. J. C.; Biochem. System. \& Ecol., 29, 947-957 (2001).

${ }^{28}$ Rahalison, L.; Benathan, M.; Monod, M.; Frenk, E.; Gupta, M. P.; Solis, P.N.; Fuzzati, N. \& Hostettmann, K.; Planta Med. 61, 360 (1995).

${ }^{29}$ Rene, R.M.; Cartana, C.; Adzet, T.; Marin, E.; Parella, T. \& Canigueral, S.; Planta Med. 62, 232 (1996).

${ }^{30}$ Nakasugi, T. \& Komai, K.; J. Agric. Food Chem. ; 46; 2560-2564 (1998).

31 Torres, L. M. B.; Gamberini, M. T.; Roque, N. F.; Landman, M. T. L.; Souccar, C.; Lapa, A. J.; Phytochemistry; 55; 617-619 (2000).

32 Oliveira, A. C. P.; Endringer, D. C.; Amorim, L. A. S.; Brandão, M. G. L.; Coelho, M. M.; J. Ethnopharm. Com.; 102; 465-469 (2005).

${ }^{33}$ Park, Y., K.; Paredes-Guzman, J., F.; Aguiar, C., L.; Alencar, S., M. \& Fujiwara, F., Y.;. J. Agric. Food Chem. 52; 1100-1103; (2004).

${ }^{34}$ Kumazawa, S.; Yoneda, M.; Shibata, I.; Kanaeda, J.; Hamasaka, T. \& Nakayama, t.. Chem. Pharm. Bull. 51; 740-742; (2003).

${ }^{35}$ Weimann, C.; Goranosson, U.; Pongprayoon-C, U.; Claeson, P.; Bohlin, L.; Rimpler, H. \& Heinrich, M.; J. Pharm. Pharmacol., 54, 99 (2002).

${ }^{36}$ Cifuente, D. A.; Simirgiotis, M. J.; Favier,L. S.; Rotelli, A. E. \& Pelzer, L. E.; Phytoter., 15, 529 (2001). 
${ }^{37}$ Heras, B. de las; Slowing, K.; Benedi, J.; Carretero, E.; Ortega, T.; Toledo, C.; Bermejo, P.; Iglesias, I.; Abad, M. J.; Gómez-Serranillos, P.; LISO, P. A.; VILLAR, A. \& Chiriboga, X.; Journal of Etnopharmacology, 61, 161-166 (1998).

${ }^{38}$ Abad, M. J.; Bermejo, P.; Gonzales, E.; Iglesias, I.; Irurzun, A.; Carrasco, L.; Gen. Pharm.; 32; 499-503 (1999).

${ }^{39}$ Fullas, F.; Hussain, R. A.; Chai, H.; Pezzuto, J. M.; Soejarto, D. D.; Kinghorn, D.; J. Nat. Prod.; 57; 801-807 (1994).

${ }^{40}$ Oh, T. Y.; Lee, J. S.; Ahn, B. O.; Cho, S. W.; Hahm, K. B.; Free Rad. Biol. \& Med.; 30, 905-915 (2001).

41 Tapia, A.; Rodriguez, J.; Theoduloz, C.; Lopes, S.; Feresin, G. E.; Hirschmann, G. S.; J. Ethnopharm.; 95; 155-161 (2004).

${ }^{42}$ Easton, P. M.; Simmonds, A. C.; Rakishev, A.; Egorov, A. M.; Candeias, L. P.; J. Am. Chem. Soc.; 118; 6619-6624 (1996).

${ }^{43}$ Brand-Williams, W.; Cuvelier, M. E.; Berset, C.; Lebensm.-Wiss. u.-Technol.; 28, $25-$ 30 (1995).

${ }^{44}$ Prior, R. L.; Wu, X.; Schaich, K.; J. Agric. Food Chem.; 53, 4290-4302 (2005).

${ }^{45}$ Barclay, L. R. C.; Locke, S.J.; Macneil, J. M.; Vankessel, J.; Burton, G. W.; Ingold, K. U. J. Am. Chem. Soc., 106, 2479-2481 (1984).

${ }^{46}$ Burton, g. h.; Hughes, L.; Ingold, K. U.. J. Am. Chem. Coc., 105, 5950-5951 (1983).

${ }^{47}$ Burton, G. W.; Doba, t.; Gabe, E. J.; Hughes, L.; Lee, F. L.; Prassad, L.; Ingold, K. U.. J. Am. Chem. Soc. 1985, 107, 7053-7065 ( 1985).

${ }^{48}$ Zuongguon, C. History of Chinese Tea; Shanghai Publishing: Shanghai, People's Republic of China, (1997).

${ }_{49}$ Mattila, P.; Astola, J.; Kumpulainen, J.; J. Agric. Food Chem.; 48; 5834-5841 (2000).

${ }^{50}$ Conkerton, E.J. \& Chapital, D.C., Journal of Chromatography, 281, 326-329 (1983).

${ }^{51}$ Eckert, C. R.; “Iniciação Científica”.

${ }^{52}$ Peixoto, M. M. M; “Iniciação Científica”.

${ }^{53}$ Heim, K. E.; Tagliaferro, A. R. \& Bobilya, D. J.; J. Nutricional Biochem.; 13, 572-584 (2002).

${ }^{54}$ Arora, A.; Nair, M. G. \& Strasburg, G. M.; Free Rad. Biol. \& Med.; 24, 1355-1363 (1998). 
${ }^{55}$ Nakamura, M. J. Biochem. 29; 245-249; (1990).

${ }^{56}$ Nakamura, M . J. Biochem. 30; 595-597; (1990).

${ }^{57}$ Nakamura, M.; Nakamura, S. Free Radical Biol.\& Med.; 24; 537-544; (1998).

58 Jones, P. \& Scowen, N. R.; Photochem. Photobiol.; 45, 283-289 (1987).

${ }^{59}$ Heijnen, C., G., m.; Haenen, G., R., M., M., Vekemans, J., A J., M., Bast, A; Envir. Tox. Pharm.; 10; 199-206; (2001).

${ }^{60}$ Heijnen, C., G., m.; Haenen, G., R., M., M., Vekemans, J., A J., M., Bast, A; Envir. Tox. Pharm.; 10; 199-206 (2001).

61 De Oliveira, S.Q.; Pizzol, F.D.; Gossmann, G.; Gullaume, D.; Moreira, J.C.F. \& Schenkel, E.P., Free Radical Research, 37, 555-559 (2003).

${ }^{62}$ Lee, J.; Seliger, H., H.; Photochem. and Photobiol.; 4; 1015-1048 (1965).

${ }^{63}$ Cotton, M. L.; Dunford, H. B.; Can. J. Chem.; 51; 582-587 (1973).

${ }^{64}$ Organic Eletronic Spectral Data, Vol. II, H. E., Ungnade, Ed., 846 (1960).

65 Armarego, W. L. F; Perrin, D. D.; Purification of Laboratory Chemicals, 4 th, Butterworth Heinemann, Oxford (1998).

${ }^{66}$ Lebeau, J.; Furman, C.; Bernier, J. -L.; Duriez, P.; Teissier, E.; Cotelle, N.; Free Radic. Biol. Med.; 29; 900-912 (2000).

${ }^{67}$ Mongelli, E.; Desmarchelier, C.; Talou, J., R.; Coussio, J.; Ciccia, G. J. Ethnopharm.; 58; 157-163; (1997).

${ }^{68}$ Barclay, L. R. C.; Locke, S.J.; Macneil, J. M.; Vankessel, J.; Burton, G. W.; Ingold, K. U. J. Am. Chem. Soc., 106, 2479-2481 (1984).

${ }^{69}$ Burton, g. h.; Hughes, L.; Ingold, K. U.. J. Am. Chem. Coc., 105, 5950-5951 (1983).

${ }^{70}$ Burton, G. W.; Doba, t.; Gabe, E. J.; Hughes, L.; Lee, F. L.; Prassad, L.; Ingold, K. U.. J. Am. Chem. Soc. 1985, 107, 7053-7065,( 1985). 